Does Art bring us together?

An Empirical Approach to the Evolutionary Aesthetics of Ellen Dissanayake

\author{
by \\ Brady Fullerton \\ A Thesis \\ presented to \\ The University of Guelph
In partial fulfilment of requirements
for the degree of
Master of Arts
in
Philosophy

Guelph, Ontario, Canada

(C) Brady Fullerton, August, 2016 


\section{ABSTRACT \\ Does Art bring us together? An Empirical Approach to the Evolutionary Aesthetics of Ellen Dissanayake}

\section{Brady Fullerton University of Guelph, 2016}

Advisor:

Professor D. Dedrick

This thesis examines criticism of Ellen Dissanyake's evolutionary account of art. In addition to offering theoretical responses to criticism leveled against her, an alternative formulation of her position is developed and subjected to empirical analysis. The implicit claim that "Ritual art promotes group cohesion" is subjected to a cross cultural analysis. A theoretical definition of ritual art is developed and a coding practice is proposed and tested using the database of SCCS cases in the eHRAF. Theoretical arguments are developed for understanding group cohesion in certain variables. These proxies are then correlated with ritual art. When all proxies for group cohesion are considered results are mixed. However, numerous variables that measure internal violence indicate significant correlations supportive of Dissanayake's position. Ultimately, the statistical results, along with theoretical arguments, call for a reassessment of Dissanayake's work. Furthermore, the project exposes important weaknesses in use of the term "group cohesion." 
For my family. 


\section{Acknowledgements}

For the completion of this project I am deeply indebted to many who offered their time, encouragement, resources, and advice.

I am grateful for my advisor, Dr. Don Dedrick, without whom this project would have been an impossibility. Your advice, guidance, and many loaned books were invaluable in keeping me on track. It was a course in aesthetics that you taught that served as the impetus for this project and redirected my entire philosophical focus. Thank you.

To Dr. Stefan Linquist, I am grateful for the immense encouragement and interest you took in this project early on. You have consistently gone above and beyond to provide me with the resources to venture out into something I had never tried. Thank you for always being open to the possibilities that this project had, and even seeing some that I missed.

To Dr. Karen Houle, who took on this project when it was nothing more than undirected passion, thank you. You helped to shape this project into something manageable, while remaining sensitive to my personal investments. Thank you for reminding me that we need to be conscious of the baggage we bring to our discipline, and that everything is wasted if we are not bettered as individuals. Thank you for being there for me when I was at my lowest. 


\section{Table of Contents}

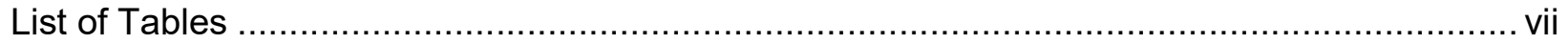

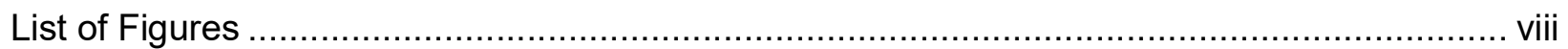

Chapter 1 - Introduction to Dissanayake and Methodology ............................................... 1

1.1 Ellen Dissanayake on Art as "Making Special"............................................................ 1

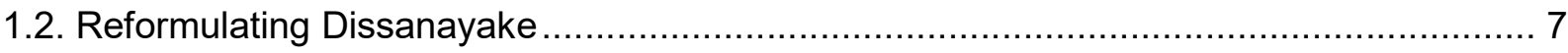

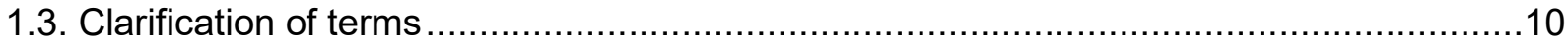

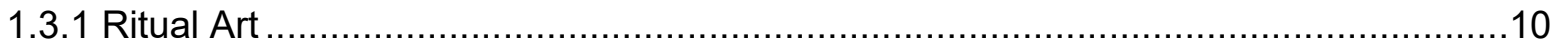

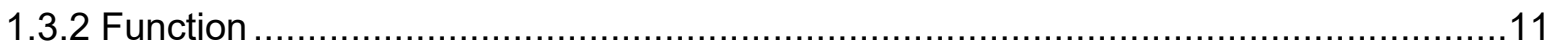

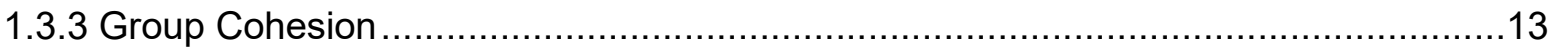

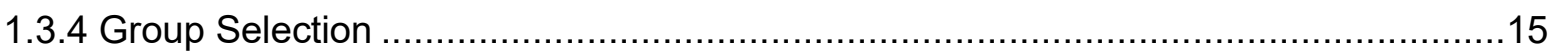

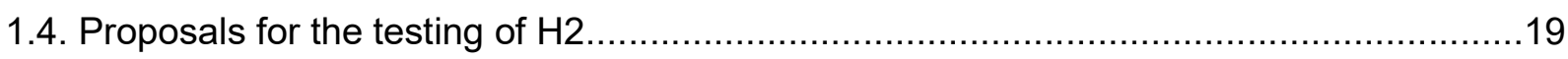

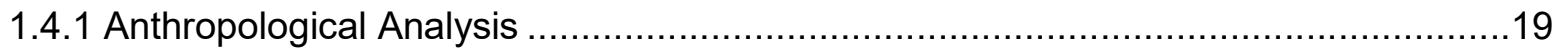

1.4.2 Phylogenetic accounts of cultural evolution ...........................................................

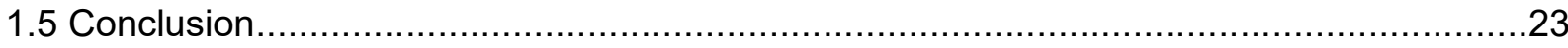

Chapter 2 - Developing a Theoretical Definition of Ritual Art....................................................

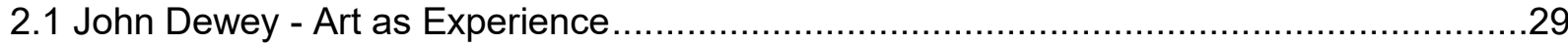

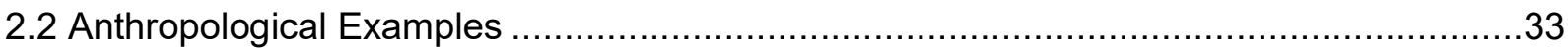

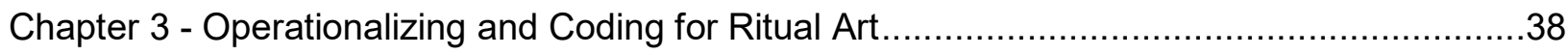

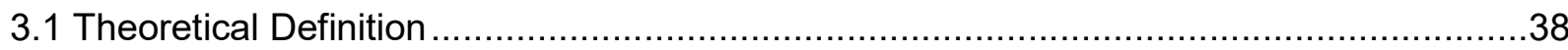

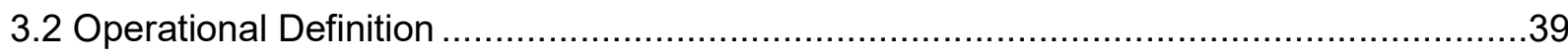

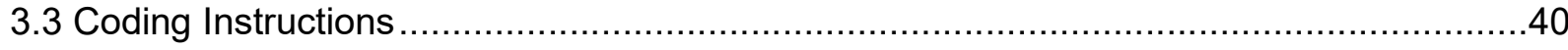

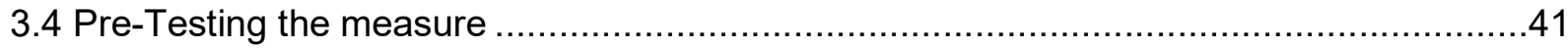

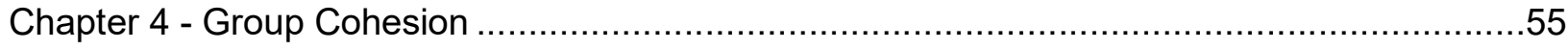

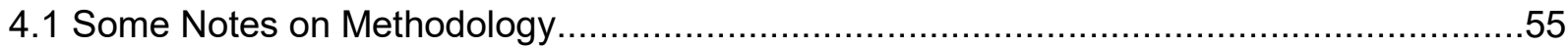

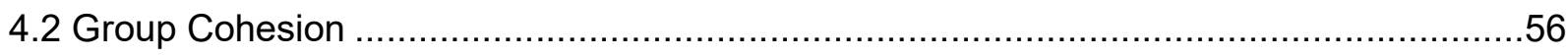

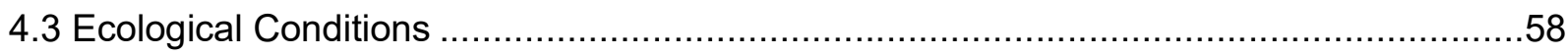

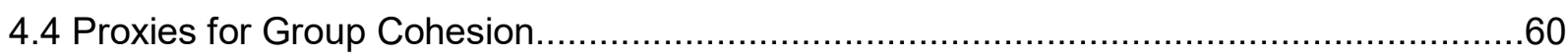

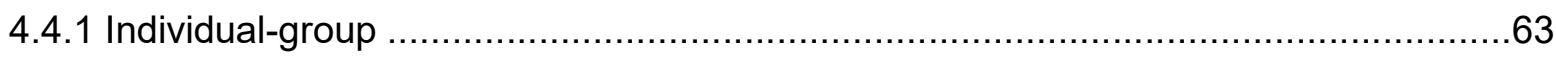

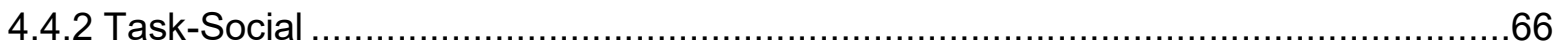

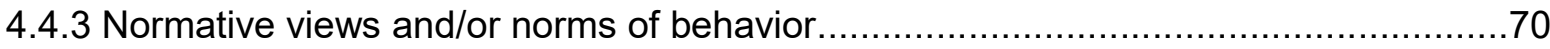

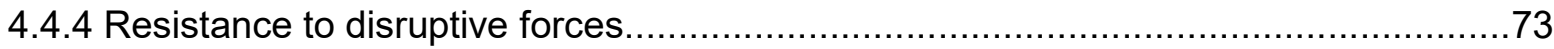

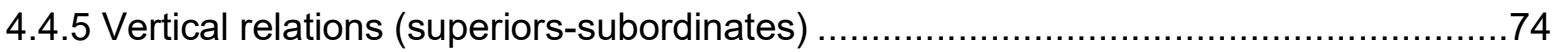




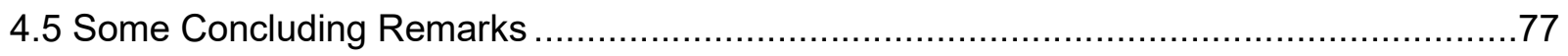

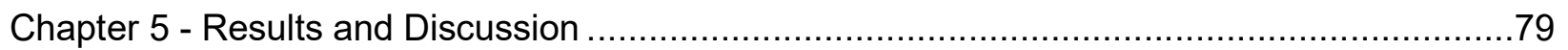

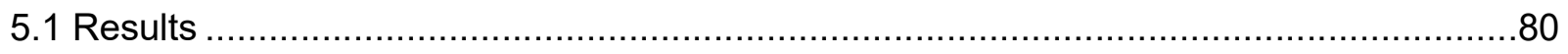

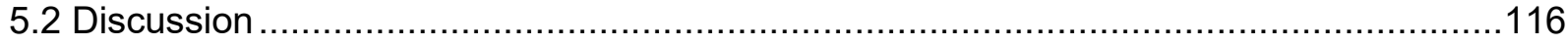

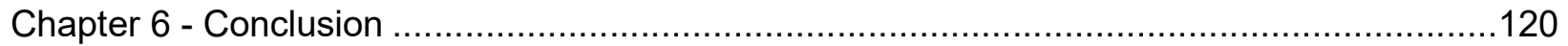

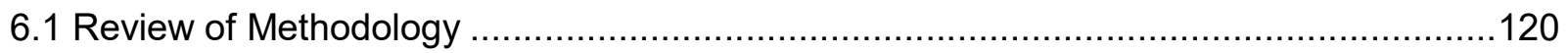

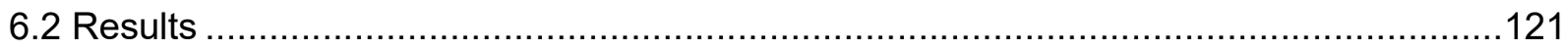

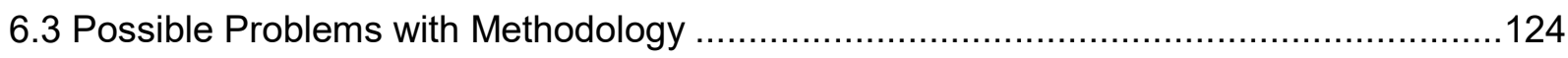

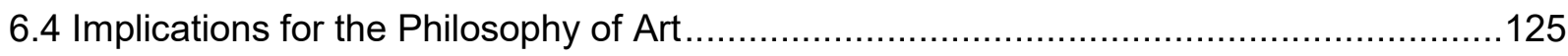

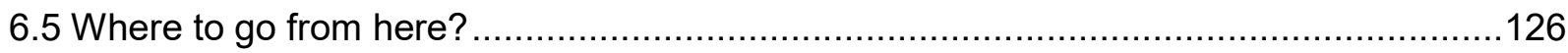

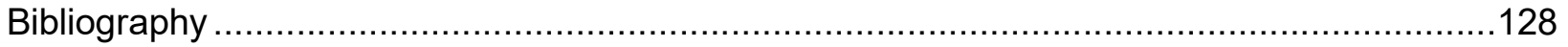




\section{List of Tables}

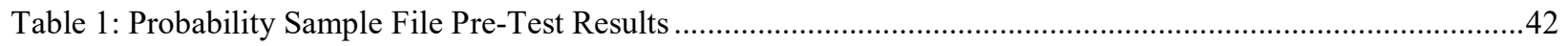

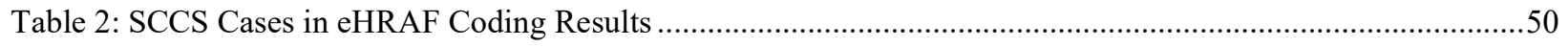

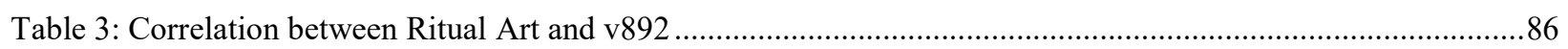

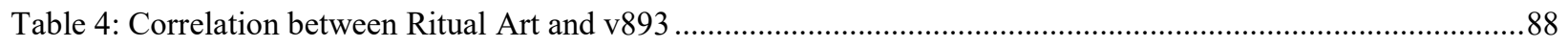

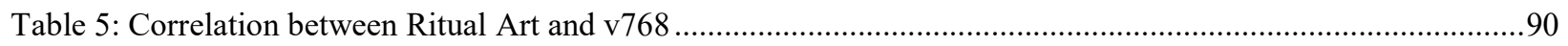

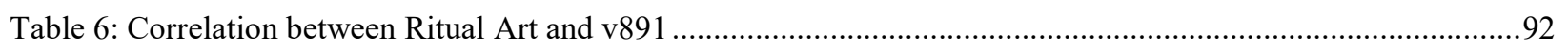

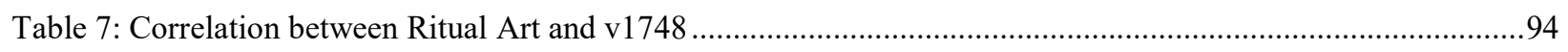

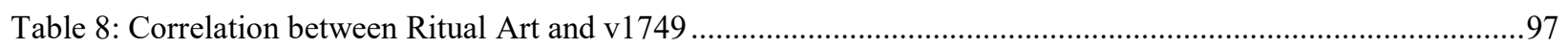

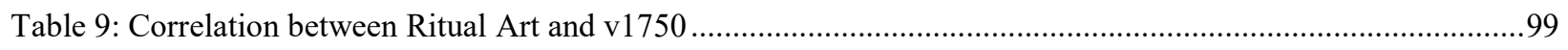

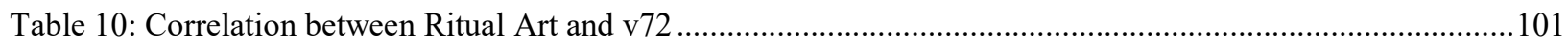

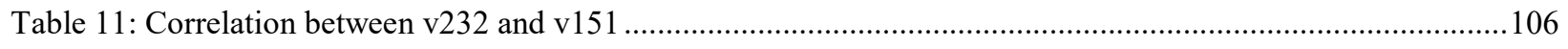

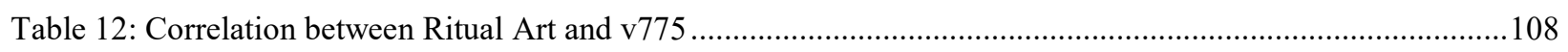

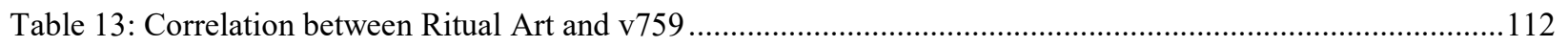

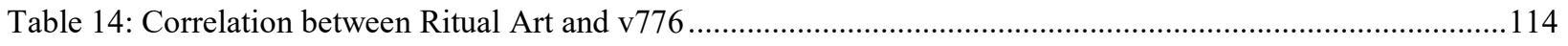

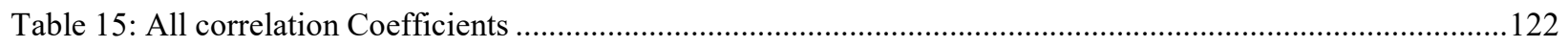




\section{List of Figures}

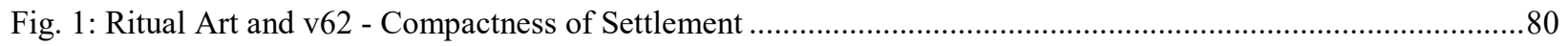

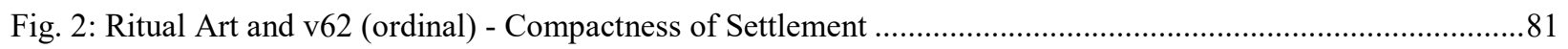

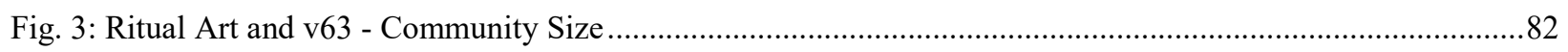

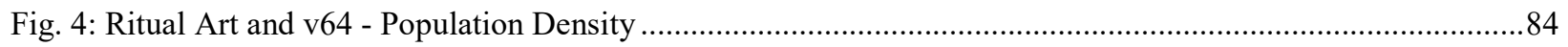

Fig. 5: Ritual Art and v892 - Frequency of External War - Attacking ....................................................................86

Fig. 6: Ritual Art and v893 - Frequency of External War - Being Attacked ...........................................................8

Fig. 7: Ritual Art and v768 - Conflict between communities of the same society ..................................................90

Fig. 8: Ritual Art and v891 - Frequency of Internal War.................................................................................92

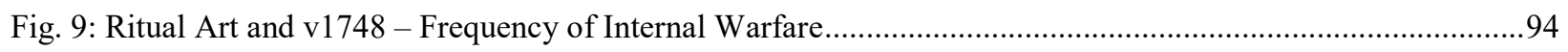

Fig. 10: Ritual Art and v1749 - Frequency of Internal Warfare ..........................................................................96

Fig. 11: Ritual Art and v1750 - Frequency of Violent Conflict Between Groups within Local Communities ...........98

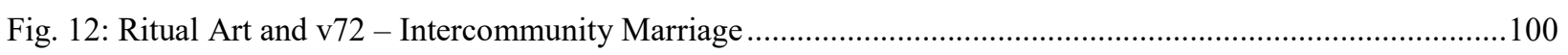

Fig. 13: Ritual Art and v72 - Intercommunity Marriage (Interpolation Line) …................................................... 101

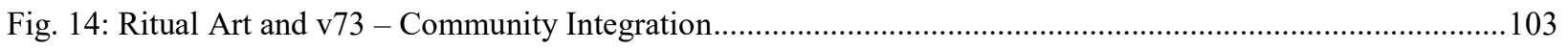

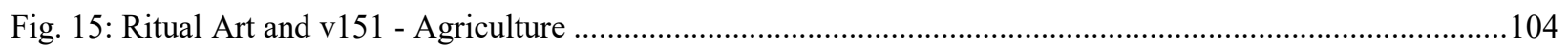

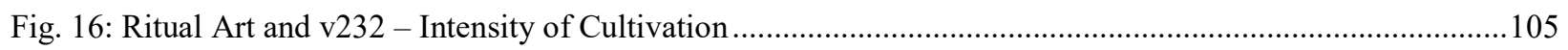

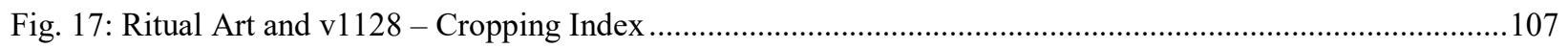

Fig. 18: Ritual Art and v775 - Compliance of Individuals w/ community norms ................................................108

Fig. 19: Ritual Art and v1684 - Threat of Weather or Pest Disasters.................................................................110

Fig. 20: Ritual Art and v1719 - Periodical Variation of Food Scarcity...............................................................111

Fig. 21: Ritual Art and v759 - Perception of Political Leader's Power.................................................................112

Fig. 22: Ritual Art and v776 - formal sanctions and enforcement for community decisions...................................114

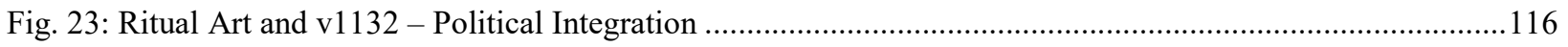




\section{Chapter 1 - Introduction to Dissanayake and Methodology}

In this paper I develop from Ellen Dissanayake's evolutionary adaptationist theory of art a more conservative hypothesis regarding the relationship between evolution and certain categories of art. I then propose several ways of rigorously testing this hypothesis and pursue one of these for the remainder of this paper. My contention is that Dissanayake's view, though not without flaws, has merited academic consideration, but has been largely rejected for reasons I call into question. Rigorous testing of her theory may serve to advance the field of the evolutionary study of art. My methodology here is largely in line with the aims of experimental philosophy. I am seeking evidential justification for specifically empirical claims. I am not replacing theoretical arguments with an experimental method. Towards that end I undertake a cross-cultural analysis in order to test a hypothetical, empirical formulation of Dissanayake's view. My intention is not to defend Dissanayake but to consider what it would look like to treat her views, and other views in the philosophy of art and biology, more rigorously. My project will, in part, consider what the role of empirical testing should be within the field of evolutionary aesthetics. The approach I advance in this paper is one that uses philosophy to theoretically frame empirical tests.

\subsection{Ellen Dissanayake on Art as "Making Special"}

Ellen Dissanayake's evolutionary theory of art holds that art is functional in "making special" (or "elaborating" as she sometimes calls it ${ }^{1}$ ) and thereby increasing group cohesion. For

\footnotetext{
${ }^{1}$ Ellen Dissanayake, Art and Intimacy: How the Arts Began. (Seattle: University of Washington Press, 2000), 134.
} 
Dissanayake making special is the process by which art highlights certain shared cultural and social values. Art is for her a behavior that originated in the same vein as ritual and play, but is distinct in its exceptional ability to "make special." Where ritual and play elevate an object or action out of the everyday, Dissanayake sees art as adaptively refined for the purpose of making an action or object unique, important, and valuable. This process, she argues, is functional in increasing group cohesion by drawing communal attention to shared experience. In revisiting the issues she raised in Homo Aestheticus (1992) she writes,

"I don't define art as 'making special,' but in the simplest sense, I do think making special characterizes what artists of all kinds do. Even more, it describes a common trait that, in a Darwinian sense, is a noteworthy feature of human nature. My concern is to emphasize a simple observation that evolutionary biologists tend to overlook: that humans sometimes are not content to leave ordinary reality alone." 2

Dissanayake's position will be discussed in greater detail in what follows. This brief sketch will suffice in establishing Dissanayake's thesis. For the purposes of this paper I interpret Dissanayake as defending the following thesis:

H1) The function of the arts is to promote group cohesion [by making special.]

\footnotetext{
${ }^{2}$ Ellen Dissanayake, "Retrospective on Homo Aestheticus," Journal of the Canadian Association for Curriculum Studies Vol. 1 No.2 (2003), 10.
} 
Dissanayake's position has been the subject of a great deal of criticism in the field of evolutionary aesthetics. Dennis Dutton and Stephen Davies offer some of the more careful treatments of her work. In The Artful Species (2012), Davies considers Dissanayake's evolutionary theory of art under the umbrella of what he terms "art-general" theories. Davies contrasts art-general theories with art-form-specific theories. While an art-general theory intends to account for all the arts, an art-form specific theory accounts for only a specific art form or tradition. ${ }^{3}$ According to Davies, if the account is to be specific to the arts, then "art-general theories should identify an evolutionarily significant function performed not only by all the arts but also by only the arts." ${ }^{4}$ Much of his criticism stems from this all and only condition, despite the fact that he admits it is only an ideal. That the function performed by the arts should be applicable to all the arts seems to be a reasonable condition given Dissanayake's claim that the arts are an adaptation. However, that the function performed should be applicable to only the arts is not as clear. Davies reasons that if the former condition is met but the latter is not then we would be better served by seeking the common practice that underlies art and non-art behaviors. In consequence the function of art would not then be unique to art, but would see art as developing out of some other common human trait. Davies sees this as a problem for adaptationist accounts generally, and art-general theories specifically. However, Davies is unjustified in both of these claims. If the conditions of all and only are explicitly committed to by Dissanayake, or if they are essential to an art-general theory, which would have to be an accurate categorization of her theory, then the criticism is justified. However, Dissanayake never makes either claim. She never commits to the idea that all art is adaptive in making special, though she does suggest that it is likely an adaptation. Instead, she willingly accepts exceptions, such as

\footnotetext{
${ }^{3}$ Stephen Davies, The Artful Species: Aesthetics, Art, and Evolution. (Oxford: Oxford University Press, 2012), 123.

${ }^{4}$ Ibid.
} 
sexual co-opting, which we will explore later. Furthermore, the very definition of art's function, for Dissanayake, is "making special" a behavior she argues developed in ritual, art, and play and remains shared with these practices. So she has never committed herself to the only position. If the art-general category is essentially a definition of what an adaptationist account must be committed to then we could fault Dissanayake for claiming that art is an adaptation while failing to meet the conditions of an adaption. However, even if we use the word "ideal," as Davies does, the requirement is simply too demanding for any adaptation. We could formulate the requirement as follows:

Ideally, a strong specific connection between $X$ and evolution, where $X$ is an adaptation, should identify the function performed by all X and only X.

However, this requirement is so demanding that few traits could meet the necessary conditions for being termed an adaptation, according to Davies. While meeting these conditions would be sufficient, it can hardly be said to be necessary. Davies seems to recognize this when he backs away from this commitment by offering a solution for his imposed category of "art-general" theories.

"One way of ameliorating this concern and of returning attention to art is by suggesting that art behaviors are specifically suited to giving expression to the adaptive trait. Perhaps they magnify its effect more than non-art behaviors that can also implement the adaptation. ... the care and 
resources lavished on art suit it to serving as one of the more dramatic forms of making special." 5

While this amelioration on Davies' part does come closer to a reasonable expectation of an adaptationist account of art, it is unclear why he offers the overly demanding conditions of all and only in the first place. These conditions have the effect of weakening adaptationist accounts with a definition that he has imposed on them, but that they are in no way committed to. This allows him to consider Dissanayake charitably but also return to implicit problems of all and only throughout his criticism.

In The Art Instinct (2010), Dennis Dutton argues, against Dissanayake, that though art may not have evolved for the purpose of sexual display, "traces of sexual selection ... tends partially to undermine the communal spirit as having a defining role in the arts." ${ }^{6}$ Dutton understands the arts as the complex expression of a number of our biological capacities. Thus, while group cohesion might very well be one effect of the arts, he asserts that this effect would be undermined by the selfish behaviors stemming from the use of the arts for sexual display. Yet Dissanayake agrees that the arts can be co-opted for sexual display and honest signaling. ${ }^{7}$ However, as Davies points out, she "argues that this does not show that the activity originated in order to enable such competition." ${ }^{8}$ Dissanayake's argument is that co-option does not abrogate the function of "making special" in art, in an etiological sense, and Davies seems to agree. Sexual co-opting does not then deny the arts the possibility of all being functional in making special under Davies' rigorous definition of art-general accounts. Instead, Davies rejects

\footnotetext{
${ }^{5}$ Ibid., 124.

${ }^{6}$ Denis Dutton, The Art Instinct: Beauty, Pleasure, \& Human Evolution. (New York: Bloomsbury Press, 2010$), 226$.

${ }^{7}$ Ellen Dissanayake, Art and Intimacy: How the Arts Began. (Seattle: University of Washington Press, 2000$), 134$.

${ }^{8}$ Stephen Davies, The Artful Species: Aesthetics, Art, and Evolution. (Oxford: Oxford University Press, 2012 ), 125.
} 
Dissanayake's art-general theory because it fails to adequately demonstrate that the function that the arts supposedly serve meets the criteria of being a function performed by only the arts. ${ }^{9}$ For Davies, Dissanayake fails to meet this criteria as the concept of "making special" "does not identify an art-specific adaptation because it includes play and ritual as well." ${ }^{10}$ Yet Dissanayake herself readily points to the role of "making special" in ritual, ceremony and play. She has not committed herself to the position that only art functions in making special. This commitment is imposed on her by Davies' requirements of an art-general adaptationist account. While Davies' requirements are unrealistic and not reflective of the commitments made by Dissanayake, I agree with his criticism insofar as Dissanayake's account is too broad and vague. Davies elaborates on this point by arguing that her criteria for art, just as her criteria for "making special" are too broad and "are too easily satisfied by items we would not think of in aesthetic terms." 11 This is a criticism that is much more compelling and it does not require that Davies commit Dissanayake to a rigid definition of adaptationist accounts.

What we are left with is a rejection of Dissanayake's functional art-general account primarily on the grounds that as an art-general theory it is too broad and unclear. This is a fair criticism, though the adaptationist conditions of all and only are not. However, this is not the only criticism that has been leveled against Dissanayake. Despite contributing to the criticism of Dissanayake as too broad, Dutton rejects Dissanayake's view not for its breadth or vagueness, but for its emphasis on group cohesion, and group selection. Even more interesting is that both Davies and Dutton appeal to Steven Pinker in rejecting Dissanayake, though in different ways.

\footnotetext{
${ }^{9}$ Ibid., 123.

${ }^{10}$ Ibid., 131.

11 Ibid.
} 
Dutton approvingly cites Pinker's criticism of group-selection as "gluey metaphors"12 and Davies cites Pinker's attempt to trace art to more fundamental biological traits. ${ }^{13}$

After considering functional art-general theories of art, Davies proposes a number of case studies of art-specific theories. These theories attempt to account for the evolutionary role of a limited aspect of the arts (e.g. music, literature) while avoiding the pitfalls of the all and only objection he posed earlier. However, none of these theories propose to address a limited interpretation of Dissanayake's account, despite the affinity that something like the intersection of ritual and art might have to an art-specific account.

\subsection{Reformulating Dissanayake}

Despite Dutton and Davies' criticism of Dissanayake, I, like Davies, commend her view for being one of the most elaborate functional accounts of art, though I share his criticisms. The view that art functions in making special is both too vague and too broad to be useful. Or, more accurately, it smacks of pseudo-science insofar as it seems always applicable but has not been formulated in such a way that it can be rigorously tested. What would it look like to test for the act of making special? To anyone partial to the view, finding a case of making special would not be difficult. But what then of the objection that this act of making special could be reduced to a more fundamental evolved trait or behavior? This is especially difficult when we consider the relationship that art has to ritual and play, according to Dissanayake. Nonetheless, much of the criticism of Dissanayake's view amounts to criticism of it as an art-general theory, but little attention is paid to the possibility that it might have explanatory power as an art-form-specific

\footnotetext{
12 Steven Pinker, How the Mind Works. (New York: W.W. Norton \& Company, 2009), 429.

13 Stephen Davies, The Artful Species: Aesthetics, Art, and Evolution. (Oxford: Oxford University Press, 2012 ), 122.
} 
theory. I would like to propose a more modest thesis derived from Dissanayake that can be understood as art-form-specific.

In order to develop this hypothesis, it is first important to avoid the pitfalls of the artgeneral theories as Davies sees them. Any explicit or implicit "all" regarding art in Dissanayake's view should then be changed to "some." In order to develop a manageable and testable hypothesis we should also specify more clearly what that "some" is. By some we cannot simply mean anecdotal accounts of "some" art, as this would apply even less rigour to the theory. Instead, we should consider a categorical subset of art, which can be systematically defined, scrutinized, and tested against the hypothesis. This limitation of the project is teased at by Davies $^{14}$ though he remains largely entrenched in the criticism of Dissanayake as an art-general theorist. As an adaptationist account we should also clarify the manner in which these arts function. Dissanayake uses the phrase "making special," but what is really meant by this is that the act of making special serves to draw communal attention to an object of appreciation. ${ }^{15}$ Thus, our categorical subset of art, if it is to be charitable, should be one that seems intuitively to serve this function. Since Dissanayake has already noted the intimate similarities between ritual and art, I propose to consider a category of art in which ritual and art are largely indistinguishable. This category_ “ritual art"—is promising for the following reasons. First, regarding ritual and art Dissanayake suggests that "In simpler societies that are nearer than we are to the type of social group in which humankind evolved, one may easily see the close, if ambiguous relationship...[between art and ritual]" ${ }^{16}$ Elsewhere she describes the two as often indistinguishable in these cultures. Furthermore, ritual has already been proposed as important in

\footnotetext{
${ }^{14}$ Ibid., 124.

${ }^{15}$ Ellen Dissanayake, Art and Intimacy: How the Arts Began. (Seattle: University of Washington Press, 2000$), 139$.

${ }^{16}$ Ellen Dissanayake, What is Art For? (Seattle: University of Washington Press, 1988), 91.
} 
promoting group cohesion by numerous anthropologists including Catherine Bell, ${ }^{17}$ Victor Turner ${ }^{18}$ and Richard Sosis. ${ }^{19}$ Since the proposition that ritual might increase group cohesion is not without precedent it is reasonable to imagine a category of behavior where ritual and art merge, such as in dancing, performance, singing, and other acts of the ritual body; ${ }^{20}$
"The beginning of art as a behavior can be said to lie in the tendency to make special or recognize specialness, although, as we have seen, it is not always possible, or desirable, to differentiate the arts from the ritual ceremonies in which they often occur."21

If we can accept the possibility of a category in which art and ritual are not distinguished, then I propose that a more conservative and specific formulation of Dissanayake's position could be advanced in the following hypothesis:

H2) The function of ritual art is the promotion of group cohesion [by making special.]

It is this hypothesis which we now consider. I think that relatively little has been done to defend similar positions, or even to adequately reject them. Few have even attempted to charitably formulate theories such as Dissanayake's in this way, though it is similar to others', such as

\footnotetext{
${ }^{17}$ Catherine Bell, Ritual Theory, Ritual Practice. (New York: Oxford University Press, 1992), 177.

${ }^{18}$ Victor Turner, The Forest of Symbols: Aspects of Ndembu Ritual (Ithaca: Cornell University Press, 1967), 104105.

${ }^{19}$ Richard Sosis, "The Adaptive Value of Religious Ritual: Rituals promote group cohesion by requiring members to engage in behavior that is too costly to fake," American Scientist Vol. 92 No.2 (2004), $166-172$.

${ }^{20}$ Catherine Bell, Ritual Theory, Ritual Practice. (New York: Oxford University Press, 1992), 98.

${ }^{21}$ Ellen Dissanayake, What is Art For?. (Seattle: University of Washington Press, 1988), 128.
} 
Susan Broadhurst's position in Liminal Acts (1999). ${ }^{22}$ Finally, though art is widespread and arguably universal, suggesting to some its candidacy for an adaptation, a more conservative hypothesis that proposes a functional role for only a certain aspect of art does not delimit the future possibility of accounting for the functional role of all art.

\subsection{Clarification of terms}

Before proposing methods of testing this hypothesis it will be essential to clarify the constituent and relevant terms of our hypothesis. This will serve partly as the theoretical scaffolding of $\mathrm{H} 2$ as well as a clarification of what methods might be required to test $\mathrm{H} 2$.

\subsubsection{Ritual Art}

The reason for the selection of ritual art as a limited category of art for $\mathrm{H} 2$ is that it is exemplary of the role that Dissanayake sees for art. Furthermore, the suggestion that ritual and art serve remarkably similar purposes is one that Dissanayake has already entertained. Regarding these functional similarities, she writes that, "In both art and ritual ceremony, 'another world,' different from the everyday, is invoked." ${ }^{23}$ Clearly she sees the process of "making special" taking place in both behaviors in analogous ways. Not only does she see ritual and art as analogous, but she is also aware of their close sociocultural relationship and even suggests that "in traditional and primitive societies, ritual ceremonies are often the chief occasions for exhibiting the objects and activities that we call art." ${ }^{24}$ Furthermore, she acknowledges that the two concepts are often inseparable. "In primitive societies where ritual and art are inseparable,

\footnotetext{
${ }^{22}$ Susan Broadhurst, Liminal Acts: A Critical Overview of Contemporary Performance and Theory. (London: Cassell, 1999).

${ }^{23}$ Ellen Dissanayake, What is Art For?. (Seattle: University of Washington Press, 1988), 89.

${ }^{24}$ Ibid., 80 .
} 
truly fine things (what would today be called art objects) are not often seen or heard other than in relation to ceremonial and ostentatious occasions, so that they acquire an aura of 'specialness'..." ${ }^{25}$ It is clear from her writing that Dissanayake is willing to admit that there are at least particular cases in which ritual and art share formal, functional and sociocultural similarities, but she is also willing to admit that there are times where they share an identity.

Regarding the role of group cohesion in $\mathrm{H} 1$ and $\mathrm{H} 2$ Dissanayake is not alone in proposing that ritual increases group cohesion. ${ }^{26}$ Furthermore, by choosing to consider ritual art in $\mathrm{H} 2$ instead of other candidates such as literature or music, I avoid these already well-trodden subjects, which I think do not adequately speak to Dissanayake's project. Proposing that we consider a category of art called "ritual art" is not, I think, an objectionable departure from her project. I admit that the term "ritual art" is not familiar and likely brings to mind only a loose collection of behaviors and practices. However, the term is not entirely without precedent, ${ }^{27}$ and other similar concepts have been developed such as Robert Bocock's "aesthetic ritual." 28 For the moment this loose sketch of the intersection of ritual and art will have to suffice until I can go on to provide a more elaborate definition in the following chapter.

\subsubsection{Function}

The term "function" in H2 needs to be unpacked carefully in light of Dissanayake's larger project. Dissanayake is proposing that art, as a special case of making special, is an adaptation. She is less clear about whether she considers it to be currently adaptive as well. In

\footnotetext{
25 Ibid., 89.

${ }^{26}$ See references to Victor Turner and Catherine Bell above.

${ }^{27}$ Cynthia Freeland, But is it Art?: An Introduction to Art Theory. (Oxford: Oxford University Press, 2002$), 2$.

${ }^{28}$ Robert Bocock, Ritual in Industrial Society: A Sociological Analysis of Ritualism in Modern England. (London: George Allen \& Unwin Ltd, 1974), 147
} 
asserting that "the arts are selectively valuable because they serve social ends" 29 it certainly appears from her use of the present tense that she is arguing that the arts are both adaptive and an adaptation. Minimally she seems committed to the notion that for traditional cultures the arts are both adaptive and an adaptation. However, as Kim Sterelny points out, "adaptiveness is neither necessary nor sufficient for a trait to be an adaptation." ${ }^{30}$ Consequently, given Dissanayake's emphasis on both, we can further unpack $\mathrm{H} 2$, into two claims:

1) Ritual art promotes group cohesion [which is fitness-enhancing.]

2) Ritual art was selected for its fitness-enhancing promotion of group cohesion.

The first claim is adaptive, the second is adaptationist. As such the first claim is synchronic and the second diachronic. By definition the second claim does not necessarily require the first, but in Dissanayake's theory she suggests that both are true. Since the first claim is weaker, and arguably easier to test, while the second is stronger and more clearly of interest to evolutionary aesthetics I will rephrase $\mathrm{H} 2$ in the following two hypotheses:

H2.1) Ritual art promotes group cohesion [which is fitness-enhancing.]

H2.2) Ritual art was selected for its fitness-enhancing promotion of group cohesion.

${ }^{29}$ Ellen Dissanayake, What is Art For? (Seattle: University of Washington Press, 1988), 62.

${ }^{30}$ Kim Sterelny and Paul E. Griffiths, Sex and Death: An Introduction to Philosophy of Biology. (Chicago: University of Chicago Press, 1999), 217. 
Since my aim is to develop from Dissanayake's theory a testable hypothesis it is the weaker hypothesis $\mathrm{H} 2.1$ that I wish to address predominantly. However $\mathrm{H} 2.2$ will be of theoretical interest and should still be considered relevant to my project and Dissanayake's. This disambiguation simply serves to clarify methodological concerns that will follow.

\subsubsection{Group Cohesion}

In what way does $\mathrm{H} 2$ propose that ritual art is functional in promoting group cohesion? First, let us unburden ourselves of the commitment to function and consider this question in relation to $\mathrm{H} 2.1$; how does ritual art promote group cohesion? Dissanayake's own account is remarkably thin. As Dutton points out, she relates art to ceremony, both analogously and in its use within ceremony. ${ }^{31}$ From this relationship of ceremony to art is derived the role of art as improving social cohesion. At least this is the interpretation that both Dutton and Davies provide. According to Davies' reading of Dissanayake:

"Art is adaptive because, along with ritual and play, it promotes community benefits that in turn improve the well-being and reproductive potential of society's members. It highlights and affirms what is important to their lives: control over nature, manual competences, group lore, genealogy, wisdom, and values. In addition, it plays a vital role in promoting cooperation, mutual identification, and social cohesiveness." ${ }^{32}$

While this account is clear it still fails to explain how highlighting and affirming confer community benefits. Instead, allow me to offer only one, among many possible accounts, of the

${ }^{31}$ Denis Dutton, The Art Instinct: Beauty, Pleasure, \& Human Evolution. (New York: Bloomsbury Press, 2010), 224.

${ }^{32}$ Stephen Davies, The Artful Species: Aesthetics, Art, and Evolution. (Oxford: Oxford University Press, 2012), 130. 
hypothetical fitness-enhancing role of ritual art. Ritual art is an excellent candidate in this case as it is not only strongly associated with ritual and play, but, as I have already suggested, at many times the boundaries between the categories collapse. Some dance, for example, can be indistinguishable at times from a ritual process. ${ }^{33}$ If Dissanayake is right in asserting that art can serve to promote group values, then the ritualization and repetition of this process might serve to preserve them as well. It is then possible to conceive of ritual art acting as a vehicle for the transmission of not only group values and traditions, but more importantly, as one of the very possibilities of cultural transmission.

The significance of art as both content and vehicle of evolutionary transmission is, I think, essential to an understanding of ritual art as increasing group cohesion. As Elliott Sober and David Sloan Wilson assert, "If group selection is a strong force in human cultural evolution, a special set of transmission rules must have evolved that make it so." ${ }^{\prime 34}$ It is not unreasonable to imagine that ritual art might serve as a type of transmission rule aligned with biased-learning strategies such as "copy the majority," "copy the powerful," etc. as discussed by evolutionary biologists Robert Boyd and Peter Richerson. ${ }^{35}$ Ritual art might be directly responsible for increased group cohesion in the way Dissanayake seems to suggest, however we might also suggest its role in indirectly improving group cohesion by providing transmission rules. Kim Sterelny's work on social scaffolding is also informative on this point. ${ }^{36}$ This brief sketch of the relation of ritual art to group cohesion has already begun to suggest the implicit fitness-

\footnotetext{
${ }^{33}$ Robert Bocock, Ritual in Industrial Society: A Sociological Analysis of Ritualism in Modern England. (London: George Allen \& Unwin Ltd, 1974), 163-5.

${ }^{34}$ Elliott Sober, and David Sloan Wilson, Unto Others: The Evolution and Psychology of Unselfish Behavior. (Cambridge: Harvard University Press, 1998), 150.

${ }^{35}$ Robert Boyd and Peter J. Richerson, The Origin and Evolution of Cultures. (Oxford: Oxford University Press, 2005), 190.

${ }^{36}$ See especially: Kim Sterelny, The Evolved Apprentice: How Evolution Made Humans Unique. (Cambridge: MIT Press, 2012).
} 
enhancing characteristics of group cohesion, but a more complete understanding will have to wait until Chapter 4.

\subsubsection{Group Selection}

Criticism leveled against Dissanayake by Dutton and Pinker relies on the assumption that Dissanayake's reference to group cohesion must be understood as relating to a fitness benefit at the group level in order for it to have any evolutionary force. On the subject of group selection Dutton is certainly critical of Dissanayake.

“...not everyone is convinced by this 'social cohesion' explanation for the arts. Steven Pinker associates it with the theory of group selection in evolution ... Leaving aside the technical objections to group selection theory as an evolutionary principle ... the case for it providing an evolved function for the arts seems to me weak."37

This type of criticism is misguided for two reasons. First, emphasis on group cohesion does not commit one to a simplistic group selectionist view of evolution, nor even to the view that group selection takes place. Group cohesion may be understood in terms of individual fitness benefits. Second, the de facto rejection of group selection seems out of date relative to the work that has been done on multi-level selection, or it creates of group selection arguments a straw man resembling the simplistic views of group selection that dominated early evolutionary thought. As Omar Tonsi Eldakar and David Sloan Wilson put it, "Group selection, which was once widely

\footnotetext{
${ }^{37}$ Denis Dutton, The Art Instinct: Beauty, Pleasure, \& Human Evolution. (New York: Bloomsbury Press, 2010), 226.
} 
rejected as a significant evolutionary force, is now accepted by all who seriously study the subject." 38

In Unto Others (1998) Elliot Sober and David Sloan Wilson suggest that group selection need not be modeled in the typical genetic language of selfishness and altruism. In a simple biological example, phenotypic traits may be understood as selfish or altruistic, but culture, especially human culture, allows the possibility that phenotypic traits are reinforced by norms. This is a suggestion I have already made in regard to ritual art. These social norms "promote behavioral uniformity within groups, thereby reducing the potential for within-group selection." ${ }^{39}$ Norms not only reduce internal variation in the group but they can serve to increase between-group variation, which may provide the conditions necessary for selection to take place. Since social norms can provide the conditions under which any behavior might become stable, the costliness and benefit of behaviors "are simply overwhelmed by the rewards and punishments that are attached by the social norms." 40

Regarding the question of whether group cohesion confers a fitness benefit in betweengroup selection, this depends on what exactly we mean by group cohesion. While I have begun the process of sketching out a definition and role for group cohesion, a project I will complete in Chapter 4, I think we have to accept that, all things being equal, the potential relationship between group cohesion and fitness benefits is largely accepted. In his paper "Altruism, Selfishness and Social Cohesion”(2011) Antonio Luigi Paolilli asserts that,

\footnotetext{
${ }^{38}$ Omar Tonsi Eldakar and David Sloan Wilson, "Eight Criticisms not to Make About Group Selection," Evolution: International Journal of Organic Evolution Vol.65 Issue 6 (2011), 1523.

${ }^{39}$ Elliott Sober, and David Sloan Wilson, Unto Others: The Evolution and Psychology of Unselfish Behavior. (Cambridge: Harvard University Press, 1998), 150-151.

${ }^{40}$ Ibid., 152.
} 
"If two groups, at the same technological level, are so close to each other to compete on the resources, even a small difference in the degree of internal cohesion ... is obviously enough to determine a clear prevalence of the most cohesive group, especially if they are numerically comparable." ${ }^{\prime 1}$

While this by no means establishes that group cohesion is always fitness-enhancing, it does demonstrate importantly that at least in the minimal definition of cohesion as something along the lines of unity and high degrees of cooperation, there are situations in which it is group fitness-enhancing.

If we were to imagine ritual art as functional in improving group cohesion and thereby conferring a fitness benefit on the group, we may not have to justify the emergence of ritual art as a costly behavior. The fact that it merely could emerge and become stable, given certain norms, and that we know that it has in fact emerged in various cultures, is enough. We need not justify its costliness in light of defection, selfishness, or other problems of within-group selection. As Sober and Wilson suggest, "Within-group selection can favor any behavior, depending on the social norm of the group. Between-group selection favors only social norms that lead to functionally adaptive groups. ${ }^{, 42}$ The problem for $\mathrm{H} 2.1$ then is to demonstrate that ritual art actually does increase group cohesion. The problem for $\mathrm{H} 2.2$ is even more explicitly to demonstrate that group cohesion is functional in between-group selection.

The first point has been addressed above and I will return to it in Chapter 4. That suggestion was that ritual art may enhance group cohesion insofar as it functions as a type of norm, in which case it serves to provide the very possibility of the emergence of group behaviors

\footnotetext{
${ }^{41}$ Antonio Luigi Paolilli, “Altruism, Selfishness and Social Cohesion,” Sociology Mind Vol. 1 Issue 4 (2011), 147.

${ }^{42}$ Elliott Sober, and David Sloan Wilson, Unto Others: The Evolution and Psychology of Unselfish Behavior. (Cambridge: Harvard University Press, 1998), 152.
} 
and their transmission. Furthermore, it seems reasonable that insofar as ritual art is a unique behavior within a group, bolstered by norms, it may increase group cohesion in the sense that it serves to draw an $u s$-them distinction for the members of the group towards other groups. ${ }^{43}$ It is possible to imagine that ritual art is uniquely positioned to draw just such a distinction, perhaps even better than many other behaviors, or at least as well as religious dietary practices, for example. $^{44}$

I will not spend any further time attempting to demonstrate that multi-level selection is an acceptable interpretation given the correct conditions. Instead, the process of testing this hypothesis might demonstrate whether the conditions for group selection exist in the cultures under consideration. What this entails is that if the relationship between ritual art and cohesion cannot be established then the group selection argument is moot. This has already been suggested by the disambiguation of $\mathrm{H} 2.1$ and $\mathrm{H} 2.2$. If, however, a relationship can be established it might demonstrate the very conditions under which group selection might occur. That being said, I have already asserted that ritual art may be instrumental in serving as a transmission rule in cultural evolution. This is not an unreasonable conjecture given that any norm can serve to increase transmission. While this might confer a fitness benefit to groups (insofar as groups could maintain a high degree of heritability) it does not demonstrate that high heritability translates to group fitness, unless the behaviors being transmitted are themselves group fitnessenhancing.

\footnotetext{
${ }^{43}$ Arthur A. Stein, "Conflict and Cohesion," Journal of Conflict Resolution Vol. 20 No. 1 (1976), 143-172.

${ }^{44}$ Victor Benno Meyer-Rochow, "Food Taboos: Their Origins and Purposes," Journal of Ethnobiology and Ethnomedicine 5:18 (2009), 9.
} 


\subsection{Proposals for the testing of $\mathrm{H} 2$}

\subsubsection{Anthropological Analysis}

As a first step towards testing $\mathrm{H} 2$ we might begin by conducting an anthropological analysis of the role of ritual art in traditional societies. While I have proposed a model in which ritual art might be fitness-enhancing for groups in mitigating within-group selection and promoting between-group selection, this does little to demonstrate the more robust claims of H2.2 and those that Dissanayake seeks for art and ritual more generally. Instead, analysis of ritual art in traditional cultures would have to reveal a tangible role in increasing group cohesion. However, the way in which Dissanayake discusses the anthropological data is largely anecdotal. What is needed is a statistical survey of ritual art across traditional communities.

In the study of religion and evolution a statistical survey of this form has been performed by Carlos A. Botero et. al. in "The Ecology of Religious Belief." 45 This project identified a high degree of correlation between ecological factors and the type of religious belief accepted by indigenous populations. Though this is certainly not conclusive it strongly suggests that the type of religious belief adopted (belief in moralizing vs. non-moralizing gods) is an adaptation to the particular ecological conditions faced by these groups. Similarly relevant data exists for ritual and art, and comparative anthropological work is replete with accounts of ritual practices. From these ritual practices one could gather data regarding ritual art. If an appropriate sampling of these accounts could be analyzed systematically against data regarding group cohesion, $\mathrm{H} 2$ could be tested by statistical correlation. Determining the correlation between ritual art, relevant ecological conditions, and group cohesion would serve in part to test H2.1. Not only could an

${ }^{45}$ Carlos A. Botero, et. al., "The Ecology of Religious Belief," PNAS Vol.111 No.47 November (2014). 1678416789. 
anthropological survey of ritual art serve as evidence for or against $\mathrm{H} 2.1$, but it is very likely to do so in a way that enhances our understanding of the relationship between ritual art and group cohesion. This might further enhance our understanding of how H2.1 and H2.2 relate, beyond the proposal that group cohesion increases the fidelity of heritable transmission.

In the study performed by Botero et. al., a high degree of correlation was found between belief in moralizing high gods and ecological conditions defined by a high degree of harshness and unpredictability, among other conditions. ${ }^{46}$ This suggests that the belief in moralizing high gods may be functional for these groups in addressing unpredictable ecological conditions. An anthropological survey that found a high degree of positive correlation between the presence and use of ritual art; group cohesion; and the ecological conditions that put greater pressure on group cohesion would be supportive of $\mathrm{H} 2.1$, as well as, to a lesser extent H2.2. Of course, these conditions might be so widespread that an anthropological survey determines that ritual art is nearly as ubiquitous as Dissanayake suggests art is. This is not harmful to her theory (H1), but it does little to test H2. If this is the case perhaps a comparative anthropological survey of traditional cultures and industrial cultures would be fruitful. If ritual is indeed less widespread in industrial cultures than it is in traditional cultures ${ }^{47}$ this may suggest that it is adaptive in traditional cultures, but neutral or maladaptive in industrial cultures. This very well might be the case, as the process of industrialization might alleviate some relevant selective pressure. This would help significantly to resolve the distinction between $\mathrm{H} 2.1$ and $\mathrm{H} 2.2$ as it offers an adaptive explanation of the current state of an adaptation.

\footnotetext{
${ }^{46}$ Ibid., 16785-16786.

${ }^{47}$ Victor Turner, "Liminal to Liminoid, in Play, Flow, and Ritual: An Essay in Comparative Symbology," The Rice University Studies Vol.60 No.3 (1974), 56.
} 


\subsubsection{Phylogenetic accounts of cultural evolution}

Another way in which we might test $\mathrm{H} 2$, and especially $\mathrm{H} 2.2$, is by means of a phylogenetic account of cultural evolution. Ruth Mace and Clare J. Holden have suggested that the fruitfulness of this methodology in studies of language might also be applied to culture more broadly. ${ }^{48}$ On this view cultures are seen as analogous to species, and phylogenetic trees are built from extant cultures and their shared ancestors. Despite the possible objection that cultural merging might be seen as disanalogous to cladistic approaches in genetics, Mace and Holden argue that splitting has been a response to growth and merging to depopulation. Therefore, "the extant anthropological record is likely to contain predominantly those cultures that experienced expansions and splits; thus a phylogenetic model should fit cultural diversification well." 49 While a phylogenetic approach that attempted to trace the cultural evolution of ritual art would be an incredibly difficult undertaking, one could instead use existing phylogenetic models of cultural difference defined by linguistic difference to study those cultures in which ritual art is present. This research would help to determine whether ritual art was widespread due to common cultural ancestry, or whether the practices emerged independently.

If it is the case that ritual art is widespread among cultures only due to common ancestry then there is the very real possibility that the practice lacks an adaptive function, beyond perhaps its role as a type of social norm, as mentioned earlier. Nonetheless, there is the possibility that the behavior is descended from a common ancestor and remains adaptive. The phylogenetic approach, however, would not suggest this conclusion immediately. If extant cultural groups make use of the shared ancestral behavior in ways that are unique to their environment we might

\footnotetext{
${ }^{48}$ Ruth Mace and Clare J. Holden, “A Phylogenetic Approach to Cultural Evolution,” TRENDS in Ecology and Evolution Vol.20 No.3 March (2005): 116-121.

${ }^{49}$ Ibid., 117.
} 
consider the behavior both adaptive and an adaptation. The evidence needed to suggest this would be far greater than mere structural similarity to the ancestral behavior, with unique modification to the local environment. In fact, this is to be expected. Instead, one would likely have to demonstrate that the behavior persists with modifications that make it better suited to its supposed fitness-enhancing role in a given environment

Though the phylogenetic approach is compelling, and may be necessary to testing $\mathrm{H} 2$, it is by no means sufficient evidence for H2.2. If, however, $\mathrm{H} 2$ was restated in light of research performed in an anthropological survey and/or certain modeling of between-group selection into a predictive hypothesis regarding the types of ecological conditions under which ritual art would arise as an adaptation, then this hypothesis could be tested for its predictive power against existing phylogenetic trees of culture distinguished by language.

Another aspect of the phylogenetic approach that I have not discussed is the possibility that ritual art coevolves with some other cultural behavior. If the phylogenetic approach suggests that ritual art has multiple independent origins, then it might be useful to attempt to trace behaviors that coevolved with ritual art, such as religion and myth. This may suggest, for example, that ritual art only exists as a consequence of a type of ritual behavior. If some other behavior is causing the widespread adoption of ritual art as a cultural behavior, then tracing the coevolution of the two behaviors might be useful in determining if one or both of them are functional. Such analysis of the coevolution of a widespread behavior would serve to answer the criticism that Davies directs towards Dissanayake for H1. Even if H2 is ultimately unsupported by this methodology, given that a more fundamental functional behavior exists for which ritual art is merely an expression, the rigorous testing of a hypothesis such as $\mathrm{H} 2$ is essential to advancing our understanding of the relationship between art and evolution more generally. 


\subsection{Conclusion}

Of the proposed strategies for testing H2 I will undertake in this paper a cross cultural analysis of ritual art and group cohesion. There are several reasons for choosing this method. First, a cross cultural analysis should be preliminary to a phylogenetic account since the results of a cross cultural analysis are very likely to determine the methods or utility of a phylogenetic account. Second, the cross cultural analysis can avoid accusations of cherry-picking given a large enough random sample. Finally, a cross cultural analysis is a manageable project given the limitations of this relatively short paper. In the following chapter I begin by offering a theoretical definition of ritual art which can be operationalized. In Chapter 3 I then offer a coding method and pre-test this measure. In Chapter 4 I develop a theoretical definition of group cohesion grounded in a review of relevant literature. This theoretical definition will be broken down into a number of dimensions that can be operationalized. I will identify not only promising proxies for group cohesion, but also measures of the ecological conditions under which group cohesion comes under selective pressure. For each variable representing "group cohesion” I will propose a hypothesis regarding the relationship between that variable and the variable "ritual art" that is in keeping with predictions we would derive from H2. Finally, in Chapter 5 the data collected for the variable "ritual art" will then be correlated independently with each variable for "group cohesion" and compared to hypotheses developed in Chapter 4. Results are expected to be merely supportive or unsupportive of H2.1. Speculation on the relationship between supportive or unsupportive results for $\mathrm{H} 2.1$ and their relationship to $\mathrm{H} 2$ will be reserved for the conclusion. 


\section{Chapter 2 - Developing a Theoretical Definition of Ritual Art}

In this chapter I explore the notion of "ritual art". My intention is to arrive at a theoretical definition of ritual art that can be used to develop an operational definition for use in the crosscultural survey that is to follow. As I have suggested already, the concurrence of ritual and art, and occasionally their mutual identity, is not foreign to Dissanayake's project. Under the heading of ceremony, a term that Dissanayake uses almost interchangeably with ritual, she writes,

"Although I have never seen it described this way, 'ceremony' is, in fact, a one-word term for what is really a collection or assembly of elaborations (of words, voices, actions, movements, bodies, surroundings, and paraphernalia) — that is, of arts (chant or song, poetic language, ordered movement and gesture or dance, mime, and drama, along with considered and even spectacular visual display).",50

While this later view of Dissanayake's comes closer to my proposed definition of ritual art, it is also problematic for reasons that are similar to those proposed by Davies. While Davies criticizes Dissanayake for being too general in the functional role she proposes for all art, the view expressed above compounds the problem by suggesting that nearly everything is art. However, we can set this problem aside if we limit ourselves to the "ritual art" of H2.1 and H2.2. I have already discussed how Dissanayake sees art and ritual related, both formally, functionally and socioculturally, however, her suggestion of something akin to "ritual art" ends there. ${ }^{51}$ With the

${ }^{50}$ Ellen Dissanayake, Art and Intimacy: How the Arts Began. (Seattle: University of Washington Press, 2000$), 138$.

${ }^{51}$ Ellen Dissanayake, What is Art For? (Seattle: University of Washington Press, 1988), 89. 
term "ritual art" I mean to define a practice in which ritual and art are indistinguishable though not by means of broad or universal definitions of the separate terms.

First, allow me to suggest in broad strokes why the phrase "ritual art" may be useful and meaningful. I will then turn to defining it carefully by considering the definition of its constituent terms. While part of the affinity between art and ritual is found, for Dissanayake, in the act of making special, they are also related in the emphasis she places on them as behaviors. It is as a behavior that Dissanayake sees art coming under selective pressure. ${ }^{52}$ Ritual theorist Catherine Bell also notably defines ritual as behavior. Instead of referring to it statically as ritual she prefers the term "ritualization." "53 It is through the concept of the ritualization of behavior that we can better understand what Dissanayake means by ritual. Bell writes,

"Ritual is not assumed to exist as a natural category of human practice.

Within this interpretive framework some activities are performed in culturally relevant ways to generate the perception that these activities are both intrinsically different from other acts and privileged in their significance and ramifications. The framework proposed here focuses, therefore, on the generation of what we call ritual as a way of acting, namely the ritualization of activity." 54

For Bell, ritual, or the ritualization of activity, is "a particular cultural strategy of differentiation linked to particular social effects and rooted in a distinctive interplay of a socialized body and the

\footnotetext{
${ }^{52}$ Ibid., 91.

${ }^{53}$ Catherine Bell, Ritual Theory, Ritual Practice. (New York: Oxford University Press, 1992), 219.

${ }^{54}$ Ibid.
} 
environment it structures." 55 This is not at all dissimilar from the way in which Dissanayake defines "making special" and discusses its role in ritual. Bell, however, offers a more concrete way of describing the activity and defining ritual. Ritual is the behavioral process of changing social perceptions of an object or action, so that it becomes differentiated and significant. When this behavior takes as its subject an object or action that we would call art, then it is the ritualization of art. When both ritualization and art take the form of action or behavior, then the two become largely indistinguishable. This would be the case, for example, with the ritualization of a dance, where the process would combine two instances of behavior; ritualization and dance. We have attempted to define ritual and then to consider when it becomes ritual art, through a process of ritualization, but writers such as Robert Bocock have also considered the inverse,
"it is possible, and necessary, to go on to differentiate within the arts, on the basis of the fact that some works of art are more 'ritualistic' than others. Those works which draw on myths, either from ancient Greece, Teutonic or Celtic Europe, Christianity, Hinduism, or whatever, and involve some kind of performance from artists, are the most crucial examples of ritual arts, or what are called here aesthetic rituals." 56

While Bell's interpretation of ritual as ritualization allows us to consider the way in which ritualization of art behavior might become what I have termed "ritual art" Bocock's approach suggests that the arts can drift into this category by their influences, structures, and performance. In this way these art forms become indistinguishable from the ritual processes they are a part of.

\footnotetext{
55 Ibid., 8.

${ }^{56}$ Robert Bocock, Ritual in Industrial Society: A Sociological Analysis of Ritualism in Modern England. (London: George Allen \& Unwin Ltd, 1974), 149.
} 
Having tried to clarify what we mean by ritual using Bell's concept of ritualization we now turn to Dissanayake's concept of making special, before attempting to define art.

Dissanayake's term "making special" is admittedly vague and does little to distinguish art as art. The act of making special is thus not a definition of art, since she thinks that other human activities also make special, but she believes that art is a distinct form of making special. So while making special might not be definitional, it is the function of art for Dissanayake. Since I will be primarily concerned with art and ritual as behaviors, I will speak predominantly of the activity of art instead of the work or object of art. In defining the concept of art as behavior Dissanayake writes,

"My own notion of art as a behavior, whose evolution will be hypothetically reconstructed... rests on the recognition of a fundamental behavioral tendency that I claim lies behind the arts in all their diverse and dissimilar manifestations from their remotest beginnings to the present day. ... I call this tendency making special and claim that it is as distinguishing and universal in humankind as speech or the skillful manufacture and use of tools." 57

Dissanayake is defining "making special" not only as an synchronic phenomenon, that is merely “a fundamental behavioral tendency," but also phylogenetically by tracing its evolution, albeit hypothetically. However, as discussed earlier, I have distinguished H2.1 and H2.2 in order to address these two aspects of function. While Dissanayake does understand the behavior of art as making special to be functional in an evolutionary sense it is unimportant to H2.1 and is only

\footnotetext{
${ }^{57}$ Ellen Dissanayake, What is Art For?. (Seattle: University of Washington Press, 1988), 92.
} 
mentioned to frame her theory properly. Having established that the act of making special is not definitive of art, though it is distinctive in its exceptional ability to make special, and that Dissanayake is proposing we consider making special as a functional behavior, it remains to determine just what this phrase means. Dissanayake writes that,

"In whatever we are accustomed to call art, a specialness is tacitly or overtly acknowledged. Reality, or what is considered to be reality is elaborated, reformed, given not only particularity (emphasis on uniqueness, or 'specialness') but import (value, or 'specialness')—what may be called such things as magic or beauty or spiritual power or significance.

Making special implies intent or deliberateness. When shaping or giving artistic expression to an idea, or embellishing an object, or recognizing that an idea or object is artistic, one gives (or acknowledges) a specialness that without one's activity or regard would not exist. Moreover, one intends by making special to place the activity or artifact in a 'realm different from the everyday." 58

Dissanayake struggles to define the phrase making special without constant recourse to the word “special/specialness" however, given Bell's definition of ritualization this idea should be slightly clearer. To make special is to differentiate a thing from its reality. This reality is merely a set of norms and socially constructed values. Ritual, art, and play are therefore activities that operate within socially constructed realities to differentiate certain activities or objects from their

${ }^{58} \mathrm{Ibid}$. 
quotidien roles. This lends the term well to its candidacy for consideration in relation to ritual art. Not only could rituals have developed culturally or biologically but, according to Bell, they satisfy the conditions of differentiating a reality defined by contractual or nominalist social norms.

\subsection{John Dewey - Art as Experience}

It is interesting to note that throughout her work Dissanayake refers to the ways in which making special, as a concept, is not particularly new. "I am not the first to characterize art as consisting of transformation, 'bracketing,' recognizing and entering an alternative realitythough I call this 'making special." "59 However she rejects other accounts for not naming the amorphous concept. In particular there is a strong connection to be drawn between Dissanayake's concept of making special and John Dewey’s notion of “an experience.”"60 Though Dewey does not refer to it as ritual, his description of aesthetic experience is remarkably similar to Dissanayake's concept of "making special" as differentiating a thing from its reality or the everyday. This similarity has also been noted by Dutton.

"He [Dewey] too wanted to show that art, though a special focus of attention, was not unique in its qualities, that a storm at sea, a Paris meal, or the climb to the top of a mountain could be a special, aesthetic experience. To this, Dissanayake adds an emphasis on the extent to which

\footnotetext{
${ }^{59}$ Ibid., 98 .

${ }^{60}$ John Dewey, Art As Experience. (New York: Penguin Group, 2005), 36.
} 
much of human cultural life is built around rituals that make aesthetic, emotional experiences possible." ${ }^{\prime 1}$

Furthermore, it is interesting to note that Dewey's work in Art as Experience (1934) is strongly influenced by evolutionary thought. For Dewey the constant negotiation between 'live creature' and environment is what amounts to perpetual experience. "An experience" on the other hand is differentiated from experience by completeness, or coherency; "we have an experience when the material experienced runs its course to fulfillment.." ${ }^{, 2}$ According to Dewey, works of art are capable of creating an experience by also being aesthetic, which for Dewey means to frame experience for the perceiver as something enjoyable. ${ }^{63}$ " The real work of an artist is to build up an experience that is coherent in perception..." ${ }^{\prime 64}$ It is in this way that I see Dewey's conception of an experience as similar to Dissanayake's concept of making special, at least insofar as it picks out and differentiates a thing from its reality. For Dewey this involves turning our constant experience into discrete units of experience. This is what Dissanayake has vaguely called making special, and it also resembles Bell's concept of ritualization. That Dewey defines art in this way; and Bell, ritual, while both share similarities with "making special" suggests the utility of the term "ritual art".

For our purposes Dewey helps to clarify Dissanayake's concept of making special. I think that Dewey's language of "an experience" and the formal elements that bring this about, can help us to understand how making special—as a concept—can be more readily identified in the practice of ritual art as a way of differentiating a thing from its social reality. This social reality,

\footnotetext{
${ }^{61}$ Denis Dutton, "Ellen Dissanayake," Philosophy and Literature 18 (1994): 207.

${ }^{62}$ John Dewey, Art As Experience. (New York: Penguin Group, 2005), 36.

${ }^{63}$ Ibid., 49.

${ }^{64}$ Ibid., 53.
} 
for Dewey, is the continuous experience of live creature and environment, but we can make use of other language in anthropology to further our theoretical definition of just what is meant by "ritual art."

What Dewey offers us is a way of understanding the mechanism by which making special works. Making special picks out an experience and gives it a unity, a fulfillment, a consummation. Dewey refers to this as the way art frames experience into an experience. While everyday experience is made up of a continuous stream of stimuli, an experience is elevated out of this milieu and given shape. Recall Dissanayake when she characterizes "...art as consisting of transformation, 'bracketing,' recognizing and entering an alternative reality..." ${ }^{65}$ At least some art, I think we can accept, is a way of framing and differentiating. Dewey certainly thinks so. I propose that ritual art offers an excellent example of a type of art that frames and differentiates in a decidedly social way. It is the ritualization of artistic behavior within a sociocultural history or framework. Thus I am excluding from my theoretical definition of ritual art such works as Casey Jenkins Casting Off My Womb (2015) or Marina Abramovic's The Artist is Present (2010), despite the fact that these works rely heavily on repetition and ritual. The repetition and ritual are self-contained within these performances. They need no sociocultural fostering, though they might benefit from a sociocultural interpretation. Furthermore, as a practice presumably facilitated by a sociocultural history of iteration, ritual art is usually a highly social activity. By this I mean that it may involve many members of the social group, or that it may have significance for many members of the social group.

While I have gone to some lengths to define ritual, as well as its intersection with the arts the reader will note that I have not provided a definition of art. Though Dewey's account is decidedly aesthetic, the failure to define art is intentional. The project of defining art is a

\footnotetext{
${ }^{65}$ Ellen Dissanayake, What is Art For?. (Seattle: University of Washington Press, 1988), 98.
} 
contentious issue in philosophy that is in a cross-cultural analysis only complicated by the risk of orientalism in attempting to define another culture's practices in the language of western art, aesthetics, and philosophy. Instead I hope to emphasize the ritualization of broadly aesthetic objects and practices. This should avoid many of the pitfalls of defining art while still being sufficiently specific for the purposes of my theoretical definition. This will also be bolstered by the consideration of certain anthropological examples of what I take to be ritual art. "Art" for our purposes can be understood very broadly as an object or behavior that is intentionally aesthetically powerful. The theoretical definition of "ritual art" can then be provided in the form of two complementary definitions:

1. An iterated aesthetically powerful activity performed in a culturally and socially relevant way in order to differentiate an object or behavior by giving it cultural and social significance.

2. An iterated activity performed in a culturally relevant way in order to differentiate an aesthetically powerful object or behavior by giving it cultural and social significance.

This theoretical definition is much closer to something we can work with than anything else thus far. Furthermore, while it may not entirely avoid a charge of orientalism it categorizes art broadly and places emphasis on the role of the behavior or object within the native culture. However, it remains insufficient. As noted, the definition of art is broad and frames it in terms of aesthetic objects and behaviors. However, getting a better grasp on what these aesthetic objects and behaviors are will require careful consideration of some anthropological examples suitable to our theoretical definition. 


\subsection{Anthropological Examples}

One of the reasons that ritual art is perhaps not a term in regular use is because it presents a certain ambiguity in the relationship between ritual and art. This ambiguity will be explored in the examples that follow. Among possible examples of ritual art one I find particularly compelling is the ritual art practices of certain Australian Aboriginals. This distinctive art style is made up of simple lines and circles in quite beautiful repetition. In Anthropology, Art and Aesthetics (1992) Robert Layton describes the work as follows,

"The commonest motif is made up of circles joined by straight lines, which typifies desert peoples' perception of their traditional way of life: camping and walking, camping and walking. Other subjects include hills, caves, vegetable foods, and stars: less obviously 'tracks' to us, but not to the artists. ... The art style also appears in ritual contexts, and [Nancy] Munn draws attention to the fact that the very simplicity of these motifs allows them to represent many things at once. They are ideally suited to depicting the transformations that ancestral heroes underwent during the 'Creation Period': the tjukurrpa or 'time of the law'. According to Aboriginal religion, both the landscape and society were shaped by the actions of ancestral heroes." 66

Here the ritual use of art is made apparent. Art functions as a medium for communicating certain cultural norms or values. It does so by elevating these symbolic elements in ritual out of the everyday. Here the art object is described as "ideally suited" to its role in ritual, which is

\footnotetext{
${ }^{66}$ Robert Layton, "Traditional and Contemporary Art of Aboriginal Australia: Two Case Studies," in Anthropology,
} Art, and Aesthetics, ed. Jeremy Coote and Anthony Shelton (Oxford: Clarendon Press, 1992), 138. 
essential to my argument that ritual art is a term still in keeping with Dissanayake's larger project. However the relationship between art and ritual is not necessarily indistinguishable in this example. Art is used within a ritual process in the description above. However, Layton goes on to explain how these same visual depictions of the environment are actively painted, as part of the ritual, on the ground, in caves, and on the bodies of ritual dancers. It is in this process that ritual and art become indistinguishable; first in the ritualized activity of painting, as opposed to the use of the static painted object, and second in the ritualized dance of a painting that has become embodied. While this example shows promise, it also demonstrates the difficulty associated with defining the prepositional relationship between ritual and art. I will consider some of these very briefly in what follows.

The use of art in ritual is likely as universal and ubiquitous as the presence of art in culture. However there are instances where art in ritual might serve as a candidate for ritual art. One such example is the use of masks in rites of initiation, such as those of the Ndembu. Victor Turner discusses the use of masks in ritual extensively in The Forest of Symbols: Aspects of Ndembu Ritual (1967). For Turner the transition between defined structures of initiation rites is facilitated by the communication of what he terms sacra. ${ }^{67}$ The sacra can assume many forms, such as masks, but the intention is to communicate certain truths or values regarding the culture in which the rites of passage take place. The sacra are communicated through three processes:

"The first is the reduction of culture into recognized components or factors; the second is their recombination in fantastic or monstrous patterns and shapes; and

\footnotetext{
${ }^{67}$ Victor Turner, The Forest of Symbols: Aspects of Ndembu Ritual (Ithaca: Cornell University Press, 1967), 102.
} 
the third is their recombination in ways that make sense with regard to the new state and status that the neophytes will enter." ${ }^{16}$

The sacra define structures and then recombine them. In this way they "differentiate an object or behavior and give it cultural and social significance." For instance, between the structures of childhood and adulthood, during the ritual of initiation, the "betwixt and between" of moral structures and values are explored. In this exploration of values being gained and left behind the structures of childhood and adulthood are further defined and the subject's position in the liminal period established by the emphasis upon the inter-structural. In keeping with Dissanayake, Turner emphasizes the importance of the communication of cultural and social values and norms in relation to rites of passage;

"When one examines the masks, costumes, figurines, and such displayed in initiation situations, one is often struck, as I have been when observing Ndembu masks in circumcision and funerary rites, by the way in which certain natural and cultural features are represented as disproportionately large or small. A head, nose, or phallus, a hoe, bow, or meal mortar are represented as huge or tiny by comparison with other features of their context which retain their normal size. ... What is the point of this exaggeration amounting sometimes to caricature? It seems to me that to enlarge or diminish or discolor in this way is a primordial

${ }^{68}$ Ibid., 106. 
mode of abstraction. The outstandingly exaggerated feature is made into an object of reflection." ${ }^{69}$

When I refer to ritual art I believe that these elements of art in ritual are closely related components of a theoretical understanding of the term "ritual art." However, the mere presence of an art object in a ritual process is insufficient to warrant use of the term. "Ritual art" does not refer to these artifacts made use of during ritual, nor to any other peripheral works of art. Instead, the use of an art object must in some way be indispensable to the ritual process and indistinguishable from it; it cannot represent merely the medium for communication that could easily be replaced with less integrated elements. In this way the use of art objects in ritual could be understood as a relationship of art and ritual. If the process of making use of an art object in a ritual is integrated in a way that cannot easily be dissociated, then this might be a candidate for a type of ritual art. The distinction between a static painting and the activity of painting made earlier demonstrates this point well. The ubiquity of art and ritual means that referring to art in ritual as ritual art can be far too broad and misleading.

Perhaps another prepositional relationship we could consider is the ritual of art. By the ritual of art, I mean the performance of art such that it becomes ritualized. Casting off my Womb (2015) would count as just such an example of the performance of art as its own ritual. Here the ritual is Jenkins' repetition of the act of inserting wool into her vagina on a daily basis for 28 days and making the knitting process a part of the ritual of a monthly cycle of menstruation. However, I would hesitate to count this type of example as ritual art under my theoretical definition because it lacks the type of extended behavioral repetition necessary for fitness. By extended I mean both culturally and historically extended. Only by being historically extended

${ }^{69}$ Ibid., 103. 
could it come under selective pressure. Here art, especially performance art, is intentionally ritualized. However, this lacks the social and cultural shared history that fosters the long-term iteration of the ritual. While aesthetically powerful, and intentionally ritualized, these works lack a greater social or cultural role that could be related to fitness.

Among other formulations we might consider ritual as art. By ritual as art I mean to refer to the simultaneity of ritual and art as one. The liminal, as described by Victor Turner and the above example of Australian Aboriginal line painting would count, I think, as such a relationship. This is one of the most promising examples of the relationship of ritual to art that I am searching for in a theoretical definition of ritual art.

Moving forward, it will be important to keep in mind not only our theoretical definition of ritual art but also the examples that temper that definition and provide us with a better understanding of what it will look like in anthropological data that will be discussed in the following chapter. 


\section{Chapter 3 - Operationalizing and Coding for Ritual Art}

In the previous chapter I developed a theoretical definition of ritual art in order to pursue a cross-cultural survey. That definition proposes that ritual art offers an excellent example of a type of art that differentiates an object or behavior and gives it cultural and social significance. However, the relationship of art to ritual and ritual to art also suggested that our theoretical definition needed two complementary forms.

In order to begin a cross cultural survey capable of testing the hypothesis that ritual art promotes group cohesion it will be necessary to first establish an effective method of measuring the presence of ritual art in a culture as a variable. The first step in this process, the theoretical definition of ritual art, has already been accomplished in the preceding chapter. It will then be necessary to establish an operational definition of this theoretical definition, prescribe a coding practice to a given dataset, and then test the operational definition and coding practice against a sub-sample. In what follows I begin this process.

\subsection{Theoretical Definition}

The theoretical definition developed thus far proposes that ritual art frames and differentiates in a decidedly social way, is ritualistic because of a behavior of ritualization that differentiates within a socially constructed reality, and is a practice facilitated by a sociocultural history, making it a highly social activity. Furthermore, this process makes use of or has as its focus an aesthetically powerful object or activity. Bear in mind that this theoretical definition is tempered by consideration of various examples of the relationship between ritual and art. The two forms of this theoretical definition are repeated here: 
1. An iterated aesthetically powerful activity performed in a culturally and socially relevant way in order to differentiate an object or behavior by giving it cultural and social significance.

2. An iterated activity performed in a culturally relevant way in order to differentiate an aesthetically powerful object or behavior by giving it cultural and social significance.

\subsection{Operational Definition}

The operational definition of ritual art that I will make use of involves textual references to ritual and art in relevant cross-cultural samples which fit with the theoretical definition provided. In plain terms the operational definition is

$$
\begin{aligned}
& \text { Number of unique “ritual art" practices. } \\
& 0=\text { no ritual art practices } \\
& 1=\text { One ritual art practice } \\
& 2=\text { Two unique ritual art practices } \\
& 3=\ldots
\end{aligned}
$$

Cultures will be ranked from 0 to any positive integer. A culture that measures 0 on this ratio scale presents no data in the cross-cultural sample to support the presence of the theoretical definition of ritual art. A rank of “.” will be assigned to any culture with unclear or ambiguous data. Each positive integer ranks the cultures by the number of unique and distinct ritual art practices present in the given cross-cultural sample. If a culture has one recorded ritual art 
practice that meets the theoretical definition then it is ranked as 1. If a culture has two unique, recorded ritual art practices that meet the operational definition then it is ranked as 2 , and so on. The assumption behind this operational definition is that it offers an objective measure that may very roughly approximate the relative complexity of a ritual art culture by presence. This definition, I think, has sufficient face validity.

\subsection{Coding Instructions}

In order to code this operational definition of ritual art I will sample all world cultures within the Probability Sample Files (PSF) of the Electronic Human Relations Area Files (eHRAF). The PSF is a random sampling of 60 cultures that reduces the eHRAF to a manageable, random, and representative sampling. In order to further simplify the process I will reduce the search of the PSF to the OWC term "Dance" (535) and the keyword "ritual." This is to be entered into the advanced search engine of the eHRAF as a Boolean conjunction. While these two terms do not capture all possible instances of the theoretical definition, they do return a high degree of relevant textual references. While music, and performance might also be promising additions they overly complicate the coding process without adding any underrepresented data. The presence of dance or music in traditional cultures is nearly always indication of the presence of the other. Further pre-testing of the measure will determine whether this coding method is appropropriate to the operational definition.

I am aware that the choice to include only the OWC term "Dance" in conjunction with the keyword "ritual" will return limited results and will also exclude other promising candidates for ritual art such as music, theater, and even, possibly, representative art. However, I think the choice is appropriate both to producing a representative and manageable sampling as well as 
ensuring the data reflects ritual art typified by the ritual body; that is the behavior of ritualization and art as identical in an act. Dance is perhaps the best example of an embodied ritual and there is good reason to treat it as an important case of the closely related "performance art."70 71 Furthermore, using the term "dance" ensures the most straightforward data and therefore supports replicability. Any possible correlation between ritual art and factors affecting group cohesion should not be adversely affected by effectively limiting the sample size.

\subsection{Pre-Testing the measure}

For the purposes of pre-testing the measure as outlined in the coding instructions I will apply the operational definition only to the subset of relevant PSF results that occur in the eHRAF region of Africa. This reduces the results to 66 paragraphs in 30 documents in 12 cultures. Of the original 16 African cultures in the PSF, 4 show no relevant data in these search parameters and are therefore immediately ranked as 0 ; they are the Amhara, Ganda, Somali, and Kanuri. I have compiled the results in a table below which includes notes on the distinct ritual art practices identified, as well as any difficulties encountered.

\footnotetext{
${ }^{70}$ Robert Bocock, Ritual in Industrial Society: A Sociological Analysis of Ritualism in Modern England. (London: George Allen \& Unwin Ltd, 1974), 164-5.

${ }^{71}$ Susan Broadhurst, Liminal Acts: A Critical Overview of Contemporary Performance and Theory. (London: Cassell, 1999), 27.
} 
Table 1: Probability Sample File Pre-Test Results

\begin{tabular}{|c|c|c|c|c|c|c|}
\hline Subregion & $\begin{array}{l}\text { Culture } \\
\text { Name }\end{array}$ & OWC & Subsistence Type & Samples & $\begin{array}{c}\text { Operational } \\
\text { Definition }\end{array}$ & Notes \\
\hline \multirow[t]{2}{*}{$\begin{array}{l}\text { Central } \\
\text { Africa }\end{array}$} & Azande & FO07 & Horticulturalists & PSF, SCCS & 2 & $\begin{array}{l}\text { (1) Mourning dance } \\
\text { ritual. }^{72} \text { (2) Ritual } \\
\text { Dancing in magic }\end{array}$ \\
\hline & Mbuti & FO04 & Hunter-Gatherers & PSF, SCCS & 3 & $\begin{array}{l}\text { (1) Makata dance } \\
\text { during Nkumbi (rite } \\
\text { of initiation) }{ }^{74}(2) \\
\text { Ekokomea during } \\
\text { Molimo Mangbo (a } \\
\text { dance that resolves } \\
\text { sexual differences, } \\
\text { also related to a ritual } \\
\text { of mourning) })^{75} \text { (3) a } \\
\text { dance related to the } \\
\text { harvesting of honey } \\
\text { and "the ritual use of } \\
\text { fire"76 }\end{array}$ \\
\hline \multirow[t]{3}{*}{$\begin{array}{l}\text { Eastern } \\
\text { Africa }\end{array}$} & Amhara & MP05 & \begin{tabular}{|l} 
Intensive \\
Agriculturalists
\end{tabular} & PSF, SCCS & 0 & \\
\hline & Ganda & FK07 & $\begin{array}{l}\text { Intensive } \\
\text { Agriculturalists }\end{array}$ & $\begin{array}{l}\text { PSF, SCCS, } \\
\text { SRS }\end{array}$ & 0 & \\
\hline & Maasai & FL12 & Pastoralists & PSF, SCCS & 5 & $\begin{array}{l}\text { (1) Dance in ritual } \\
\text { preparation of the } \\
\text { child (2) Ritual dance } \\
\text { of initiation (a-ipak) } \\
\text { (3) lion dance (4) } \\
\text { emosiroi (5) } \\
\text { enkipaata (ritual war } \\
\text { dance) }{ }^{77} \text { [The Maasai } \\
\text { literature revealed } \\
\text { some difficulties in } \\
\text { the operational } \\
\text { definition. It was } \\
\text { difficult to separate } \\
\text { the a-ipak, for } \\
\text { instance, from the }\end{array}$ \\
\hline
\end{tabular}

${ }^{72}$ Evans-Pritchard, E. E. (Edward Evan). 1928. "Dance.” Africa. London: Oxford University Press. Accessed August 10, 2016, http://ehrafworldcultures.yale.edu/document?id=fo07-006.

${ }^{73}$ Evans-Pritchard, E. E. (Edward Evan). 1937. "Witchcraft, Oracles And Magic Among The Azande.” Oxford: Clarendon Press. Accessed August 10, 2016, http://ehrafworldcultures.yale.edu/document?id=fo07-071.

${ }^{74}$ Turnbull, Colin M. 1965. "Mbuti Pygmies: An Ethnographic Survey." Anthropological Papers. New York: American Museum of Natural History. Accessed August 10, 2016, http://ehrafworldcultures.yale.edu/document?id=fo04-001.

75 Turnbull, Colin M. 1983. "Mbuti Pygmies: Change And Adaptation." Case Studies In Cultural Anthropology. Orlando, Fla.: Harcourt Brace Jovanovich College Publishers. Accessed August 10, 2016, http://ehrafworldcultures.yale.edu/document?id=fo04-005.

${ }^{76}$ Turnbull, Colin M. 1965. "Wayward Servants: The Two Worlds Of The African Pygmies." N Garden City, N.Y.: The Natural History Press. Accessed August 10, 2016, http://ehrafworldcultures.yale.edu/document?id=fo04-002.

${ }^{77}$ Spencer, Paul. 1988. "Maasai Of Matapato: A Study Of Rituals Of Rebellion." International African Library. Bloomington, Ind.: Indiana University Press. Accessed August 10, 2016, http://ehrafworldcultures.yale.edu/document?id=fl12-020. 


\begin{tabular}{|c|c|c|c|c|c|c|}
\hline & & & & & & $\begin{array}{l}\text { enkipaata, since they } \\
\text { are both similar } \\
\text { dances though } \\
\text { performed during } \\
\text { different rituals. The } \\
\text { lion dance and the } \\
\text { emosiroi are also } \\
\text { complementary } \\
\text { dances which make } \\
\text { up the eunoto.] }\end{array}$ \\
\hline & Somali & MO04 & Pastoralists & PSF, SCCS & 0 & \\
\hline \multirow[t]{2}{*}{$\begin{array}{l}\text { Northern } \\
\text { Africa }\end{array}$} & $\begin{array}{l}\text { Libyan } \\
\text { Bedouin }\end{array}$ & MT09 & Pastoralists & PSF & 1 & $\begin{array}{l}\text { (1) dancing ritual } \\
\text { performed as part of } \\
\text { nuptials }\end{array}$ \\
\hline & Shluh & MW11 & $\begin{array}{l}\text { Intensive } \\
\text { Agriculturalists }\end{array}$ & PSF & 1 & $\begin{array}{l}\text { (1) "very } \\
\text { complicated dance } \\
\text { ritual"79 [dubious } \\
\text { reference*] }\end{array}$ \\
\hline \multirow[t]{2}{*}{$\begin{array}{l}\text { Southern } \\
\text { Africa }\end{array}$} & Bemba & FQ05 & Horticulturalists & PSF, SCCS & 2 & $\begin{array}{l}\text { (1) Mbumba and } \\
\text { Cisunga - Dance } \\
\text { strongly and } \\
\text { repeatedly related to } \\
\text { the communication } \\
\text { of traditional } \\
\text { values. }^{80}(2) \text { Dance } \\
\text { and initiation }\end{array}$ \\
\hline & Lozi & FQ09 & $\begin{array}{l}\text { Other Subsistence } \\
\text { Combinations }\end{array}$ & PSF, SCCS & 1 & $\begin{array}{l}\text { (1) Large scale } \\
\text { dancing ceremonies } \\
\text { of unclear purpose } \\
\text { used for various } \\
\text { communal rituals. }^{82}\end{array}$ \\
\hline $\begin{array}{l}\text { Western } \\
\text { Africa }\end{array}$ & Akan & FA12 & Horticulturalists & PSF, SCCS & 0 & $\begin{array}{l}\text { (0) Search results } \\
\text { returned by the } \\
\text { eHRAF did not meet } \\
\text { the criteria of the } \\
\text { operational } \\
\text { definition. }\end{array}$ \\
\hline
\end{tabular}

\footnotetext{
${ }^{78}$ Peters, Emrys L. -, Jack Goody, and Emanuel Marx. 1990. "Bedouin Of Cyrenaica: Studies In Personal And Corporate Power." Cambridge Studies In Social And Cultural Anthropology. Cambridge: Press Syndicate of the University of Cambridge. Accessed August 10, 2016, http://ehrafworldcultures.yale.edu/document?id=mt09-017.

${ }^{79}$ Berque, Jacques, and Jane Bigwood. 1955. "Social Structures Of The High Atlas." Paris: Presses Universitaires de France. Accessed August 10, 2016, http://ehrafworldcultures.yale.edu/document?id=mw11-001.

${ }^{80}$ Maxwell, Kevin B. (Kevin Burns). 1983. "Bemba Myth And Ritual: The Impact Of Literacy On An Oral Culture." American University Studies. New York: P. Lang. Accessed August 10, 2016, http://ehrafworldcultures.yale.edu/document?id=fq05-011.

${ }^{81}$ Richards, Audrey I. (Audrey Isabel). 1956. "Chisungu: A Girls' Initiation Ceremony Among The Bemba Of Northern Rhodesia." London, England: Faber and Faber. Accessed August 10, 2016, http://ehrafworldcultures.yale.edu/document?id=fq05-003.

${ }^{82}$ Prins, Gwyn. 1980. "Hidden Hippopotamus: Reappraisal In African History." African Studies Series. Cambridge [Eng.]: Cambridge University Press. Accessed August 10, 2016, http://ehrafworldcultures.yale.edu/document?id=fq09-011.
} 


\begin{tabular}{|c|c|c|c|c|c|}
\hline Dogon & FA16 & $\begin{array}{l}\text { Intensive } \\
\text { Agriculturalists }\end{array}$ & PSF & 3 & \begin{tabular}{|l|} 
(1) Sigui dance \\
ceremony ${ }^{83}(*)$ vague \\
reference, unclear \\
$(2)$ A dance of sexual \\
reversal (mourning) \\
$(*)$ Dance referred to \\
as "a highly elaborate \\
language" among the \\
Dogon ${ }^{86}(3)$ male \\
dancing ritual during \\
the mourning \\
process ${ }^{87}(*)$ Textual \\
references to \\
mourning dance \\
rituals are extensive. \\
Distinguishing ritual \\
dance is extremely \\
difficult. Confusion \\
occurs because dance \\
has been split into \\
funerary and more \\
performative dance \\
which is actually \\
done for the benefit \\
of tourists and has \\
little to no ritual \\
importance.
\end{tabular} \\
\hline Hausa & MS12 & $\begin{array}{l}\text { Other Subsistence } \\
\text { Combinations }\end{array}$ & PSF, SCCS & 0 & $\begin{array}{l}\text { (0) Search results } \\
\text { returned by the } \\
\text { eHRAF did not meet } \\
\text { the criteria of the } \\
\text { operational } \\
\text { definition. }\end{array}$ \\
\hline Kanuri & MS14 & $\begin{array}{l}\text { Intensive } \\
\text { Agriculturalists }\end{array}$ & PSF & & \\
\hline Tiv & FF57 & Horticulturalists & PSF, SCCS & 1 & $\begin{array}{l}\text { (1) Dance and } \\
\text { initiation ritual }{ }^{88}(*) \\
\text { other references are } \\
\text { too vague to meet } \\
\text { operational }\end{array}$ \\
\hline
\end{tabular}

${ }^{83}$ Van Beek, W. E. A. 1992. "Becoming Human In Dogon, Mali." Coming Into Existence : Birth And Metaphors Of Birth, Edited With An Introduction By Göran Aijmer. Goteborg, Sweden: Institute for Advanced Studies in Social Anthropology. Accessed August 10, 2016, http://ehrafworldcultures.yale.edu/document?id=fa16-028.

${ }^{84}$ Calame-Griaule, Geneviève. 1986. "Words And The Dogon World." Philadelphia: Institute for the Study of Human Issues. Accessed August 10, 2016, http://ehrafworldcultures.yale.edu/document?id=fa16-010.

${ }^{85}$ Calame-Griaule, Geneviève. 1986. "Words And The Dogon World." Philadelphia: Institute for the Study of Human Issues. Accessed August 10, 2016, http://ehrafworldcultures.yale.edu/document?id=fa16-010.

${ }^{86}$ Calame-Griaule, Geneviève. 1986. "Words And The Dogon World." Philadelphia: Institute for the Study of Human Issues. Accessed August 10, 2016, http://ehrafworldcultures.yale.edu/document?id=fa16-010.

${ }^{87}$ Ganay, Solange de, and Sherri L. Granka. 1942. "Dogon Mottoes.” Travaux Et Mémoires. Paris: Institut 'Ethnologie. Accessed August 10, 2016, http://ehrafworldcultures.yale.edu/document?id=fa16-014.

${ }^{88}$ Downes, Rupert Major. 1971. "Tiv Religion.” [Ibadan, Nigeria]: Ibadan University Press. Accessed August 10, 2016, http://ehrafworldcultures.yale.edu/document?id=ff57-035. 


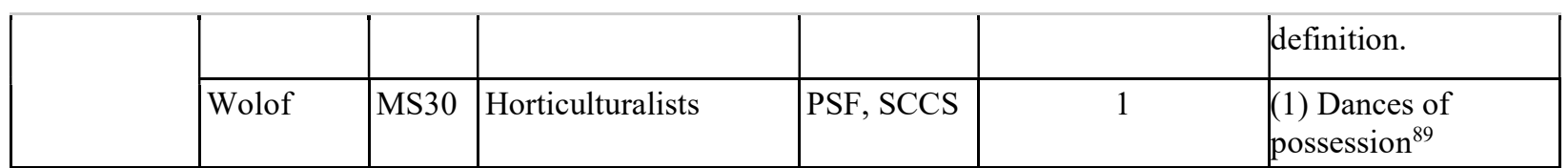

* All culture names are presented exactly as they appear in the eHRAF database.

**All citations preserve the format provided by the eHRAF.

Results of pre-testing the measure were promising. First, coding returned cultures with no data whatsoever, which suggests that the coding practice is not too broad. Second, of results that returned data two did not meet the criteria of the theoretical definition and were ranked as zero according to the operational definition. This suggests that the operational definition is able to parse data well enough to not return false positives. More precisely, it demonstrates that merely mentioning the terms "dance" and "ritual" is insufficient to meeting the operational definition. Finally, of the cultures surveyed, a wide range of results were returned, which is very promising as uniform or binary data would not be appropriate to an interval scale. ${ }^{90}$

Since the definition of ritual art and my coding practice are without significant precedent I would like to include an example of a textual reference returned by the search, so that it should be clear what exactly I am identifying in the data.

"It is no wonder then that in their religious life the Mbuti ritualized this potential and experienced conflict in so many ways. I have already described the tug of war, a ritual battle between the sexes. Even more dramatic was ekokomea, a dance that always occurred during a molimo mangbo as part of the almost anarchic reversal that so frequently accompanies any rite of passage. For the Mbuti it was as though death were itself a reversal, an abnormality which could only be put right by reversing everything else. Ekokomea was such a reversal technique, and, like the tug of war, it made gender the focal point. Men drew their bark cloths up tight between their legs, in the manner of women, and women dropped theirs low in the manner of men. Each then, to the accompaniment of the ekokomea music, began to ridicule the others as

\footnotetext{
${ }^{89}$ Faladé, Solange. 1963. "Women Of Dakar And The Surrounding Urban Area." Women Of Tropical Africa. London: Routledge and Kegan Paul. Accessed August 10, 2016, http://ehrafworldcultures.yale.edu/document?id=ms30-042.

${ }^{90}$ I did experience some difficulty (as noted above) in parsing between examples of ritual art that are too similar. If anything needs to be changed the theoretical and operational definition must find a way of accounting for the type of fine grained distinctions that have to be made between ritual art practices among the Maasai for instance.
} 
they danced. Women ridiculed manhood by putting enormous lumps of wood into their bark cloths, and they swung these back and forth as they danced around, like enormous ungainly testicles between their legs. This was really hitting where it hurt, and the men were not to be outdone. Their favorite way of ridiculing womanhood was to pretend that they had pots of water and were continually washing very smelly private parts. As with the tug of war, each individual sought to outdo the others in his or her mime and ridicule, and before long the whole camp would have joined in and the dancers would end in convulsions on the ground, laughing as much at themselves as at anyone else. By expressing the latent conflict, it was to a large extent expelled, and the norm of sexual differentiation was reinforced." 91

The relevant result here describes a fascinating dance called the Ekokomea in which men and women resolve sexual tensions through a process that resembles Turner's description of exaggerated sacra offered in the previous chapter. Differences are expressed in physical objects and the activity of dancing, and in both they are ridiculous and exaggerated in order to point to their symbolic roles. This dance, intrinsic to the ritual process, communicates the sexual conflict to the community as a whole as well as the individual participants. The final result is described as reinforcing a norm. What is most promising is that the ritual art practice appears to be resolving internal conflict, which, I think, could very reasonably be seen as increasing group cohesion.

While the results of pre-testing the measure were largely positive I also encountered two rather damning complications in attempting to extend the method to a larger sample. One of these was, as mentioned, the difficulty of parsing between similar ritual art practices and determining which to count as distinct and which to count as mere variations. This is a major challenge to the replicability of the practice. More worrisome, however, was the fact that certain results were counter intuitive to the very texts they were drawn from. This was because it was

\footnotetext{
${ }^{91}$ Turnbull, Colin M. 1983. "Mbuti Pygmies: Change And Adaptation.” Case Studies In Cultural Anthropology. Orlando, Fla.: Harcourt Brace Jovanovich College Publishers. Accessed August 10, 2016, http://ehrafworldcultures.yale.edu/document?id=fo04-005.
} 
often the case that ritual art practices that were incredibly prominent to the culture and mentioned numerous times by different anthropologists would only be ranked as 1 on the operational definition. Other ritual art practices that seemed ancillary, or even divisive, were ranked higher because they had more variations. The problem is essentially that the presence of numerous ritual art practices does not seem to necessarily reflect the intensity, prominence, or importance of ritual art in the culture when those cases demonstrate that the numerous ritual art practices are indicative of social divisions and schisms that reflect fractured cultural identity. Furthermore, cultures that seem to exhibit very prominent ritual art practices of great social importance are ranked relatively low by the current coding practice. Take the Dogon for example. The eHRAF search returns 31 paragraphs in 11 documents by 8 different authors. Ritual art seems to be a prominent topic to all of these anthropologists. And yet our coding practice ranks them as a 3 . While each passage does not describe a distinct ritual art practice they do describe a pervasive ritual art practice that is adapted to nearly all aspects of life. Consider this example from the Bemba as well:

"In the oral world of the Bemba, music in all of its vocal, instrumental and choreographic rhythms clearly meets the demands of acoustic memory and validation (Cf Havelock 1982, 2023, 344-45). Dancing, singing and drumming are musically reverberating devices employed by the oral society to set knowledge to meter and enshrine wisdom in dramatic ritual representation. The Bemba use these devices as quasi-linguistic signifiers, which are capable of communication at the highest level, with nuances, subtleties and refinements of thought. Through music, Bemba moral codes are transmitted, history is remembered, tribal interaction is stimulated, women are rallied, personal grievances are publicized, social cohesion is promoted, laws are promulgated, political procedures are influenced, spiritual realities are conjured up, religious duties are discharged--in short, music, the sound par excellence, ensures the continuity of Bemba tradition (Mapoma 1980, 36 and 66ff)." 92

\footnotetext{
${ }_{92}$ Maxwell, Kevin B. (Kevin Burns). 1983. "Bemba Myth And Ritual: The Impact Of Literacy On An Oral Culture.” American University Studies. New York: P. Lang. Accessed August 10, 2016, http://ehrafworldcultures.yale.edu/document?id=fq05-011.
} 
Here the prominence of a ritual art practice and its importance to all aspects of culture is made clear. This type of intensity is not captured by a low rank of 2. Finally, consider another passage from the Mbuti, which I referenced earlier. This passage exposes the social conflict at root in the presence of two rituals; the molimo and the nkumbi.

The connection between the molimo, as performed by the Mbuti in the village, and the nkumbi was made all the more evident when on one molimo occasion the two members of the kpara's family stood up and performed a dance only seen otherwise in the initiation camp. [Page 79] On another occasion the kpara himself did exactly the same thing. In the first instance the kpara was Ndaka, in the second, Bira. The villagers evidently believe that whatever molimo ritual the Mbuti have, it was learned from the village, if badly learned and performed with illegitimate variations. As with the elima, perhaps also for fear of exposure to the malevolent forest spirits, the villagers do not seek to interfere too much with Mbuti molimo celebrations. We shall see that these celebrations are quite divorced from the village molimo, regardless of whether or not the origin of the two was common. Also, we shall see that the Mbuti molimo has none of the connections that evidently exist between the village molimo and the nkumbi.$^{93}$

In my coding practice I had to distinguish between the nkumbi and molimo despite the fact that they seem intuitively to contradict our theoretical definition of ritual art insofar as they seem culturally and socially relevant only in a limited way since they do not apply to the entire culture or social group.

These problems with my coding practice, and concerns over replicability, can largely be remedied by a pragmatic solution. Instead of counting the unique ritual art practices in the literature our operational definition will count the number of relevant paragraphs per relevant document. This coding practice is not as elegant as the one proposed earlier, but it has a number of distinct advantages. First, this method is perfectly replicable. Second, it avoids the counterintuitive weighing of multiple unique divisive ritual art practices more heavily than single

\footnotetext{
93 Turnbull, Colin M. 1965. "Wayward Servants: The Two Worlds Of The African Pygmies.” Garden City, N.Y.: The Natural History Press. Accessed August 10, 2016, http://ehrafworldcultures.yale.edu/document?id=fo04-002.
} 
prominent ritual art practices. Finally, it generally avoids the problem of giving too much weight to an anthropologist who has simply mentioned ritual art numerous times due to his or her own interest, as opposed to any actual prominence of the ritual art practice, by dividing paragraphs by documents in order to average the results. ${ }^{94}$

The operational definition has thus changed. And while it now less clearly measures the presence of ritual art in culture, it is not unreasonable to assume that the prominence of a ritual art practice as an observable phenomenon will be generally reflected in the literature. The operational definition can be defined as follows:

Number of paragraphs referring to ritual art per document [paragraphs/documents].

The results will not be rounded or limited in any way. There is no normal expected value in such an operational definition so we cannot reasonably determine what amounts to an outlier. Since data will not be normally distributed Spearman's rho will be applied, and since it is not very sensitive to outliers there is still less reason to remove them. As far as changes in the coding practice, because the operational definition is now merely counting paragraphs per document it is essential that paragraphs returned are relevant, that the terms are agreed upon, and that the results are replicable. The search parameters will thus be extended to the following Boolean phrasing:

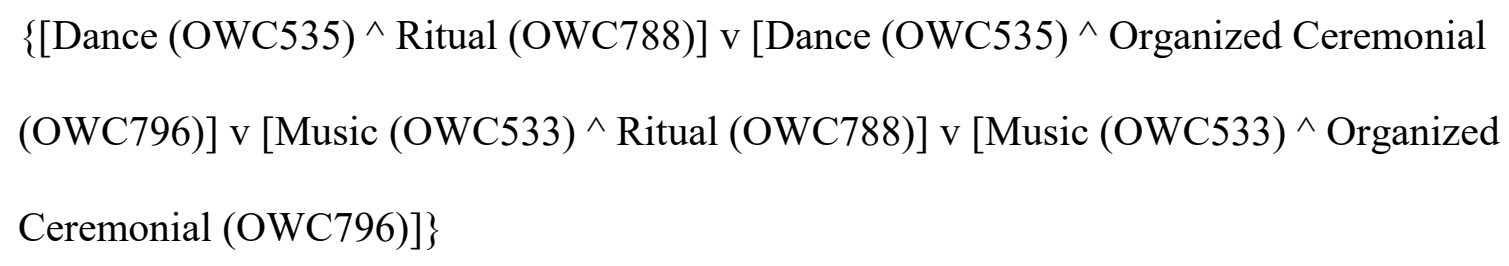

\footnotetext{
94 This will not always be the case but given a large enough sample the effect of averaging results should be to limit this problem.
} 
This formulation consistently returns relevant results, which have already been pre-coded, so paragraphs returned can be relied on with only minimal review of their relevance. As this simplification of the process allows for the use of an even larger data set, and since use of the PSF has been compromised by the rejection of results that might be interpreted as not to our liking, I will instead code from the cross-referenced data set of Standard Cross Cultural Sample (SCCS) cultures in the eHRAF. This provides a number of advantages. First, it ensures that all data collected from a single culture comes from a distinct period of time. Second, it gives us access to the thousands of variables that have already been coded in the SCCS. While the SCCS does provide us with a database of largely independent cultures it does not meet the requirements of a phylogenetic approach. Common ancestry may influence results and this should be considered carefully. That being said, the SCCS is arguably still one of the best datasets currently available for this type of research.

The coded results of this new data set are contained in the following table:

Table 2: SCCS Cases in eHRAF Coding Results

\begin{tabular}{|c|c|c|c|c|c|c|}
\hline Subregion & $\begin{array}{l}\text { Culture Name } \\
\text { HRAF }\end{array}$ & $\begin{array}{l}\text { Culture No. } \\
\text { SCCS }\end{array}$ & OWC & Documents & Paragraphs & $\begin{array}{l}\text { Operational } \\
\text { Definition Para/Doc }\end{array}$ \\
\hline Southern Africa & Khoi & 1 & FX13 & & & 0.00 \\
\hline Southern Africa & San & 2 & FX10 & 8.00 & 34.00 & 4.25 \\
\hline Southern Africa & Tsonga & 3 & FT06 & & & 0.00 \\
\hline Southern Africa & Lozi & 4 & FQ09 & 3.00 & 4.00 & 1.33 \\
\hline Southern Africa & Ovimbundu & 5 & FP13 & & & 0.00 \\
\hline Southern Africa & Bemba & 7 & FQ05 & 2.00 & 16.00 & 8.00 \\
\hline Eastern Africa & $\begin{array}{l}\text { Nyakyusa and } \\
\text { Ngonde }\end{array}$ & 8 & FN17 & 1.00 & 1.00 & 1.00 \\
\hline Eastern Africa & Gikuyu & 11 & FL10 & & & 0.00 \\
\hline Eastern Africa & Ganda & 12 & FK07 & 2.00 & 3.00 & 1.50 \\
\hline Central Africa & Mbuti & 13 & FO04 & 2.00 & 20.00 & 10.00 \\
\hline
\end{tabular}




\begin{tabular}{|c|c|c|c|c|c|c|}
\hline Central Africa & Mongo & 14 & FO32 & & & 0.00 \\
\hline Western Africa & Tiv & 16 & FF57 & 2.00 & 13.00 & 6.50 \\
\hline Western Africa & Igbo & 17 & FF26 & 15.00 & 68.00 & 4.53 \\
\hline Western Africa & Akan & 19 & FE12 & 6.00 & 49.00 & 8.17 \\
\hline Western Africa & Mende & 20 & FC07 & & & 0.00 \\
\hline Western Africa & Wolof & 21 & MS30 & 3.00 & 10.00 & 3.33 \\
\hline Western Africa & Bambara & 22 & FA08 & 3.00 & 6.00 & 2.00 \\
\hline Western Africa & Tallensi & 23 & FE11 & 3.00 & 13.00 & 4.33 \\
\hline Western Africa & Hausa & 26 & MS12 & 6.00 & 18.00 & 3.00 \\
\hline Central Africa & Azande & 28 & FO07 & 1.00 & 2.00 & 2.00 \\
\hline Eastern Africa & Shilluk & 31 & FJ23 & & & 0.00 \\
\hline Eastern Africa & Kaffa & 33 & MP14 & & & 0.00 \\
\hline Eastern Africa & Maasai & 34 & FL12 & 2.00 & 8.00 & 4.00 \\
\hline Eastern Africa & Somali & 36 & MO04 & 3.00 & 11.00 & 3.67 \\
\hline Eastern Africa & Amhara & 37 & MP05 & 1.00 & 10.00 & 10.00 \\
\hline Central Africa & Teda & 40 & MS22 & 2.00 & 5.00 & 2.50 \\
\hline Northern Africa & Tuareg & 41 & MS25 & 1.00 & 1.00 & 1.00 \\
\hline Northern Africa & $\begin{array}{l}\text { Berbers of } \\
\text { Morocco }\end{array}$ & 42 & MX03 & & & 0.00 \\
\hline Northern Africa & Fellahin & 43 & MR13 & 3.00 & 11.00 & 3.67 \\
\hline Middle East & Rwala Bedouin & 46 & MD04 & & & 0.00 \\
\hline Middle East & Turks & 47 & MB01 & 1.00 & 1.00 & 1.00 \\
\hline Southeastern Europe & Albanians & 48 & EG01 & & & 0.00 \\
\hline Southern Europe & Imperial Romans & 49 & EI09 & 1.00 & 1.00 & 1.00 \\
\hline Scandinavia & Saami & 52 & EP04 & 5.00 & 8.00 & 1.60 \\
\hline North Asia & Nenets & 53 & RU41 & & & 0.00 \\
\hline Caucasus & Abkhazians & 55 & RI03 & 1.00 & 1.00 & 1.00 \\
\hline Middle East & Kurds & 57 & MA11 & 1.00 & 4.00 & 4.00 \\
\hline Middle East & Basseri & 58 & MA10 & & & 0.00 \\
\hline South Asia & Gond & 60 & AW32 & 4.00 & 215.00 & 53.75 \\
\hline South Asia & Toda & 61 & AW60 & 1.00 & 1.00 & 1.00 \\
\hline South Asia & Santal & 62 & AW42 & 6.00 & 105.00 & 17.50 \\
\hline South Asia & Uttar Pradesh & 63 & AW 19 & & & 0.00 \\
\hline
\end{tabular}




\begin{tabular}{|c|c|c|c|c|c|c|}
\hline South Asia & Burusho & 64 & AV07 & 1.00 & 13.00 & 13.00 \\
\hline Central Asia & Kazakh & 65 & RQ02 & 1.00 & 3.00 & 3.00 \\
\hline Central Asia & Mongolia & 66 & AH01 & 2.00 & 3.00 & 1.50 \\
\hline East Asia & Yi & 67 & AE04 & & & 0.00 \\
\hline Central Asia & Lepcha & 68 & AK05 & 5.00 & 15.00 & 3.00 \\
\hline South Asia & Garo & 69 & AR05 & 4.00 & 11.00 & 2.75 \\
\hline Southeast Asia & Burmans & 71 & AP04 & 3.00 & 10.00 & 3.33 \\
\hline Southeast Asia & Vietnamese & 73 & AM11 & 5.00 & 30.00 & 6.00 \\
\hline Southeast Asia & Cambodians & 75 & AM04 & 2.00 & 12.00 & 6.00 \\
\hline Southeast Asia & Central Thai & 76 & AO07 & 8.00 & 40.00 & 5.00 \\
\hline Southeast Asia & Semang & 77 & AN07 & 3.00 & 12.00 & 4.00 \\
\hline South Asia & Andamans & 79 & AZ02 & & & 0.00 \\
\hline South Asia & Vedda & 80 & AX05 & 1.00 & 68.00 & 68.00 \\
\hline Southern Africa & Tanala & 81 & FY08 & & & 0.00 \\
\hline Southeast Asia & Malays & 82 & AN05 & 3.00 & 5.00 & 1.67 \\
\hline Southeast Asia & Javanese & 83 & OE05 & 2.00 & 4.00 & 2.00 \\
\hline Southeast Asia & Balinese & 84 & OF07 & 4.00 & 22.00 & 5.50 \\
\hline Southeast Asia & Iban & 85 & OC06 & 8.00 & 94.00 & 11.75 \\
\hline Southeast Asia & Eastern Toraja & 87 & OG11 & 4.00 & 114.00 & 28.50 \\
\hline Southeast Asia & Alorese & 89 & OF05 & & & 0.00 \\
\hline Australia & Tiwi & 90 & OI20 & 1.00 & 2.00 & 2.00 \\
\hline Australia & Aranda & 91 & OI08 & 7.00 & 29.00 & 4.14 \\
\hline Melanesia & Orokaiva & 92 & OJ23 & 4.00 & 23.00 & 5.75 \\
\hline Melanesia & Kapauku & 94 & OJ29 & 1.00 & 1.00 & 1.00 \\
\hline Melanesia & Kwoma & 95 & OJ13 & 3.00 & 22.00 & 7.33 \\
\hline Melanesia & Manus & 96 & OM06 & 1.00 & 1.00 & 1.00 \\
\hline Melanesia & Lesu & 97 & OM24 & & & 0.00 \\
\hline Melanesia & Trobriands & 98 & OL06 & 5.00 & 17.00 & 3.40 \\
\hline Polynesia & Tikopia & 100 & OT11 & 6.00 & 188.00 & 31.33 \\
\hline Polynesia & Maori & 104 & $\mathrm{OZ04}$ & 2.00 & 3.00 & 1.50 \\
\hline Polynesia & Marquesas & 105 & OX06 & 1.00 & 7.00 & 7.00 \\
\hline Polynesia & Samoans & 106 & OU08 & & & 0.00 \\
\hline Micronesia & Marshallese & 108 & OR11 & 1.00 & 12.00 & 12.00 \\
\hline
\end{tabular}




\begin{tabular}{|c|c|c|c|c|c|c|}
\hline Micronesia & Chuuk & 109 & OR19 & 1.00 & 1.00 & 1.00 \\
\hline Micronesia & Yapese & 110 & OR22 & 4.00 & 17.00 & 4.25 \\
\hline Micronesia & Belau & 111 & OR15 & 2.00 & 3.00 & 1.50 \\
\hline Southeast Asia & Ifugao & 112 & OA19 & 2.00 & 3.00 & 1.50 \\
\hline East Asia & Manchu & 115 & AG04 & 1.00 & 1.00 & 1.00 \\
\hline East Asia & Korea & 116 & AA01 & 4.00 & 14.00 & 3.50 \\
\hline East Asia & Okayama & 117 & AB43 & 5.00 & 11.00 & 2.20 \\
\hline East Asia & Ainu & 118 & AB06 & 1.00 & 4.00 & 4.00 \\
\hline North Asia & Nivkh & 119 & RX02 & 3.00 & 6.00 & 2.00 \\
\hline North Asia & Chukchee & 121 & RY02 & 2.00 & 19.00 & 9.50 \\
\hline Arctic and Subarctic & Aleut & 123 & NA06 & & & 0.00 \\
\hline Arctic and Subarctic & Copper Inuit & 124 & ND08 & & & 0.00 \\
\hline Arctic and Subarctic & Innu & 125 & NH06 & 3.00 & 3.00 & 1.00 \\
\hline Eastern Woodlands & Mi'kmaq & 126 & NJ05 & 2.00 & 9.00 & 4.50 \\
\hline Arctic and Subarctic & Ojibwa & 127 & NG06 & 6.00 & 63.00 & 10.50 \\
\hline Arctic and Subarctic & Kaska & 129 & ND12 & 2.00 & 2.00 & 1.00 \\
\hline $\begin{array}{l}\text { Northwest Coast and } \\
\text { California }\end{array}$ & Nuxalk & 132 & NE06 & 6.00 & 157.00 & 26.17 \\
\hline $\begin{array}{l}\text { Northwest Coast and } \\
\text { California }\end{array}$ & Yurok & 134 & NS31 & 7.00 & 86.00 & 12.29 \\
\hline $\begin{array}{l}\text { Northwest Coast and } \\
\text { California }\end{array}$ & Pomo & 135 & NS18 & 11.00 & 124.00 & 11.27 \\
\hline $\begin{array}{l}\text { Northwest Coast and } \\
\text { California }\end{array}$ & Yokuts & 136 & NS29 & 4.00 & 32.00 & 8.00 \\
\hline Southwest and Basin & Northern Paiute & 137 & NR13 & 2.00 & 3.00 & 1.50 \\
\hline Plains and Plateau & Klamath & 138 & NR10 & 1.00 & 2.00 & 2.00 \\
\hline Plains and Plateau & Gros Ventre & 140 & NQ13 & 4.00 & 37.00 & 9.25 \\
\hline Plains and Plateau & Pawnee & 142 & NQ18 & 9.00 & 362.00 & 40.22 \\
\hline Plains and Plateau & Omaha & 143 & NQ21 & 3.00 & 173.00 & 57.67 \\
\hline Eastern Woodlands & Creek & 145 & NN11 & 3.00 & 10.00 & 3.33 \\
\hline Plains and Plateau & Comanche & 147 & NO06 & 5.00 & 21.00 & 4.20 \\
\hline Southwest and Basin & Eastern Apache & 148 & NT08 & 1.00 & 68.00 & 68.00 \\
\hline Southwest and Basin & Zuni & 149 & NT23 & 10.00 & 107.00 & 10.70 \\
\hline Southwest and Basin & Havasupai & 150 & NT14 & 3.00 & 15.00 & 5.00 \\
\hline Southwest and Basin & O'odham & 151 & NU79 & 7.00 & 115.00 & 16.43 \\
\hline
\end{tabular}




\begin{tabular}{|c|c|c|c|c|c|c|}
\hline Central America & Miskito & 156 & SA15 & 2.00 & 23.00 & 11.50 \\
\hline Central America & Talamancans & 157 & SA19 & & & 0.00 \\
\hline Central America & Kuna & 158 & SB05 & 5.00 & 13.00 & 2.60 \\
\hline $\begin{array}{l}\text { Northwestern South } \\
\text { America }\end{array}$ & Goajiro & 159 & $\mathrm{SC} 13$ & 3.00 & 24.00 & 8.00 \\
\hline Caribbean & Haitians & 160 & SV03 & 4.00 & 71.00 & 17.75 \\
\hline Caribbean & Island Carib & 161 & ST13 & & & 0.00 \\
\hline Amazon and Orinoco & Warao & 162 & SS18 & 8.00 & 61.00 & 7.63 \\
\hline Amazon and Orinoco & Yanoama & 163 & SQ18 & 1.00 & 1.00 & 1.00 \\
\hline Amazon and Orinoco & $\begin{array}{l}\text { Barama River } \\
\text { Carib }\end{array}$ & 164 & SR09 & & & 0.00 \\
\hline Amazon and Orinoco & Saramaka & 165 & SR15 & & & 0.00 \\
\hline Amazon and Orinoco & Mundurucu & 166 & SQ13 & 4.00 & 6.00 & 1.50 \\
\hline Amazon and Orinoco & Tukano & 167 & SQ19 & 9.00 & 85.00 & 9.44 \\
\hline $\begin{array}{l}\text { Northwestern South } \\
\text { America }\end{array}$ & Chachi & 168 & SD06 & 1.00 & 1.00 & 1.00 \\
\hline Amazon and Orinoco & Jivaro & 169 & SD09 & 2.00 & 4.00 & 2.00 \\
\hline Central Andes & Inka & 171 & SE13 & 5.00 & 8.00 & 1.60 \\
\hline Central Andes & Aymara & 172 & SF05 & 5.00 & 36.00 & 7.20 \\
\hline Amazon and Orinoco & Sirionó & 173 & SF21 & 1.00 & 1.00 & 1.00 \\
\hline Amazon and Orinoco & Nambicuara & 174 & SP17 & & & 0.00 \\
\hline Amazon and Orinoco & Trumai & 175 & SP23 & 1.00 & 8.00 & 8.00 \\
\hline $\begin{array}{l}\text { Eastern South } \\
\text { America }\end{array}$ & Canela & 176 & SO08 & 3.00 & 79.00 & 26.33 \\
\hline $\begin{array}{l}\text { Eastern South } \\
\text { America }\end{array}$ & Tupinamba & 177 & SO09 & & & 0.00 \\
\hline $\begin{array}{l}\text { Eastern South } \\
\text { America }\end{array}$ & Xokleng & 180 & SM03 & & & 0.00 \\
\hline $\begin{array}{l}\text { Eastern South } \\
\text { America }\end{array}$ & Guaraní & 181 & SM04 & 6.00 & 16.00 & 2.67 \\
\hline $\begin{array}{l}\text { Southern South } \\
\text { America }\end{array}$ & Abipón & 183 & SI04 & 1.00 & 1.00 & 1.00 \\
\hline Central Andes & Mapuche & 184 & SG04 & 4.00 & 17.00 & 4.25 \\
\hline $\begin{array}{l}\text { Southern South } \\
\text { America }\end{array}$ & Tehuelche & 185 & SH05 & & & 0.00 \\
\hline $\begin{array}{l}\text { Southern South } \\
\text { America }\end{array}$ & Yahgan & 186 & SH06 & & & 0.00 \\
\hline
\end{tabular}

* All culture names are presented exactly as they appear in the eHRAF database. 


\section{Chapter 4 - Group Cohesion}

\subsection{Some Notes on Methodology}

It is important to consider certain difficulties and limitations of the following approach before continuing. First, Dissanayake's account is at its core an adaptationist evolutionary project and thus suffers from all the criticisms that have been leveled against adaptationism. ${ }^{95}$ Second, it is easy for adaptationist accounts to assume that a behavior that is presently adaptive in a group indicates a biological adaptation. But the inference from adaptive to adaptation is fallacious, as discussed earlier. Therefore, if evidence suggests that ritual art is in fact effective in promoting group cohesion, there is no way of demonstrating with this method that this reflects an evolutionary function. The behavior might at best be adaptive, though not necessarily an adaptation. Second, this method is by no means exhaustive. Correlations are only supportive or unsupportive of a given hypothesis, they can hardly be said to prove it. Finally, since all the variables under consideration are historical, there is no way to manipulate variables, and therefore no way to demonstrate the direction of causation in this account. High degrees of correlation between group cohesion and ritual art may just as easily suggest that group cohesion promotes ritual art as they would the inverse, though there are good theoretical reasons to suspect the direction of causation is otherwise. This last difficulty could be amended by a future study of small groups of artists, performers, and audiences using a questionnaire to measure cohesion. Similar studies have been undertaken in the field of small group research using the Group

\footnotetext{
95 See especially Stephen Jay Gould and Richard C. Lewontin, "The Spandrels of San Marco and the Panglossian Paradigm: A Critique of the Adaptationist Programme," Proceedings of the British Royal Society B Volume 205 (1979): 581-598.
} 
Environment Questionnaire (GEQ.) ${ }^{96}$ However, this would only provide evidence for the role and causal relationship of performance/ritual art and group cohesion synchronically. Thus, while one could develop a causal account the results would only be supportive or unsupportive of H2.1 and not H2.2. Nonetheless, these sets of hypotheses and correlations are sufficient to the purposes of this paper in addressing H2.1 and should be suggestive of where future work on the subject can be pursued

\subsection{Group Cohesion}

Since all variables in our cross cultural analysis, aside from ritual art, will come under the heading of group cohesion, it is important to begin with a strong theoretical definition of what group cohesion is. This will allow us to make use of already coded data in the SCCS. The literature regarding group cohesion is wide ranging. In evolutionary studies the definition of cohesion is often taken for granted as meaning increased cooperation or altruism and the strength of social bonds. This is often rendered as a merely mathematical concept. Elsewhere in evolutionary studies "Group cohesion may be defined using three criteria: stability, coordination and proximity." 97 This is not dissimilar to what Albert Carron has defined in sport theory as "a dynamic process which is reflected in the tendency for a group to stick together and remain united in the pursuit of its goals and objectives"98 In many of these evolutionary examples, however, a single variable is chosen as representative of group cohesion, or as an indicator of

\footnotetext{
${ }^{96}$ Sarah M. Whitton and Richard B. Fletcher, "The Group Environment Questionnaire A Multilevel Confirmatory Factor Analysis," Small Group Research Volume 45 no. 1 (2014): 68-88.

${ }^{97}$ Cédric Sueur et. al., "Group size, grooming and fission in primates: A modelling approach based on group structure," Journal of Theoretical Biology 273 (2011): 156.

${ }^{98}$ Albert V. Carron, "Cohesiveness in Sport Groups: Interpretations and Considerations," Journal of Sport Psychology 4 (1982): 124.
} 
group cohesion, such as allogrooming in primates. ${ }^{99}$ Alternatively, literature on group cohesion from the disciplines of small group research and sports theory define group cohesion in largely psychological terms. In this discipline group cohesion is discussed in relationship to group performance, and results fairly consistently suggest that group cohesion promotes group performance. ${ }^{100}$ This is important to note as it is suggestive of the possible fitness benefits of group cohesion. Nonetheless, in this discipline as well, the definition of group cohesion and agreement on how it should be measured is a point of much debate. ${ }^{101}$ For our purposes it will be sufficient to determine a number of variables that serve as proxies for group cohesion and others that represent the ecological conditions under which it arises. We can avoid some of the debate over group cohesion by not claiming to be exhaustive.

In an evolutionary approach when we discuss correlations we must make a strong distinction between those variables that represent a trait and those variables which represent the ecological conditions under which we expect it to arise. Having good theoretical justification for this distinction, for the direction of causation, and accurate representation avoids the problem that arises in broad analysis — such as Exploratory Factor Analysis (EFA) —identified by Albert Carron, of "confusing the antecedents and consequences of cohesion with cohesiveness itself."102

\footnotetext{
${ }^{99}$ See for example: R. I. M. Dunbar, "Determinants of Group size in Primates: A General Model," Proceedings of the British Academy Volume 88 (1996): 33-57. As well as J. Lehmann, et. al., "Group size, Grooming and Social Cohesion in Primates," Animal Behaviour 74:6 (2007): 1617-1629.

${ }^{100}$ Charles R. Evans and Kenneth L. Dion, “Group Cohesion and Performance: A Meta-Analysis,” Small Group Research 43:6 (2012): 694.

${ }^{101}$ Lindred L. Greer, “Group Cohesion: Then and Now,” Small Group Research 43:6 (2012): 655-661.

102 Albert V. Carron and Lawrence R. Brawley, "Cohesion: Conceptual and Measurement Issues,” Small Group Research 43:6 (2012): 735.
} 


\subsection{Ecological Conditions}

In terms of ecological conditions that predict group cohesion there are many that we could hypothesize but there are two that stand out as widely accepted in the literature; they are the conflict-cohesion paradigm and the group size-cohesion hypothesis. The conflict-cohesion paradigm is applicable to most primates and predicts that under conditions of inter-group conflict group cohesion will increase. ${ }^{103}$ Variables measuring external violence and inter-group conflict have been coded in the SCCS, and can be used to test the relationship between inter-group conflict (as a predictor of cohesion) and ritual art (as a practice that promotes group cohesion). If ritual art does in fact promote group cohesion, then we might suspect that it would arise under these conditions in order to improve group cohesion. However, there is also the alternative argument that conflict itself increases cohesion rather than placing pressure on groups to develop cohesion-promoting behaviors. Still, regarding the relationship of ritual art and inter-group conflict H2.1 would predict a positive correlation. The group size-cohesion hypothesis develops primarily from work on primates. It suggests that increased group size places pressure on groups to develop behaviors that increase cohesion since the cortex-group size hypothesis predicts that larger groups place greater psychological strain on individuals. ${ }^{104} \mathrm{H} 2.1$ would predict a positive correlation between group size and ritual art. However, there is the possibility that all cultures considered in our dataset are already too large for the group size-cohesion hypothesis to apply.

Having established the significance of group size and inter-group conflict as ecological conditions that should predict higher degrees of group cohesion, it remains to determine what

\footnotetext{
${ }^{103}$ Kyriacos C. Markides and Steven F. Cohn, "External Conflict/Internal Cohesion: A Reevaluation of an Old Theory," American Sociological Review Vol. 47 No. 1 (1982): 88-98.

${ }^{104}$ See for example: R. I. M. Dunbar, "Determinants of Group size in Primates: A General Model," Proceedings of the British Academy Volume 88 (1996): 33-57. As well as J. Lehmann, et. al., "Group size, Grooming and Social Cohesion in Primates," Animal Behaviour 74:6 (2007): 1617-1629.
} 
data best represents these variables. Group size is relatively straightforward, though population density is likely an even better predictor given an already large group. Relevant codes for group size in the SCCS are as follows:

\section{COMPACTNESS OF SETTLEMENT \\ $182=$ Dispersed \\ 203 = Spatially separated subsettlements \\ 444 = Partially dispersed with central core \\ 1041 = Compact \\ * Note: Recode Ordinally}

\section{COMMUNITY SIZE}

$1 .=$ Missing Data

$281=<50$

$282=50-99$

$453=100-199$

$324=200-399$

$295=400-999$

$156=1,000-4,999$

$57=5,000-49,999$

$38=>50,000$

\section{POPULATION DENSITY}

$2 .=$ Missing Data

$361=<1$ person per 5 sq. mile

$222=$ person per $1-5$ sq. mile

$253=1-5$ persons per sq. mile

$274=1-25$ persons per sq. mile

$345=26-100$ persons per sq. mile

$206=101-500$ persons per sq. mile

$207=$ over 500 persons per sq. mile

* Coded variables presented in boxes in this chapter are quoted directly from the SCCS Codebook Volumes I and II.

While variable v63 seems most relevant to the group size hypothesis, community size doesn’t tell the whole story because it doesn't actually account for the pressures placed on individuals to interact with a large number of conspecifics. Compactness of settlement does a better job of accounting for this, as does population density. H2.1 would predict a positive correlation 
between ritual art and of v62, v63, and v64. As to the inter-group conflict hypothesis intergroup conflict can be measured in a number of ways. While inter-group conflict can be assessed by related codes regarding war and violence v892 and v893 are arguably the clearest.

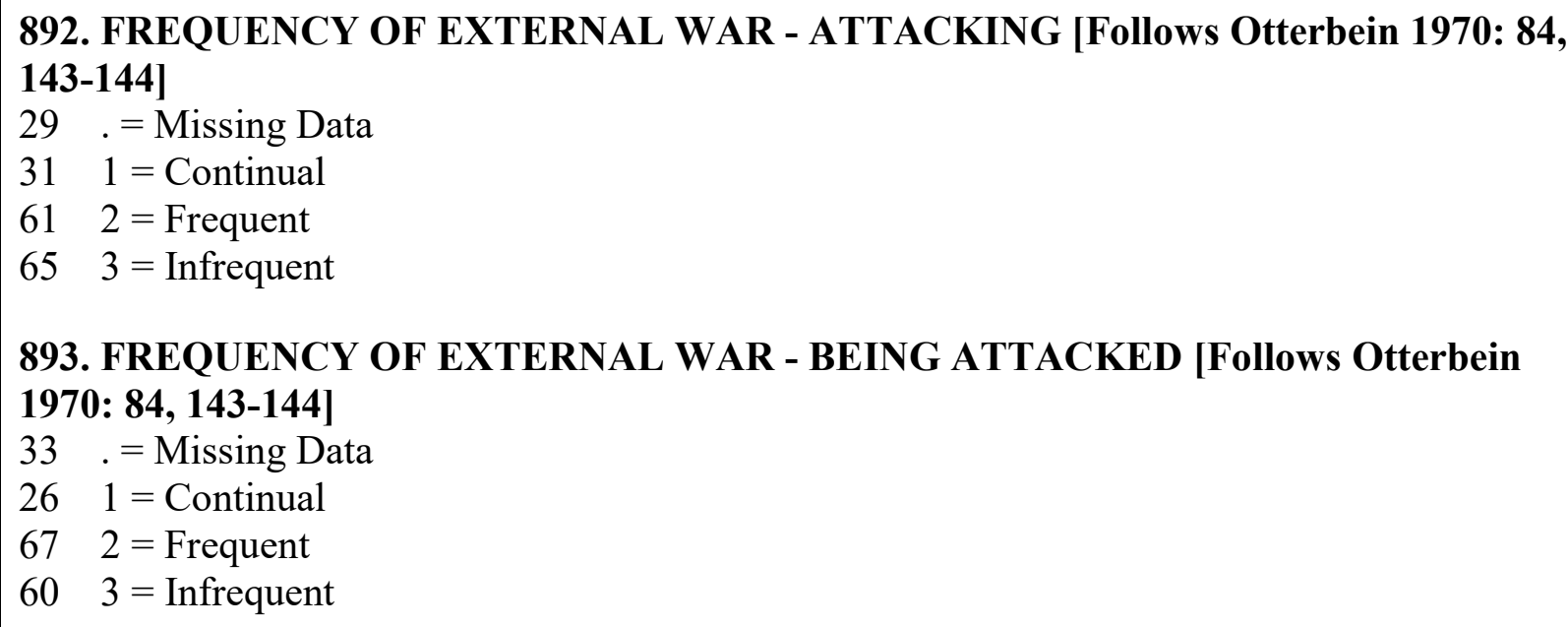

While conflict variables are more extensive than v892 and v893, these other variables will be discussed below as I argue that some represent intra-group conflict more accurately than intergroup conflict. According to H2.1 we would predict that v892 and v893 would demonstrate a negative correlation with ritual art.

\subsection{Proxies for Group Cohesion}

In a review of the literature regarding group cohesion Albert A. Cota et. al. suggest a heuristic in which cohesiveness should be understood through primary and secondary dimensions. ${ }^{105}$ Primary dimensions, they argue, will apply to all types of groups, while secondary dimensions may only apply to specific groups. The primary dimensions are

${ }^{105}$ Albert A. Cota et. al., "The Structure of Group Cohesion," Personality and Social Psychology Bulletin Vol. 21 No. 6 (1995): 576. 
individual-group, task-social, normative views (values) and/or norms of behavior, and resistance to disruptive forces. The secondary dimensions they propose are risk-taking, vertical (superiorssubordinates), and valued roles. The dimensions of individual-group and task-social are derived largely from the work of Albert Carron. ${ }^{106}$ Carron asserts that group cohesion should be considered in relation to these two dimensions. The first, individual-group, requires that a distinction is drawn by the researcher between individual feelings towards other members of the group, and group cohesion measured as Attractiveness To the Group (ATG) for the individual. In a cross cultural analysis access to psychological positions of individuals is incredibly difficult. As such we must consider the concept more abstractly in order to measure cohesion. This will require us to look for indications of both attraction between members and attraction of members to the whole. The second dimension, Task-Social, draws a distinction between groups that are unified by social ends, and those that are unified by tasks. As such, group cohesion must be assessed in relation to the purpose of the group and not otherwise. Task groups should be assessed in relation to commitment to task and/or task success, and social groups should be assessed in relation to social benefits. However, in relation to group cohesion in a cross-cultural analysis I believe we can assume that the groups in question will be defined to a large degree by both of these characteristics. Nonetheless, that the cohesion of groups can be considered along these two axes is significant in considering which proxies to use for group cohesion. We can then distinguish between proxies that account for task-commitment and those that account for social benefits. The next dimension proposed by Cota et. al., normative views/norms, has been thoroughly defended by a number of researchers. ${ }^{107}$ Furthermore, within the evolutionary

\footnotetext{
${ }^{106}$ Albert V. Carron et. al., "The development of an instrument to assess cohesion in sport teams: The Group Environment Questionnaire," Journal of Sport Psychology 7 (1985): 244-266.

107 Albert A. Cota et. al., "The Structure of Group Cohesion," Personality and Social Psychology Bulletin Vol. 21 No. 6 (1995): 576.
} 
framework we have developed here I believe that the presence and degree of normative views/norms in a cultural group has face validity as a measure of that group's cohesion. This is because of the role that norms can serve in social scaffolding and transmission. Resistance to disruptive forces is another dimension that has been proposed and defended by various authors. Furthermore, with the implicit reference to fitness in $\mathrm{H} 2.1$ this dimension should require no defense. This is instead one of the most common examples in evolutionary theory and even resembles closely the measure group fitness in Boyd and Richerson's 1995 paper "Can Groupfunctional Behaviors Evolve by Cultural Selection?" ${ }^{108}$ Risk-taking is a dimension relevant to clinical psychology but, as a secondary dimension, I can't see any justification for its use in a cross-cultural analysis. The dimension of verticality is largely derived from an enormous study of military groups, which identified the importance of relations understood as horizontal (peerpeer) and vertical (superior-subordinate). ${ }^{109}$ Since other dimensions proposed by Cota et. al. account for the horizontal dimension it is the vertical relationship that we must consider. Though this dimension was originally developed in relation to military groups I think it is a relevant measure of cohesion along social, political, and military axes. For example, caste systems establish vertical relations in the social realm, complex governance establishes vertical relations in the political realm, and the presence of any structured leadership in the military is representative of vertical relations in the military realm. However, since data on this last point may be sparse (or too broad) the verticality of social and political relations should be our focus. Finally, the dimension of valued roles identified by Yukelson et. al. is largely applicable to sports theory. There this dimension, identified in a factor analysis, accounts for the individual

\footnotetext{
${ }^{108}$ Joseph Soltis et. al., "Can Group-functional Behaviors Evolve by Cultural Selection?," Current Anthropology Vol. 36 No. 3 (1995): 473-494.

109 Albert A. Cota et. al., "The Structure of Group Cohesion," Personality and Social Psychology Bulletin Vol. 21 No. 6 (1995): 575.
} 
psychological feeling that one's position is recognized by members of the group as valuable. As a psychological dimension I feel this dimension is too difficult to measure in our analysis for the same reason that I reject consideration of the individual ATG in the individual-group dimension.

I propose that in comparing cultural groups, which are rather large by the standards of most group cohesion literature, all primary dimensions and the secondary dimension of vertical superiors and subordinates will be considered relevant. It is now critical to choose appropriate proxies for each of these dimensions given that traditional group cohesion studies have involved sampling so small that questionnaires were appropriate. It is also important to note that the application of these small group cohesion concepts to cultures may be problematic given the size of the cultures. It might be objected that families or other sub-groups should be considered instead of the culture as a whole. While this may in fact be true for measures of group cohesion in relation to evolution more generally, our theoretical definition of ritual art is unlikely to promote group cohesion solely at a group level that is not uniquely involved with it. If ritual art is practiced by entire cultures then any possible group cohesion that it promotes should be expected to be conferred on that large group and not smaller units, unless their practices are unique. $^{110}$

\subsubsection{Individual-group}

As I have already discussed, the individual aspect of the individual-group dimension involves the degree of attraction between members of the group. This is a largely inaccessible measure for our purposes though it is possible that an argument could be made for accounting for kin-terms as representative. The nature of kin relations and kin-terms is likely to be indicative of

\footnotetext{
110 This returns to my first attempt to develop a coding practice in Chapter 3 and may be suggestive of future areas of fruitful study.
} 
group-cohesion at the family level, however. This is unlikely to reflect group cohesion at the social or cultural level. Nonetheless, we might hypothesize that certain kin relations and kinterms were reflective of low cohesion at the cultural or social level but a difficult case would have to be made for this hypothesis. Perhaps the degree to which individuals felt the need to differentiate their kin from their larger social group, or the degree to which they needed to identify with one or the other in language might be indicative of their attraction to the group as a whole. While this is not unreasonable I believe it is too hard to justify, and should be left for future study. Instead, let us consider the group aspect of the individual-group dimension. The group aspect is also psychological insofar as it represents the attraction of an individual to the group as a whole. It seems then that this entire dimension, though entirely relevant, remains largely inaccessible to a cross-cultural analysis.

While a traditional conception of the group aspect of the individual-group dimension is inaccessible to our study, it seems intuitive that a group made up of a high percentage of members with an attraction to the group is likely to reflect less conflict within the group as more members have psychological reasons to preserve the group. While this data is accessible it might be very problematic for the following reason. It is also possible that a high percentage of ATG could in some cases cause greater degrees of intra-group conflict. This is because those members that wished to preserve the group and felt attracted to it would be more inclined to preserve it against even small groups of dissenters. Violence in highly patriotic nations, for example, should not be a foreign concept.

While these concerns are credible I think the relationship between intra-group conflict and ritual art, is worth exploring. The pre-coded variables in the SCCS that best represent this concept are as follows: 


\section{Conflict between Communities of the Same Society}

$97 .=$ Missing data

25 1= Endemic: High physical violence, feuding, and/or raiding occur regularly

232 = Moderately High, often involving physical violence

$213=$ Moderate: Disputes may occur regularly but tendency to manage them in a more or less peaceful manner

$204=$ Mild or rare

\section{FREQUENCY OF INTERNAL WAR}

Otterbein's (1970: 3, 84, 143) definition of internal war excludes feuding: warfare between political communities within the cultural unit, i.e., continguous [sic] political communities that are culturally similar. p. 3: "Warfare is defined as armed combat between political communities. Armed combat, which is fighting with weapons, is performed by military organizations. When political communities within the same cultural unit engage in warfare, this is considered to be internal war." p. 143: "If there is more than one military organization within a political community, and these ... engage in armed combat, this is considered feuding or civil war, depending on the scope of the conflict."

$26 .=$ Missing Data

$171=$ Continual

$542=$ Frequent

$893=$ Infrequent

1748. Frequency of internal warfare; i.e. between local communities within unit of maximal political authority

96. $=$ missing data

$510=$ no political office above the level of the local

* community (variable 1740 coded as 1,2 , or 7)

* (original code 88 )

$151=$ rare or never

112 = occasional

$113=$ often

$24=$ permanent

1749. Frequency of internal warfare involving non-territorially organized groups within unit of maximal political authority

96. = missing data

$510=$ no political office above the level of the local

* community (variable 1740 coded as 1,2 , or 7)

* (original code 88) 201 = rare or never

$92=$ occasional

$73=$ often

$34=$ permanent

1750. Frequency of violent conflict between groups within local communities

$114 .=$ missing data

$511=$ rare or never 
122 occasional

$73=$ often

$24=$ permanent

According to $\mathrm{H} 2.1$ we should expect that greater frequencies of conflict will be predicted by low rates of ritual art. Thus the relationship between ritual art and intra-group conflict, as coded in $\mathrm{v} 1748$, v1749, and v1750, should be a negative correlation. As for v768, this variable is less clearly concerned with warfare, but conflict and its degree of violence more generally. Variable v891 is promising because it offers a definition that excludes civil war, which would arguably represent the conflict between two already very distinct groups within a larger community, in which case it would not be applicable to this dimension of our study. Since the coding of v768 and v891 is inverted compared to v1748-v1750 we would expect a positive correlation between v768 and ritual art and v891 and ritual art.

\subsubsection{Task-Social}

The task-social dimension identified by Cota et. al. but elaborated first by Carron, suggests again a dimension that has two aspects. Group cohesion must then be assessed in relation to task commitment in task-oriented groups, and social commitment in socially-oriented groups. While this distinction might be clear at the small group level - a group of construction workers make up a task-oriented group, while a reading group is a socially oriented group - the lines become blurred in larger cultures. Arguably these larger social groups come together for reasons of both task and social commitment, and can be assessed in equal parts by both aspects. For Carron, this dimension is, once again, primarily concerned with the individual. The measure is thus of how committed an individual is to the goals of the group or the social relationships 
present in the group. Again, individual positions are largely inaccessible to our project but the aspects of this dimension are still instructive in what variables would best measure the degree to which a group is made up of task and/or socially committed individuals. While groups have historically come together for a number of task related reasons one of the most prominent, well documented, and understood group tasks is agriculture. Boyd and Richerson have written regarding agricultural development that,

"Once a more intensive subsistence system is possible, it will, over the long run, replace the less intensive subsistence system that preceded it. The reason is simple: all else equal, any group that can use a tract of land more efficiently will be able to evict residents that use it less efficiently. More intensive uses support higher population densities, or wealthier societies per capita, or both."111

What this demonstrates is a relationship between agriculture and group fitness, but it also supports our hypotheses regarding the relationship between group cohesion, population size and density if cohesion, measured along the task axis, is likely to promote innovation, such as in subsistence systems. Since the task aspect of the task-social dimension is defined as individual commitment to the goals of the group it does not seem unreasonable to surmise that populations with high degrees of task-commitment (cohesion) would be more likely to make progress or innovate in their given social task; in this case, agriculture.

\footnotetext{
${ }^{111}$ Peter J. Richerson, et. al., "Was Agriculture Impossible during the Pleistocene but Mandatory during the Holocene? A Climate Change Hypothesis," American Antiquity Vol. 66 No. 3 (2001): 389.
} 
The social aspect of the task-social dimension is at first glance more difficult to quantify in our cross-cultural analysis. What would commitment along this axis look like? Once again, the answer seems to be largely psychological. However, since we have resorted to understanding these psychological positions in population terms wherever possible, commitment to social goals would largely express themselves in degrees of commitment to, or prevalence of, normative views and norms of behavior. This will largely be measured in the dimensions that are to follow so aside from these variables I will refrain from further discussion here:

\section{INTERCOMMUNITY MARRIAGE \\ 1. = Missing data \\ $111=$ Local endogamy $90-100 \%$ \\ 502 = Local endogamy $61-89 \%$ (agamous) \\ $513=$ Local endogamy 40-60\% (agamous) \\ 384 = Local endogamy $11-39 \%$ (agamous) \\ $5=$ Local endogamy $0-10 \%$ (exogamy)}

\section{COMMUNITY INTEGRATION}

61 = Lacking or low compared to community segments or larger polity

262 = By common residence only

$163=$ Common Identity, dialect, subculture

784 = Overlapping Kin ties

$85=$ Common social or economic status

$206=$ Common political ties

$327=$ Common religious ties

Variable v72 seems intuitively to reflect an individual commitment to the social ends of the community insofar as marriage within the community perpetuates the group as such. Arguably this might also be understood under the aspect of group cohesion captured by individual attraction to members of the group. Insofar as the family is an important and essential element of the social community, the choice to marry within the community could be very reasonably understood as reflective of commitment to these social ends of the community. As for variable 
v73, not only does it seem appropriate to measuring social commitment, but it also accounts for earlier discussion of kin relations and more generally aligns with a broad common-sense understanding of what group cohesion means. H2.1 would predict a negative correlation between v72 and ritual art. v73 on the other hand is not clearly ordinal and no correlation can be predicted. Consideration of the scatterplot developed would, however, be of interest.

Regarding the measure of task-commitment through agriculture the SCCS provides us with a number of promising pre-coded variables as agriculture has been the subject of extensive study:

151. SCALE 3- AGRICULTURE

$381=$ None

$172=10 \%$ food supply

$113=10 \%$; secondary

634 = Primary; not intensive

575 = Primary; intensive

\section{INTENSITY OF CULTIVATION}

$421=$ No agriculture

102 = Casual agriculture, incidental to other subsistence modes

553 = Extensive or shifting agriculture, long fallow, and new fields cleared annually

$184=$ Horticulture, vegetal gardens or groves of fruit trees

325 = Intensive agriculture, using fertilization, crop rotation, or other techniques to shorten or eliminate fallow period

296 = Intensive irrigated agriculture

1128. Cropping Index (Rough indicator of Fallowing) for Major Crops Percentage of total land used for major crops used in any given year (Tree crops are considered to have no fallow)

24. = Missing Data

$380=$ Agriculture not practiced or confined to non-food crops less than $10 \%$ of land used per year

$221=10 \%-29 \%$ of land used per year

$262=30 \%-49 \%$ of land used per year

$153=50 \%-99 \%$ of land used per year

$324=100 \%$ or more of land used per year,

$295=100 \%$ or more of land used per year, (over 100\% due to double cropping) 
While there are many more codes present in the SCCS for agriculture, many are too specific, or cannot be accurately ranked and correlated. For instance, the difference between types of agriculture is not necessarily an indication of progress, but may very well be a consequence of ecological conditions. While the three variables proposed above are all promising we should reject v1128 because, though it appears to represent intensity, it may merely be a consequence of population density or other environmental conditions unrelated to cohesion. Regardless of what we think cohesion means, it just seems unlikely that certain environments can handle rank 4 or 5 . Therefore it isn't a very good indication of task-commitment. Nonetheless I will include its scatterplot out of interest. Variable v151 on the other hand is less likely to be influenced by environmental conditions that limit population density or land use. Variable 232 is also promising because it captures a different kind of agricultural intensity that comes closer to measuring innovation without making distinctions between subsistence types that might be merely consequences of environment. Given our assertion that task-commitment (as a dimension of group cohesion) will be represented in agricultural intensity and/or innovation, the relationship between variables v151 and v232, respectively, and ritual art, according to H2.1, should be a positive correlation.

\subsubsection{Normative views and/or norms of behavior}

The presence of normative views and/or norms of behavior is the proverbial low-hanging fruit in our cross cultural analysis. Data on norms and normative views is extensive, and the relationship with cohesion has been suggested by many, especially if we consider normative 
views in terms of religious belief. ${ }^{112}$ As opposed to the dimensions discussed above, normative views/norms are relatively easy to understand in relation to social cohesion. We have already discussed how norms can function to maintain group traditions, behaviors, and reinforce other behaviors. Dissanayake's own view gives us numerous ways to conceive of norms in relation to social cohesion, especially collective attention. However, some justification should be made for my assertion that the social aspect of the task-social dimension could be discussed under the heading of normative views and norms.

As discussed above, the social aspect of the task-social dimension is a measure of cohesion through the commitment of individuals to the social ends of a group. At the scale of small groups, such as a reading group, this is fairly straightforward. The reading of a book is not seen as a task to be completed but as the facilitation of other social interactions. These social interactions are essential to humans as social animals. Or, more minimally, individuals are attracted to and take pleasure in socializing. The question then is how does this express itself in large cultural groups? Religion, ritual, initiation rites, and other socially—scaffolded, but nonpolitical activities seem to all be promising candidates for this dimension. They certainly align with our understanding of normative views and/or norms. However, this also reveals a problem for our cross-cultural analysis. If we intend to explore the relationship between ritual art and group cohesion, and we allow that ritual, initiation rites, and, to a lesser extent, religious belief are representative of a dimension of group cohesion then we risk achieving nothing more than an auto-correlation. It is in fact not even clear if we are now comparing ritual art to group cohesion, so much as attempting to define ritual art as group cohesion through a dimension such as ritual. This cannot be an acceptable position. We must then discount any promising norms, normative

\footnotetext{
112 Richard Sosis, "The Adaptive Value of Religious Ritual: Rituals promote group cohesion by requiring members to engage in behavior that is too costly to fake," American Scientist Vol. 92 No.2 (2004), $166-172$.
} 
behaviors, or views that share too much similarity with ritual art. Ritual, understood broadly, is obviously discounted on these grounds. Initiation rites, or rites of passage, should also be discounted for their ubiquity within ritual. ${ }^{113}$ Norms, understood broadly, however, should pose little risk of auto-correlation. Appropriate codes in the SCCS will have to account for these concepts generally. While many codes exist for variations in norms, only those that account for degrees of presence or intensity should be considered. For example, many cultures have different norms regarding postpartum sex taboos. However, the difference between immediate intercourse and two years of abstinence cannot reasonably be understood as the intensity or degree to which a culture possesses norms; both of these are norms that may be maintained with equally intensity. The following coded variable is promising.

$$
\begin{aligned}
& \text { 775. Compliance of Individuals with Community Norms and Decisions } \\
& 100 .=\text { Missing data } \\
& 43 \quad 1=\text { High } \\
& 312=\text { Moderate } \\
& 123=\text { Highly Variable }
\end{aligned}
$$

Variable v775 is especially promising, though the amount of missing data is discouraging. Still, the measure aligns very appropriately with our understanding of norms and normative views in relation to group cohesion. Variable v775 should, according to $\mathrm{H} 2.1$, be negatively correlated with ritual art.

\footnotetext{
${ }^{113}$ Arnold Van Gennep, The Rites of Passage, trans. Monika B. Vizedom and Gabrielle L. Caffee (Chicago: The University of Chicago Press, 1992), 191.
} 


\subsubsection{Resistance to disruptive forces}

The quality of resistance to disruptive forces is a difficult measure even in small group studies because it would require manipulation of groups in order to introduce disruptive forces and assess group resistance. ${ }^{114}$ For our purposes resistance to disruptive forces is not only an appropriate measure of group cohesion given the heuristic suggested by Cota et. al. but also because it captures an implicit evolutionary understanding of what group cohesion means. If group cohesion is related to group fitness, then cohesion should manifest as resistance to the disruption of the group (dissolution, emigration, dispersal, extinction, fission etc.). While this dimension has already been considered in an antecedent sense in relation to inter-group conflict, measuring the ability to resist disruption is difficult because it is not a synchronic property. However, since we assume that extant groups are the product of previous extinctions and splits it is reasonable to assume that any group that persists in a given environment (allowing for the appropriate evolutionary history) is resistant to the disruptive forces of certain features of that environment. One measure of resistance to disruptive forces could then be the prevalence or frequency of disruptive forces in a given culture's environment. ${ }^{115}$ Here are two promising codes for disruptive forces that may be informative, though comparison with other measures of cohesion might first be necessary.

\footnotetext{
${ }^{114}$ Albert A. Cota et. al., "The Structure of Group Cohesion," Personality and Social Psychology Bulletin Vol. 21 No. 6 (1995): 573.

${ }^{115}$ While this might be useful in and of itself it is possible that more is needed. If we were to recode a new variable that combined the frequency or prevalence of disruptive forces with a broad measure of social success (size, density, etc.) then we might create a measure that did not just account for the antecedent of group cohesion in disruptive forces, nor the assumed property itself, given evolutionary history, but by comparing the antecedents (disruptive forces) with the consequents (size, density, etc.) we might better achieve a measure of group cohesion as resistance to disruptive forces.
} 


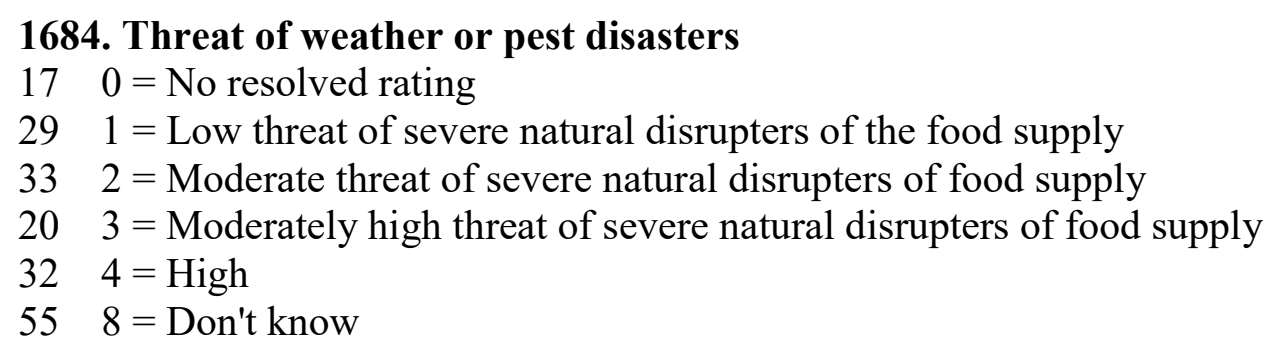

1719. Periodical variation of food scarcity

$95 .=$ missing data

261 = food supply constant, no scarcity (original code 10)

202 = periodical food scarcity (original code 20 )

103 = aperiodical food scarcity (e.g. as caused by natural disasters), no further information on frequency of occurrence (original code 30 )

74 = seldom (occurrence uncommon) (original code 31 )

$65=$ often (occurrence common) (original code 32 )

$26=$ periodical as well as aperiodical food scarcity (original code 40)

$17=$ chronic food scarcity (original code 50)

198 = food scarcity occurs, no further information on frequency (original code 60)

As opposed to other measures of disruptive forces variables v1684 and v1719 account for decidedly environmental factors that do not overlap directly with conflict as explored above. In the case of v1684, aside from value 8 "Don't know," H2.1 would predict positive correlation between this variable and ritual art. However, this treats v1684 as an antecedent of group cohesion and may fail to account for it as a measure of group cohesion. The same goes for v1719 (aside from value 8 which is not necessarily as severe as 7.)

\subsubsection{Vertical relations (superiors-subordinates)}

As discussed above the dimension of vertical relations as opposed to horizontal (captured by the individual aspect of the individual-group dimension) was developed in relation to the military. However, in many of the cultures under consideration the military is not sufficiently representative of the culture as a whole. Instead the dimension of verticality should be 
understood abstractly. In this case it is most appropriately measured in political and social verticality. We will have to be careful however to ensure that social verticality is not redundant with the social aspect of the task-social dimension discussed above. The variables we seek then should account for the presence or absence and orientation of such vertical relationships in social and political systems. Furthermore, the variables should do so in a way that can be reasonably understood as more or less vertical, so that intensity or degree can be correlated with the presence of ritual art. As a final note, it seems reasonable to assume that in a multidimensional model of cohesion (or a heuristic as Cota calls it) applied to a group as large and complex as culture it is entirely possible that certain dimensions of group cohesion will conflict with others. This may especially be the case for dimensions such as verticality, which Cota et. al. describe as secondary. With this in mind it seems reasonable to believe that some forms of vertical social and political structures will not create more cohesive societies but may cause rifts in the societies.

759. Perceptions of Political Leaders' Power as seen by Society

96. $=$ Missing data

241 = Very powerful

292 = Somewhat powerful, often variable across leaders, situations

373 = Limited

776. Formal Sanctions and Enforcement for Community Decisions

96. $=$ Missing data

$231=$ Great sanctioning power available

$322=$ Some

$353=$ Little or none

1132. POLITICAL INTEGRATION (WES COL 15; EA VAR 89)

$12 .=$ Missing data

$480=$ Insufficient information, or not coded

101 = Absence, even at local level

462 = Autonomous local communities (not $>1,500)$

43 = Peace groups transcending local community 
274 = Minimal States $(1500-10,000)$

95 = Little States $(10,000-100,000)$

$226=$ States (at least 100,000)

88 = Dependent societies

The dimension of verticality proves exceedingly complex when available data is explored. While a great deal of coding had to be rejected for unclear coding or missing data the options offered above are sufficient. Though v759 is missing substantial amounts of data it is an intriguing code because it appears to account for a psychological position that has been so difficult to address in our cross-cultural analysis. v759 is a measure of individual perceptions of political power, or of the strength of the vertical political relationship. As such, despite missing data it may be very useful to explore its relationship to ritual art. Our relevant hypothesis, H2.1, would predict a negative correlation between v759 and ritual art. However, given the amount of missing data the sample size may be insufficient for our purposes and may skew the results. v776 like v759 lacks a great deal of data but what it does explore is not merely the presence of verticality but the efficacy of it. If efficacy is indicative of the integration of verticality then this would be a useful measure. H2.1 would predict a negative correlation between v759 and ritual art. v1132 proposes to measure nearly exactly what we seek in identifying verticality, it has very little missing data though it does have a fair amount of insufficient data. Aside from rank 8, which is an outlier from political integration, the code appears to represent increasing levels of political integration as code numbers rise. As such, H2.1 would predict a positive correlation between ritual art and v1132. 


\subsection{Some Concluding Remarks}

The definition of group cohesion that has been offered here is not complete. Sufficient definitions of group cohesion are severely lacking and hotly debated in small group studies literature. However, in my research I was unable to find any substantial work being done in evolutionary biology on the concept of cohesion. This is an area that demands further study before substantial evolutionary claims can be made regarding the concept. At best we are left with the minimal definition borrowed from chemistry that treats organisms in groups as akin to intermolecular attraction. This definition is not entirely inaccurate, though it is impoverished.

Allow me to also add that the process of defining group cohesion using the heuristic proposed by Cota et. al. to identify relevant dimensions and determine coded variables to represent them as adequately as possible has raised a theoretical red flag for $\mathrm{H} 2$. This concern arises in the fact that while the relationship between ritual art and group cohesion seems theoretically reasonable, it is also broadly accepted (as I have already discussed) that ritual has declined in industrial societies. However, if our measures of group cohesion indicate that it will be increased in so-called progressive societies then one may wonder why industrial societies largely lack ritual practices. Perhaps the notion that ritual decreases in industrial societies is incorrect, and it is simply masked in other cultural practices. On the other hand the relationship between ritual art and group cohesion may not be linear. It is possible that there is a cultural period in which ritual art increases group cohesion and then is overtaken in this role by the conditions it fostered (urbanization, agriculture, political complexity, etc.) With this in mind I will not only present correlation values and significance in what follows. Instead, I will also provide plots of the data which may demonstrate patterns that have not been adequately considered up to this point. This is not to hedge my bets on the results and methodology that is to 
follow, but it does offer a possible consideration for future study and demonstrates, once more, that the methodology used here, though rigorous, is not exhaustive. 


\section{Chapter 5 - Results and Discussion}

In the previous chapter I discussed a number of variables for group cohesion and ecological pressures. Due to the extensive list of variables that were tested for correlation with Ritual Art this chapter will be structured in the same way as the previous chapter in order to discuss the implications of each result separately. Wherever possible I have made use of Spearman's Rho as variables were not normally distributed. I have not assumed monotonicity but instead present the scatter plots that were used to test the assumption of monotonicity prior to performing a Spearman's Rank Order correlation. 


\subsection{Results}

Fig. 1: Ritual Art and v62 - Compactness of Settlement

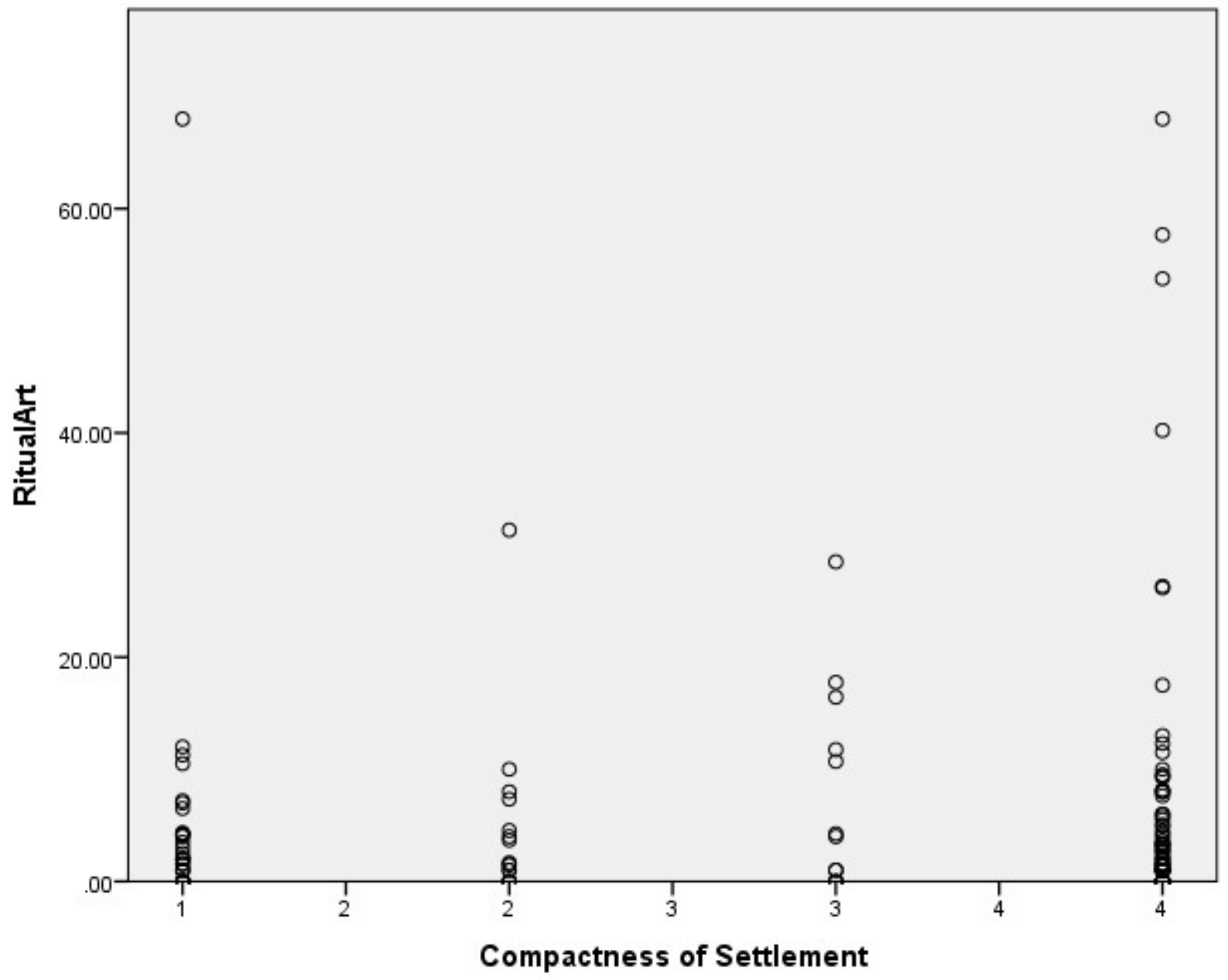


Fig. 2: Ritual Art and v62 (ordinal) - Compactness of Settlement

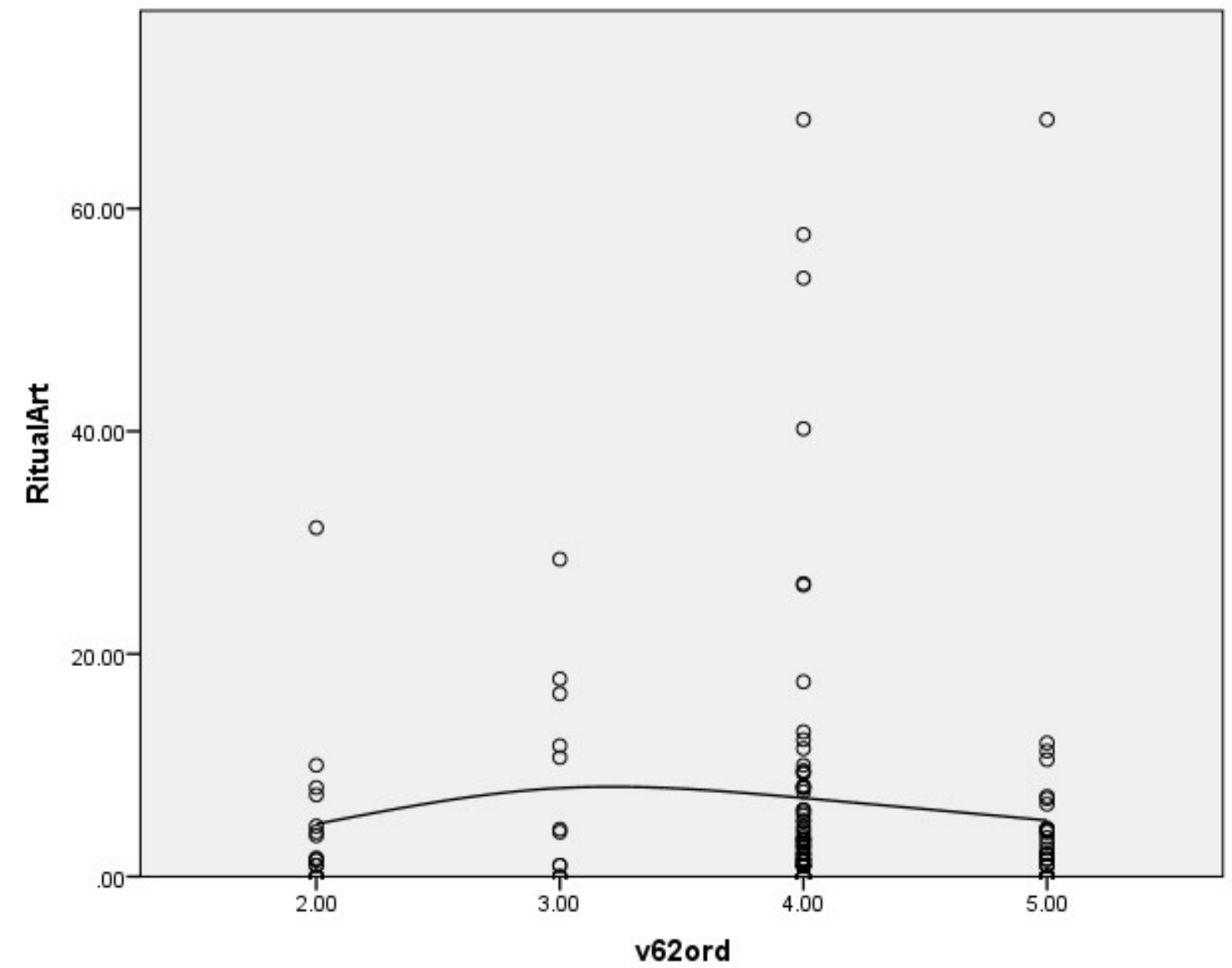

* This scatterplot has recoded v62 ordinally, as suggested by the SCCS codebook, by replacing all values of 1 with 5 .

The relationship between "Ritual Art" and v62 is non-monotonic and not normally distributed. It is thus not subject to Spearman's Rho or Pearson's R. No significant trend is demonstrated by the scatter plot, and as such it is unsupportive of H2. ${ }^{116}$

\footnotetext{
116 Unsupportive results will be interpreted as unsupportive of $\mathrm{H} 2$, while supportive results will be interpreted as supportive of only $\mathrm{H} 2.1$. This is because of the disambiguation proposed earlier. While support of $\mathrm{H} 2.1$ is necessary for $\mathrm{H} 2$, it is not sufficient.
} 
Fig. 3: Ritual Art and v63 - Community Size

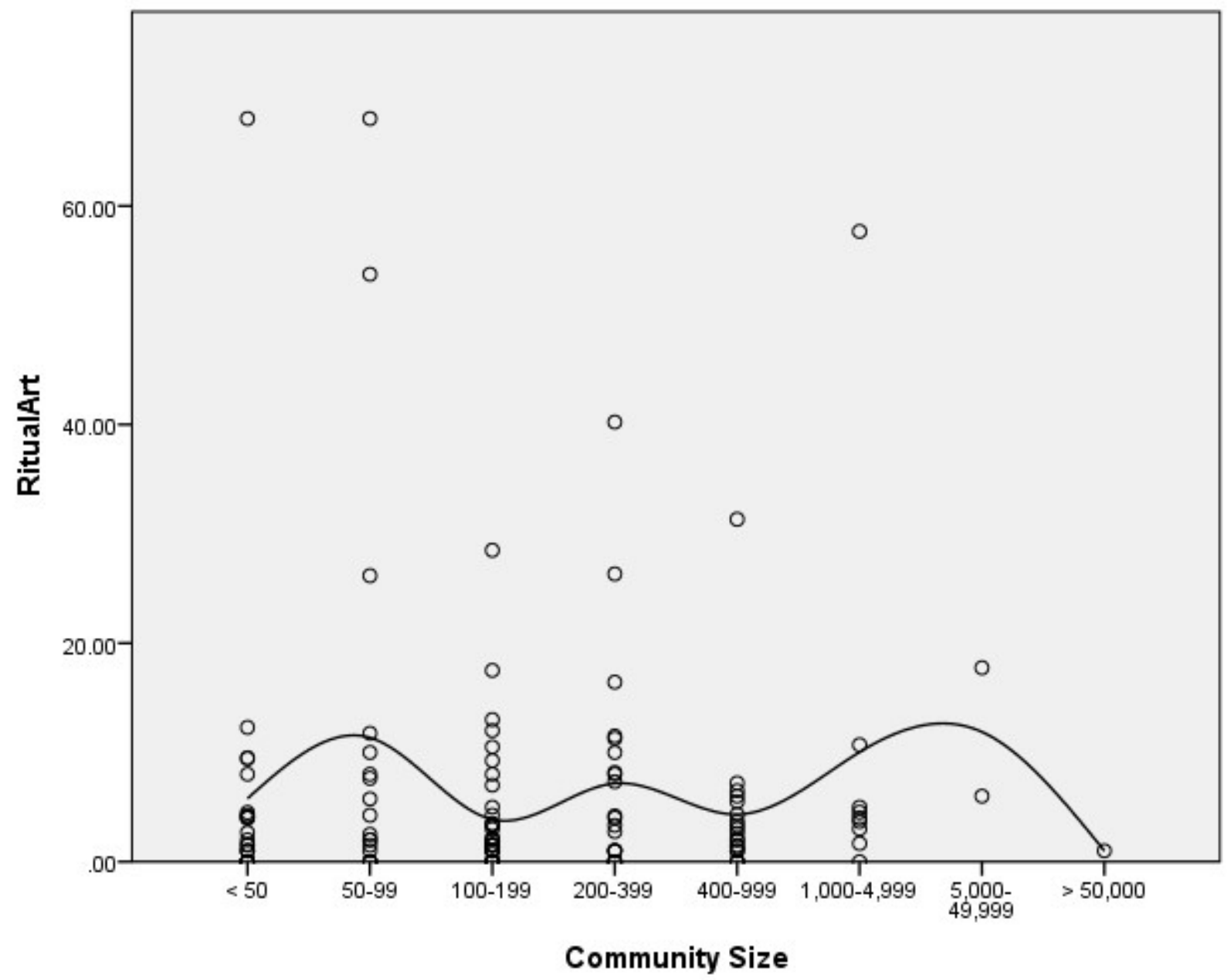

The relationship between community size and ritual art is non-monotonic and not normally distributed. It is thus not subject to Spearman's Rho or Pearson's R. No significant trend is demonstrated by the scatter plot, and as such it is unsupportive of the prediction we derived from H2.1.

The relationship between ritual art and community size, as demonstrated by the scatter plot above, cannot be interpreted as supportive of $\mathrm{H} 2.1$. This might be for a number of reasons. Community size might be a bad measure of an ecological condition that promotes group cohesion, or group cohesion could be unrelated to ritual art. Community size seems theoretically to have some relationship to group cohesion, as suggested in the previous chapter, however it is 
unclear exactly what that relationship is, given other variables such as population size.

Ultimately, the results here are unsupportive of $\mathrm{H} 2$. 
Fig. 4: Ritual Art and v64 - Population Density

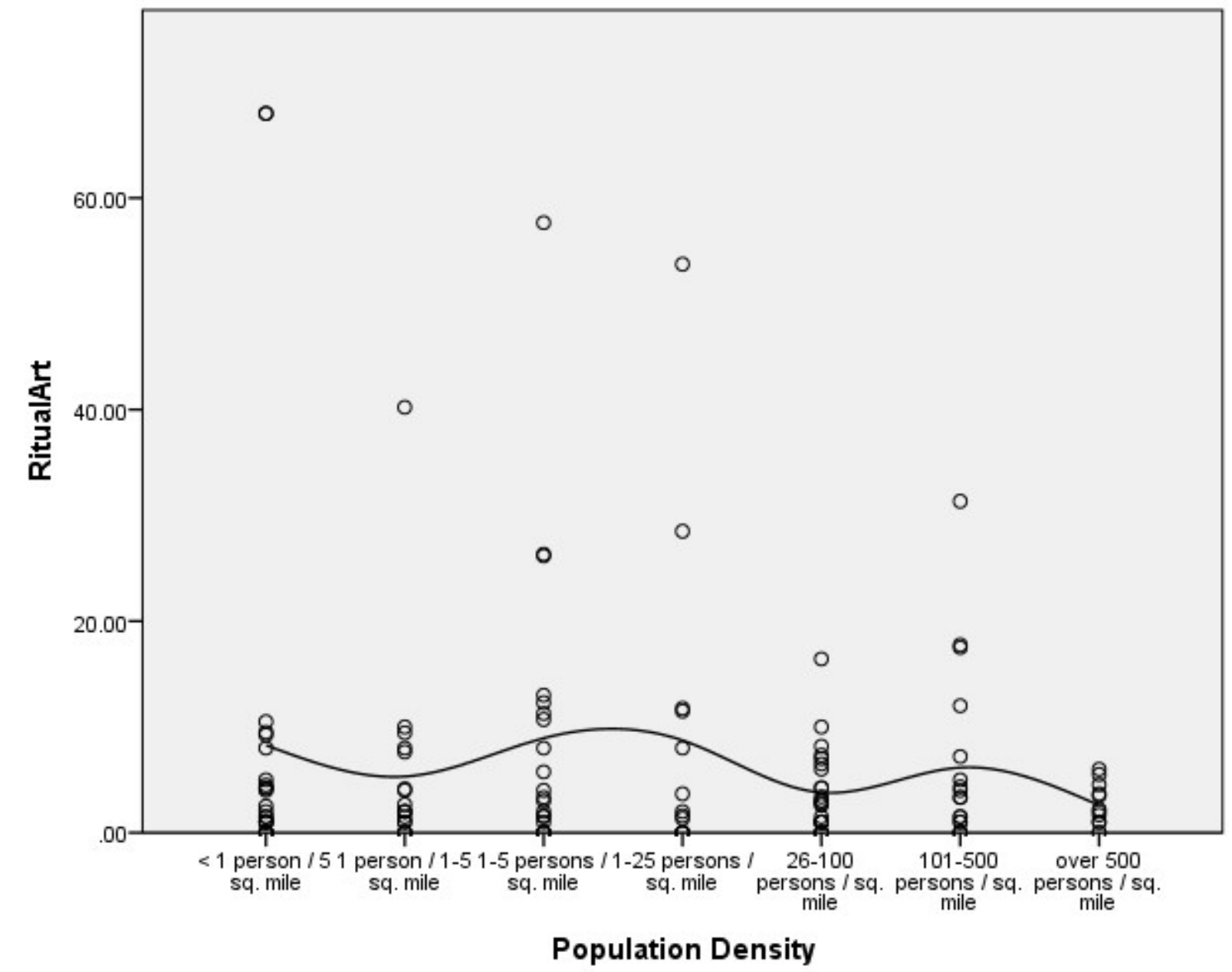

The relationship between population density and ritual art is non-monotonic and not normally distributed. It is thus not subject to Spearman's Rho or Pearson's R. No significant trend is demonstrated by the scatter plot, and as such it is unsupportive of the prediction we derived from $\mathrm{H} 2.1$.

The relationship between ritual art and population density, as demonstrated by the scatter plot above, cannot be interpreted as supportive of $\mathrm{H} 2$ This might be for a number of reasons. Population density might be a bad measure of an ecological condition that promotes group cohesion, or group cohesion could be unrelated to ritual art. Population density seems 
theoretically to have some relationship to group cohesion, as suggested in the previous chapter, however it is unclear exactly what that relationship is, given other variables such as population size. Ultimately, the results here are unsupportive of $\mathrm{H} 2$. 
Fig. 5: Ritual Art and v892 - Frequency of External War - Attacking

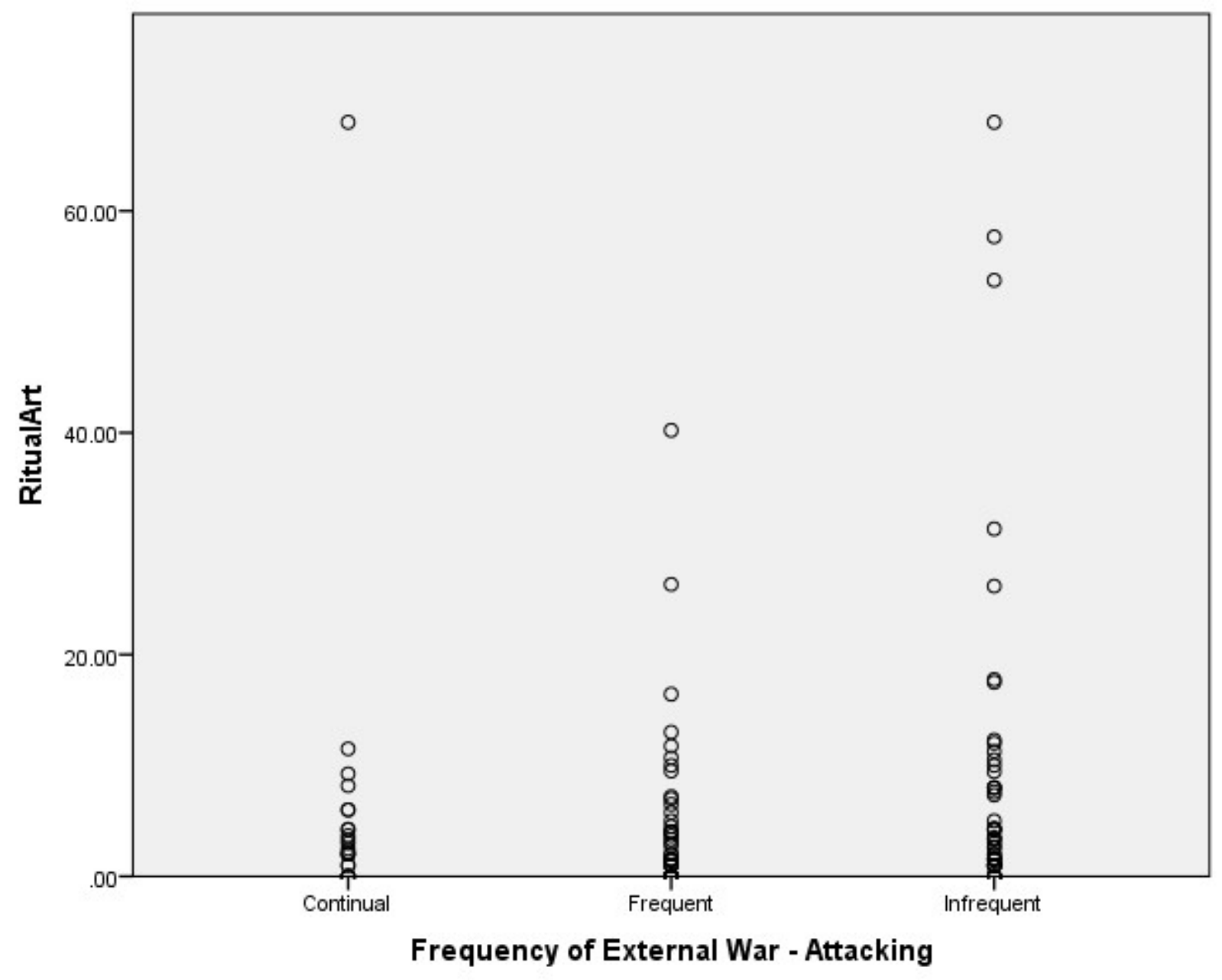

Table 3: Correlation between Ritual Art and v892

\begin{tabular}{|lll|r|r|}
\hline & & & $\begin{array}{r}\text { Frequency of } \\
\text { External War - } \\
\text { Attacking }\end{array}$ \\
\hline Spearman's rho & RitualArt & Correlation Coefficient & 1.000 & .123 \\
& & Sig. (1-tailed) &. & .088 \\
& $\mathrm{~N}$ & 133 & 122 \\
\cline { 2 - 5 } & Frequency of External War - & Correlation Coefficient & .123 & 1.000 \\
& Sig. (1-tailed) & .088 & 122 \\
& $\mathrm{~N}$ & 122 &. \\
& &
\end{tabular}


The correlation between "Ritual Art" and v892 is statistically significant at $\mathrm{P}=.088$. While the correlation is weakly positive, it is not negative as was predicted in the previous chapter. This result is therefore not supportive of $\mathrm{H} 2$. However, this counterintuitive result is statistically unlikely to be due to mere chance. As such it would be interesting to explore further why this result is contrary to our prediction and whether there is some significant relationship to be explored here. Perhaps belligerence on the part of a society (attacking) should be considered as distinct from inter-group conflict. The following result sheds some light on this. 
Fig. 6: Ritual Art and v893 - Frequency of External War - Being Attacked

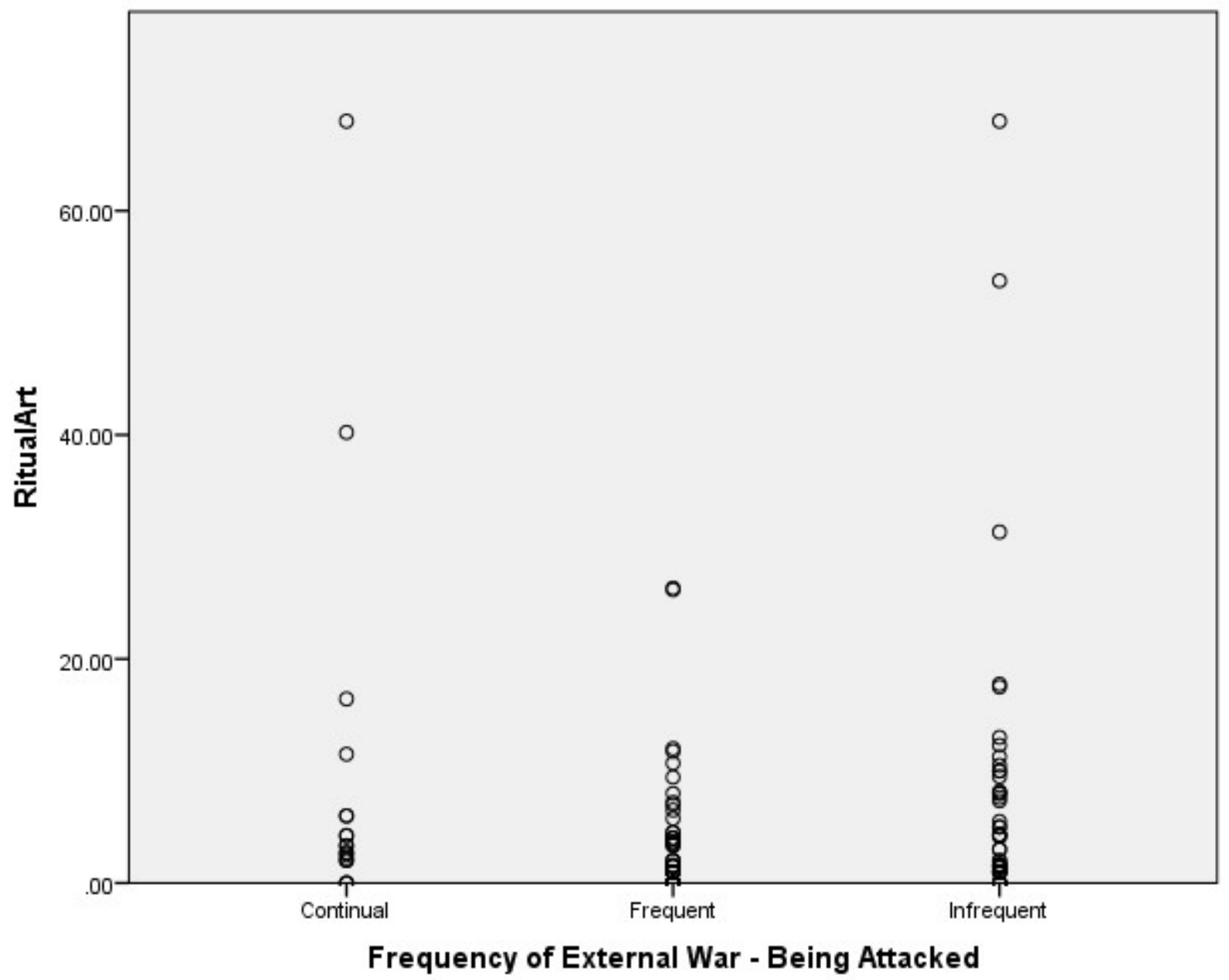

Table 4: Correlation between Ritual Art and v893

\begin{tabular}{|lll|r|r|}
\hline & & & $\begin{array}{r}\text { Frequency of } \\
\text { External War - } \\
\text { Being Attacked }\end{array}$ \\
\hline Spearman's rho & RitualArt & Correlation Coefficient & 1.000 & .052 \\
& & Sig. (1-tailed) &. & .289 \\
& $\mathrm{~N}$ & 133 & 116 \\
\cline { 2 - 5 } & Frequency of External War - & Correlation Coefficient & .052 & 1.000 \\
& Sig. (1-tailed) & .289 & 116 \\
& $\mathrm{~N}$ & 116 \\
\hline
\end{tabular}


The correlation between "Ritual Art" and v893 is statistically insignificant. The correlation is very weakly positive. However, in the previous chapter we predicted a positive correlation based on $\mathrm{H} 2.1$. This counterintuitive result is less important than the previous result, however it still calls into question our assumptions regarding the relationship between intergroup conflict and ritual art/cohesion. This result is unsupportive of $\mathrm{H} 2$. 
Fig. 7: Ritual Art and v768 - Conflict between communities of the same society

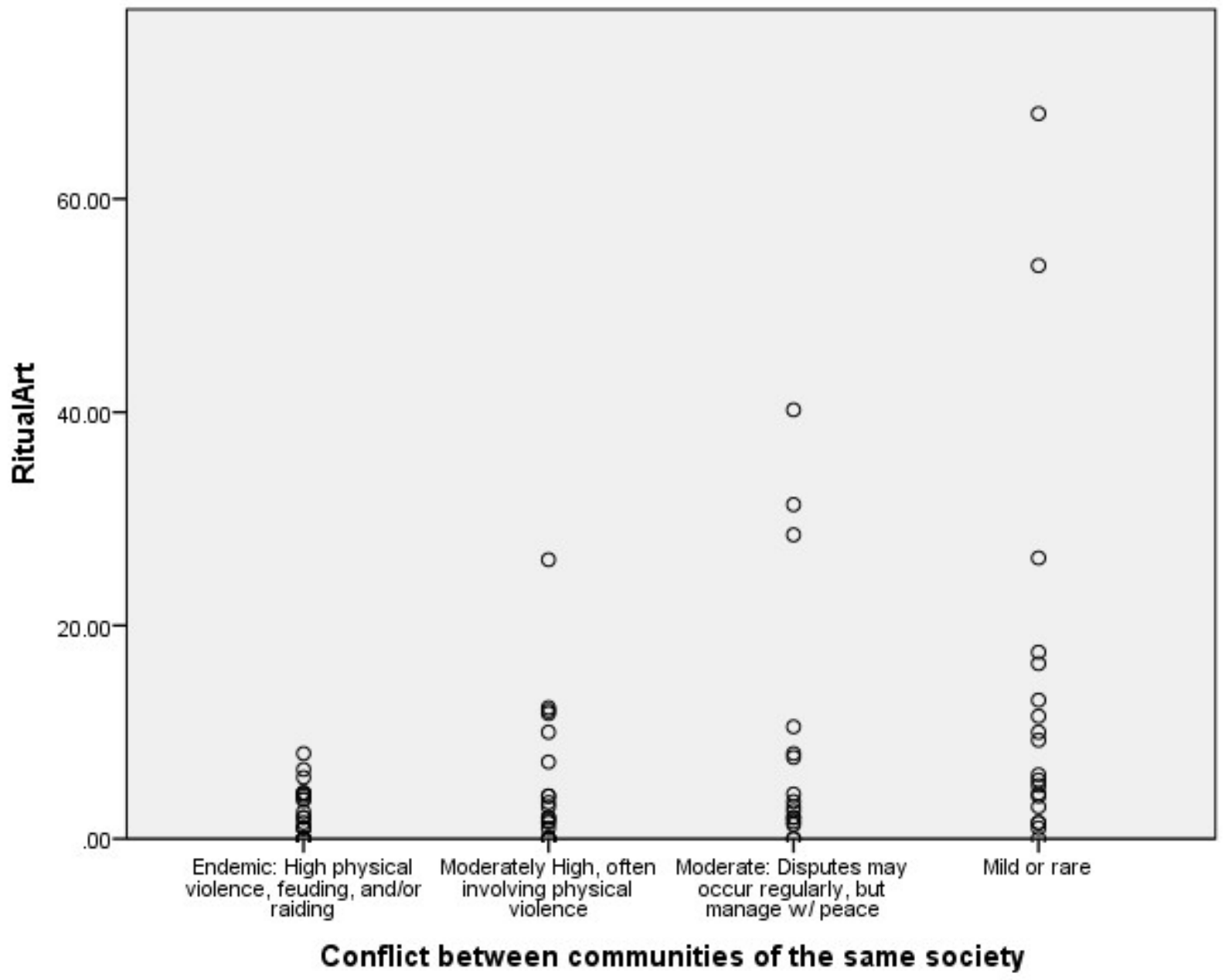

Table 5: Correlation between Ritual Art and v768

\begin{tabular}{|c|c|c|c|c|}
\hline & & & RitualArt & $\begin{array}{l}\text { Conflict between } \\
\text { communities of } \\
\text { the same society }\end{array}$ \\
\hline \multirow[t]{3}{*}{ Spearman's rho } & RitualArt & $\begin{array}{l}\text { Correlation Coefficient } \\
\text { Sig. (1-tailed) } \\
\text { N }\end{array}$ & $\begin{array}{r}1.000 \\
\cdot \\
133 \\
\end{array}$ & $\begin{array}{r}.354^{* *} \\
.001 \\
77 \\
\end{array}$ \\
\hline & $\begin{array}{l}\text { Conflict between communities } \\
\text { of the same society }\end{array}$ & $\begin{array}{l}\text { Correlation Coefficient } \\
\text { Sig. (1-tailed) }\end{array}$ & $\begin{array}{r}.354^{* *} \\
.001\end{array}$ & 1.000 \\
\hline & & $\mathrm{N}$ & 77 & 77 \\
\hline
\end{tabular}

**. Correlation is significant at the 0.01 level (1-tailed). 
The correlation between "Ritual Art" and v768 is statistically significant. Furthermore, as predicted, the correlation is positive. This moderately strong correlation is thus supportive of $\mathrm{H} 2.1$. The significance of this correlation is very promising to $\mathrm{H} 2.1$ and also $\mathrm{H} 2$. 
Fig. 8: Ritual Art and v891 - Frequency of Internal War

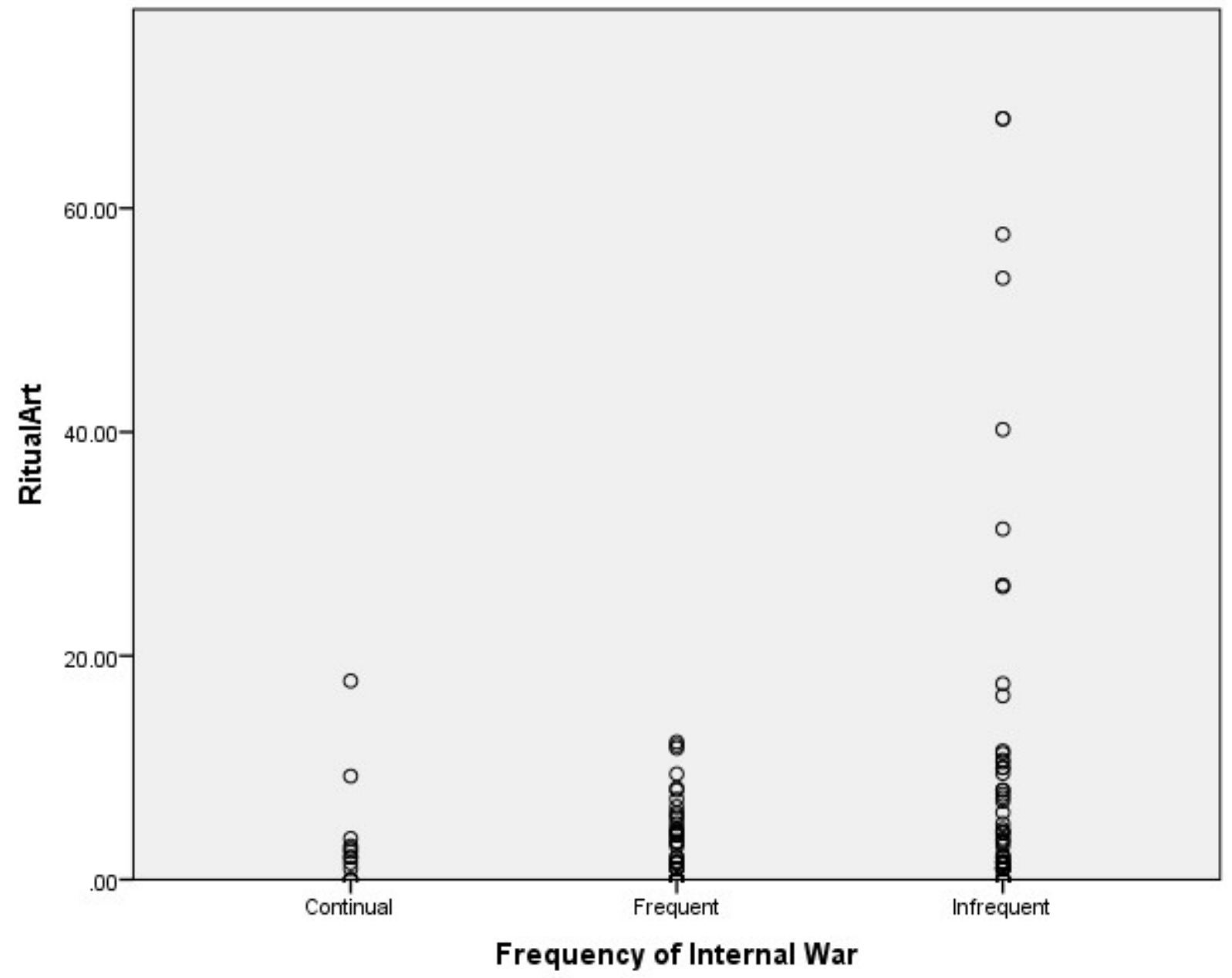

Table 6: Correlation between Ritual Art and v891

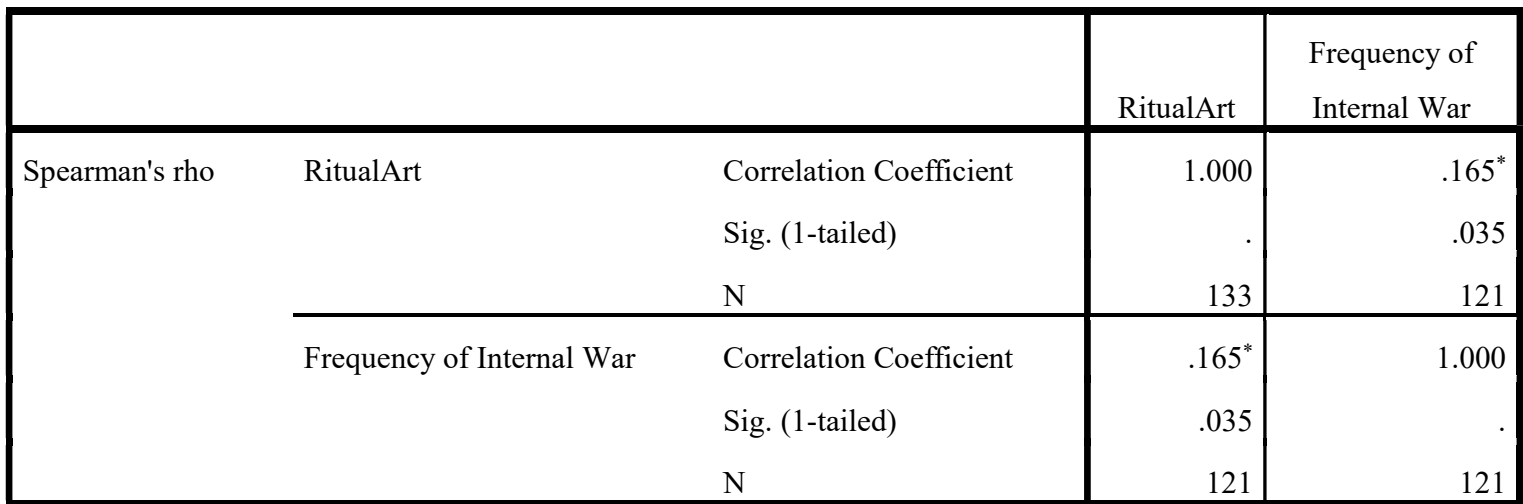

*. Correlation is significant at the 0.05 level (1-tailed). 
The correlation between "Ritual Art" and v891 is statistically significant. Furthermore, as predicted, the correlation is positive. This weak correlation is thus supportive of H2.1. The significance of this correlation is very promising to $\mathrm{H} 2.1$ and also $\mathrm{H} 2$. 
Fig. 9: Ritual Art and v1748 - Frequency of Internal Warfare

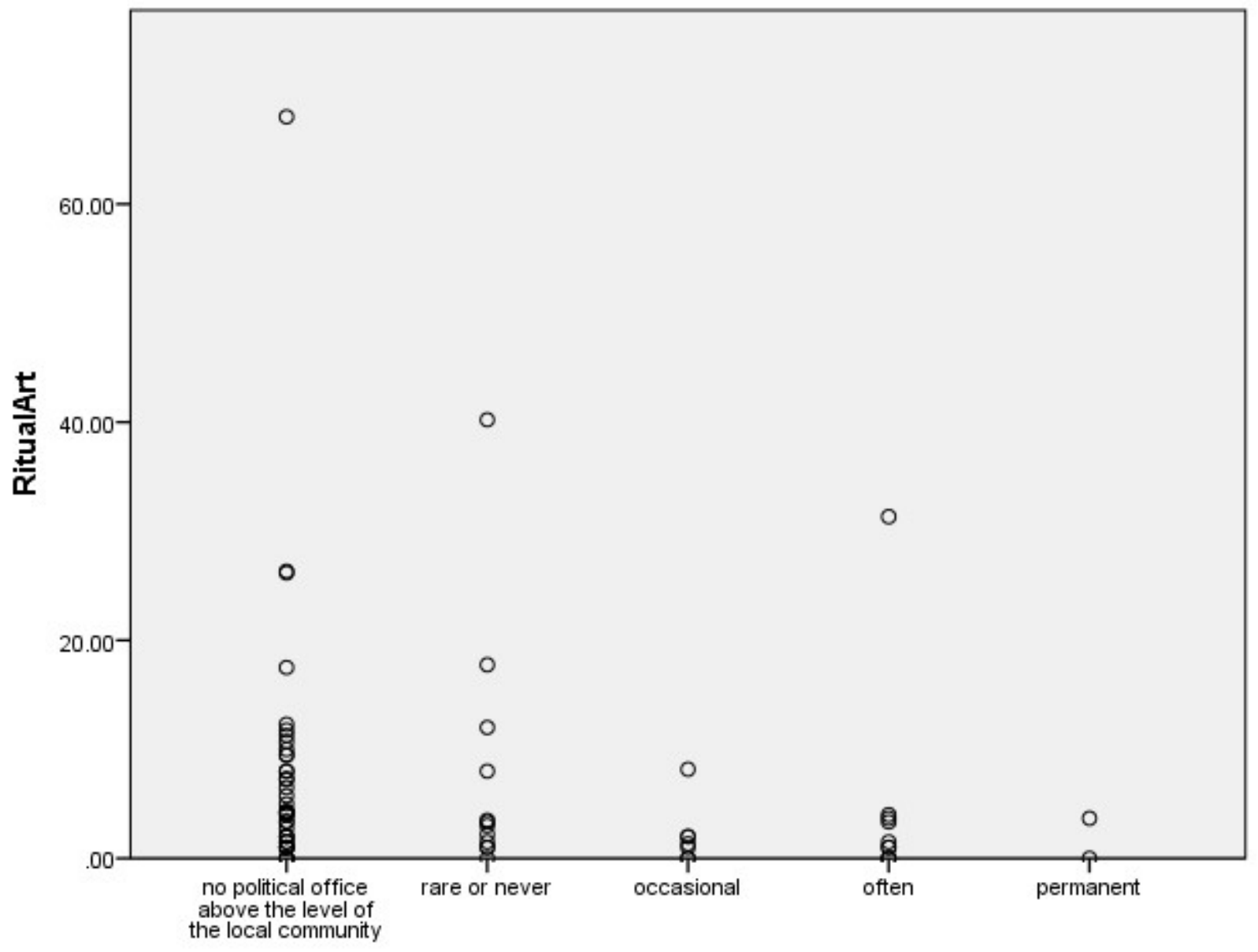

Frequency of Internal Warfare

Table 7: Correlation between Ritual Art and v1748

\begin{tabular}{|lll|r|r|}
\hline & & & $\begin{array}{c}\text { Frequency of } \\
\text { Internal Warfare }\end{array}$ \\
\hline Spearman's rho & RitualArt & Correlation Coefficient & 1.000 &. \\
& Sig. (1-tailed) & $-.307^{* *}$ \\
& & $\mathrm{~N}$ & 133 & .004 \\
\cline { 2 - 5 } & Frequency of Internal Warfare & Correlation Coefficient & $-.307^{* *}$ & 73 \\
& Sig. (1-tailed) & .004 & 1.000 \\
& $\mathrm{~N}$ & 73 &. \\
\hline
\end{tabular}

**. Correlation is significant at the 0.01 level (1-tailed). 
The correlation between "Ritual Art" and v1748 is statistically significant. Furthermore, as predicted, the correlation is negative. This moderately strong negative correlation is thus supportive of $\mathrm{H} 2.1$. The significance of this correlation is very promising to $\mathrm{H} 2.1$ and also $\mathrm{H} 2$. 
Fig. 10: Ritual Art and v1749 - Frequency of Internal Warfare

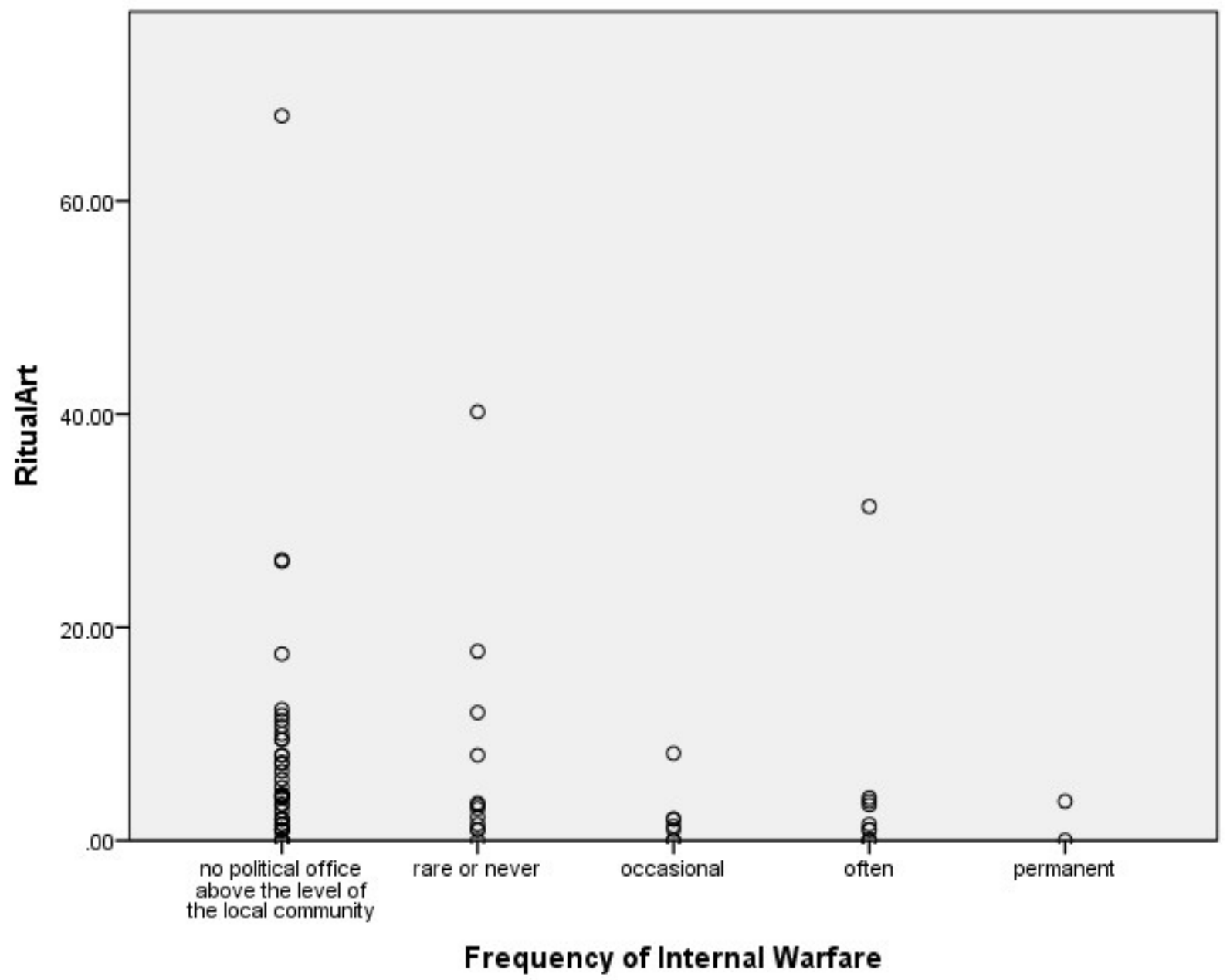




\begin{tabular}{|c|c|c|c|c|}
\hline & & & RitualArt & $\begin{array}{c}\text { Frequency of } \\
\text { Internal Warfare } \\
\text { Involving Non- } \\
\text { territorially } \\
\text { Organized } \\
\text { Groups within } \\
\text { Unit of Maximal } \\
\text { Political } \\
\text { Authority }\end{array}$ \\
\hline \multirow[t]{2}{*}{ Spearman's rho } & RitualArt & $\begin{array}{l}\text { Correlation Coefficient } \\
\text { Sig. (1-tailed) } \\
\mathrm{N}\end{array}$ & $\begin{array}{r}1.000 \\
\cdot \\
133 \\
\end{array}$ & $\begin{array}{r}-.221^{*} \\
.030 \\
73 \\
\end{array}$ \\
\hline & $\begin{array}{l}\text { Frequency of Internal Warfare } \\
\text { Involving Non-territorially } \\
\text { Organized Groups within Unit } \\
\text { of Maximal Political Authority }\end{array}$ & $\begin{array}{l}\text { Correlation Coefficient } \\
\text { Sig. (1-tailed) } \\
\text { N }\end{array}$ & $\begin{array}{r}-.221^{*} \\
.030 \\
73\end{array}$ & $\begin{array}{r}1.000 \\
73\end{array}$ \\
\hline
\end{tabular}

*. Correlation is significant at the 0.05 level (1-tailed).

The correlation between "Ritual Art" and v1749 is statistically significant. Furthermore, as predicted, the correlation is negative. This weak to moderately strong correlation is thus supportive of H2.1. The significance of this correlation is very promising to H2.1 and also H2. 
Fig. 11: Ritual Art and v1750 - Frequency of Violent Conflict Between Groups within Local Communities

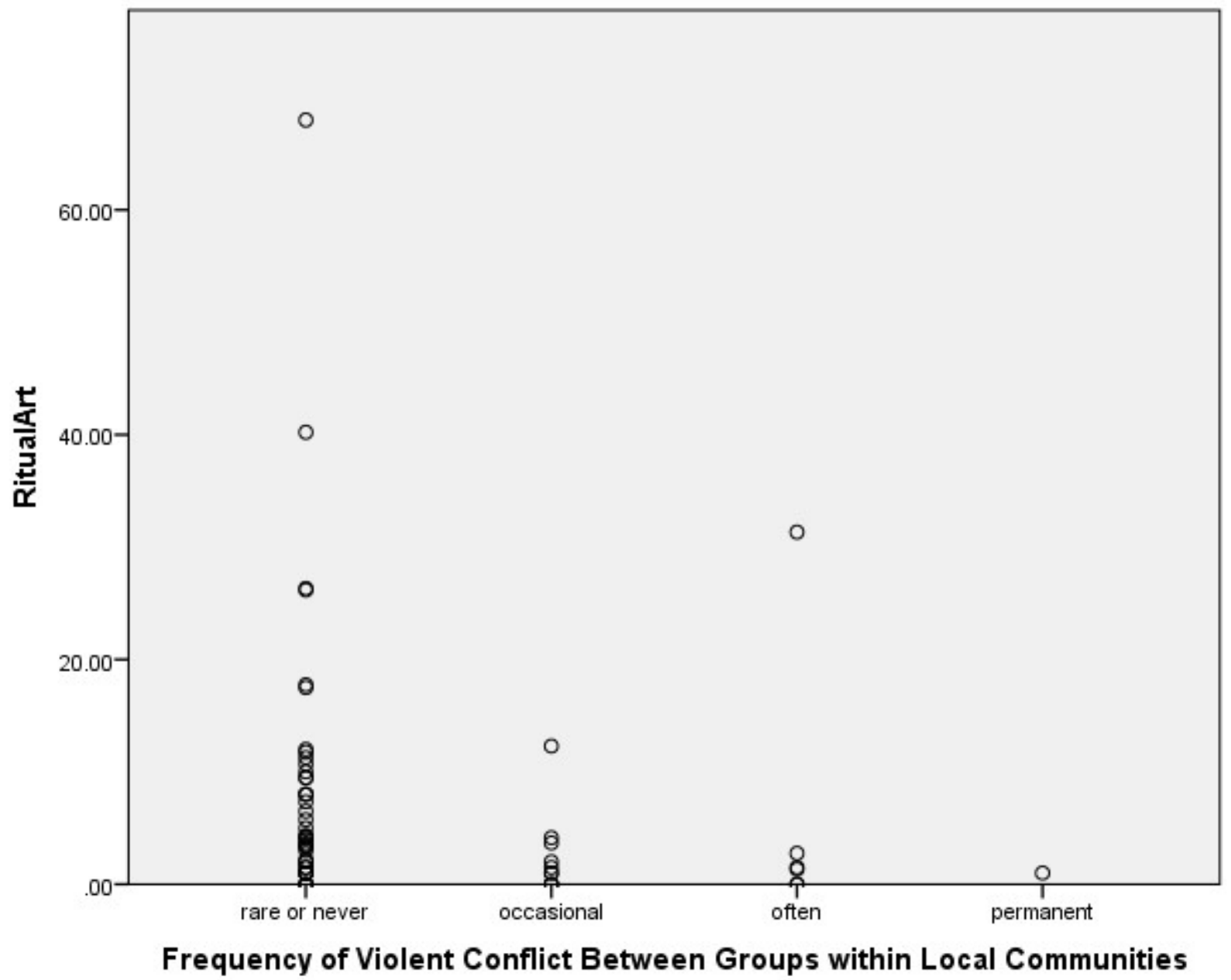


Table 9: Correlation between Ritual Art and v1750

\begin{tabular}{|rll|r|r|}
\hline & & & $\begin{array}{r}\text { Frequency of } \\
\text { Violent Conflict } \\
\text { Between Groups } \\
\text { within Local } \\
\text { Communities }\end{array}$ \\
\hline Spearman's rho & RitualArt & & RitualArt \\
& & Correlation Coefficient & 1.000 & $-.349^{* *}$ \\
& Sig. (1-tailed) & .003 \\
& N & 133 & 60 \\
\cline { 2 - 5 } & Frequency of Violent Conflict & Correlation Coefficient & $-.349^{* *}$ & 1.000 \\
& Between Groups within Local & Sig. (1-tailed) & .003 &. \\
& Communities & & 60 \\
\hline
\end{tabular}

**. Correlation is significant at the 0.01 level (1-tailed).

The correlation between "Ritual Art" and v1750 is statistically significant. Furthermore, as predicted, the correlation is negative. This moderately strong negative correlation is thus supportive of H2.1. The significance of this correlation is very promising to H2.1 and also H2. 
Fig. 12: Ritual Art and v72 - Intercommunity Marriage

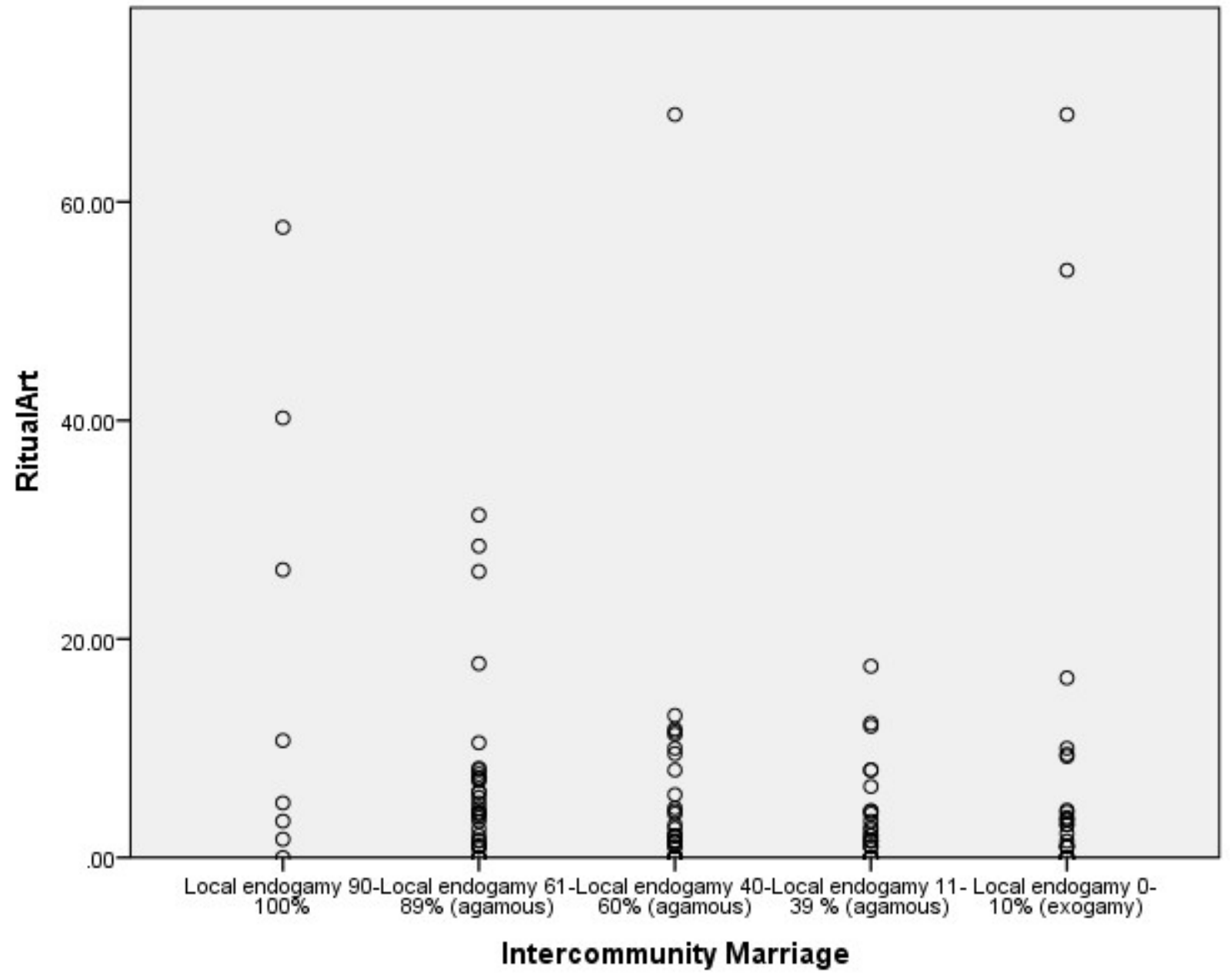


Fig. 13: Ritual Art and v72 - Intercommunity Marriage (Interpolation Line)

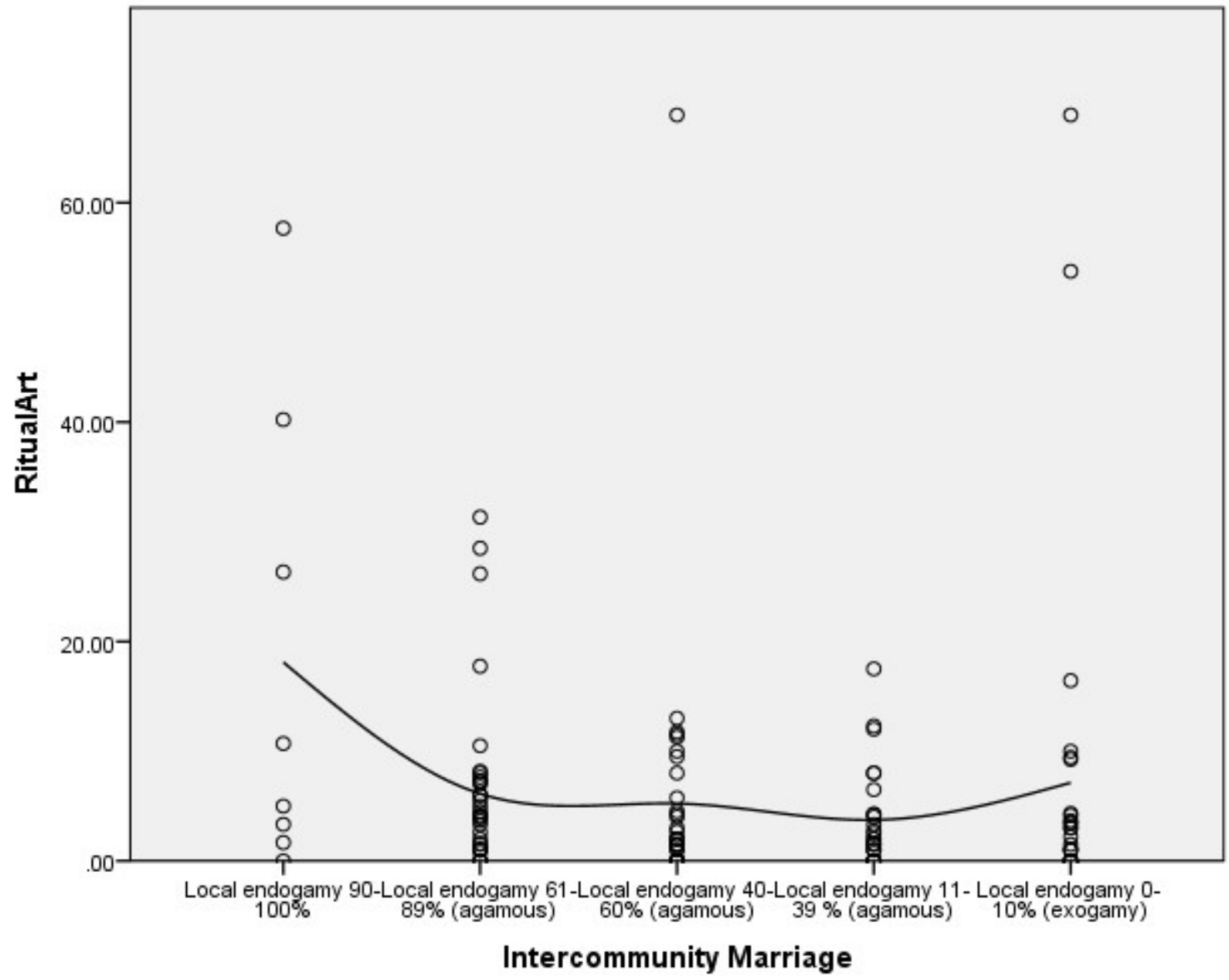

Table 10: Correlation between Ritual Art and v72

\begin{tabular}{|lll|r|r|}
\hline & & RitualArt & $\begin{array}{c}\text { Intercommunity } \\
\text { Marriage }\end{array}$ \\
\hline Spearman's rho & RitualArt & Correlation Coefficient & 1.000 & $-.189^{*}$ \\
& & Sig. (1-tailed) &. & .015 \\
& $\mathrm{~N}$ & 133 & 133 \\
\cline { 2 - 5 } & Intercommunity Marriage & Correlation Coefficient & $-.189^{*}$ & 1.000 \\
& Sig. (1-tailed) & .015 &. \\
& $\mathrm{~N}$ & 133 & 133 \\
\hline
\end{tabular}

*. Correlation is significant at the 0.05 level (1-tailed). 
While it is not entirely clear whether the relationship between "Ritual Art" and v72 is monotonic, and thus whether Spearman's rho can be properly applied, the correlation is significant and negative, as predicted. The strength of the correlation, however, is weak. Nonetheless, this result is supportive of $\mathrm{H} 2.1$. 
Fig. 14: Ritual Art and v73 - Community Integration

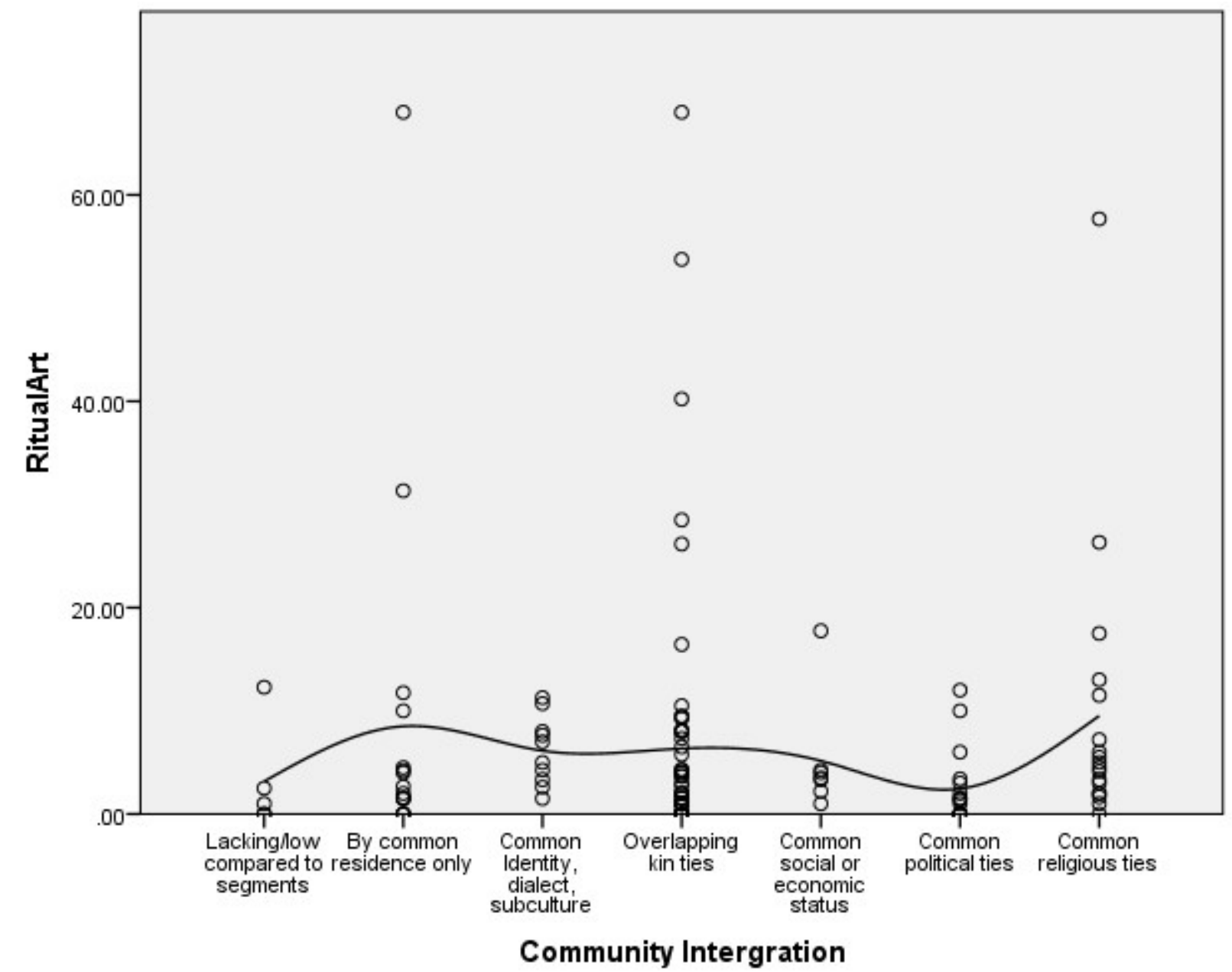

The relationship between "Ritual Art" and v73 is non-monotonic, which may be reflective of an insignificant relationship between the two variables, or the fact that v73 is not clearly ordinal. I provide it here simply for the reader's consideration. The spike along common religious ties is not, for example, very surprising. 
Fig. 15: Ritual Art and v151 - Agriculture

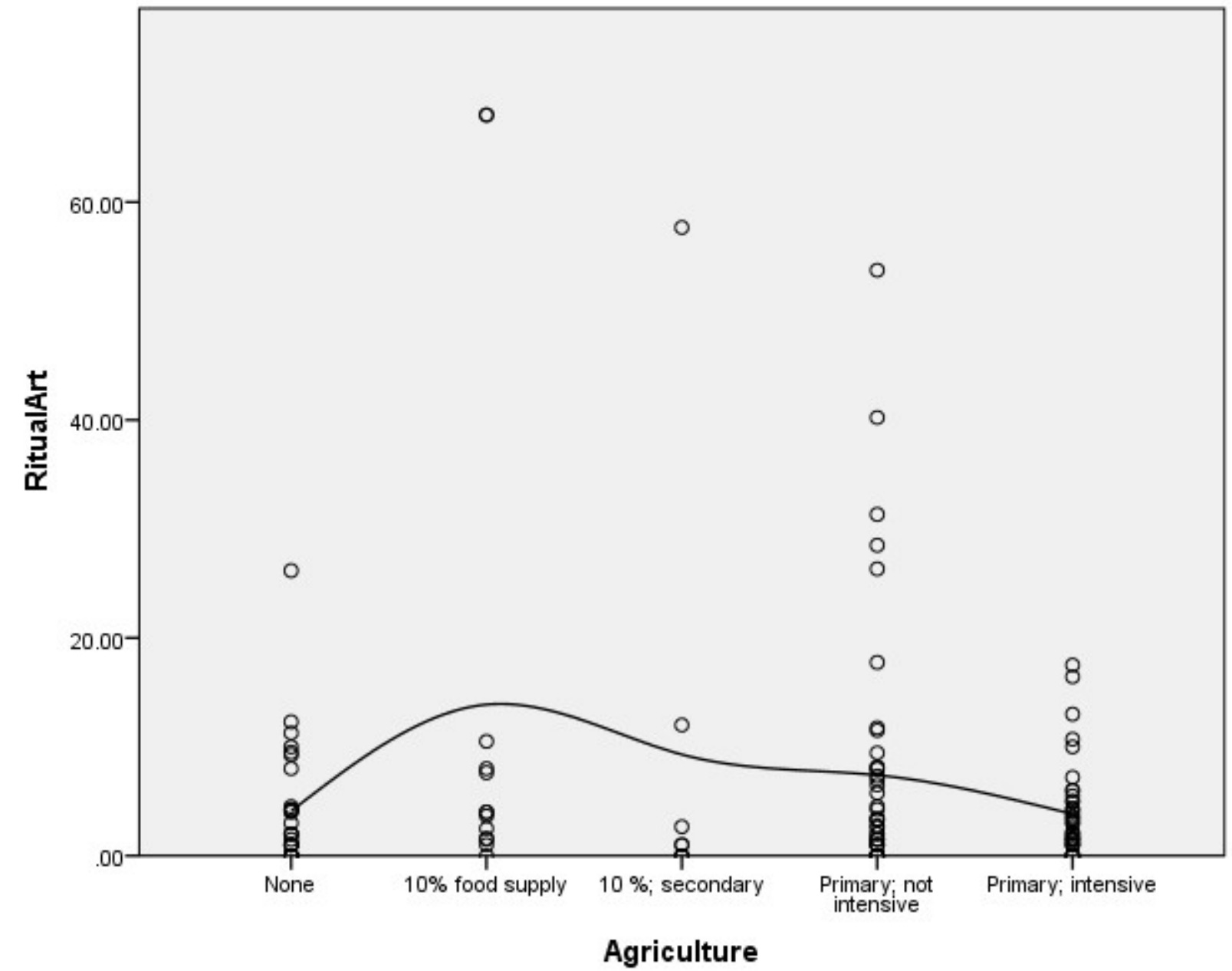

The relationship between "Ritual Art" and v151 is non-monotonic, which may be reflective of an insignificant relationship between the two variables, or a non-linear relationship as the curve peaks at " $10 \%$ food supply" and then drops off consistently towards "primary; intensive." This relationship is not the positive relationship predicted earlier, though it might be reflective of the hypothesis briefly forwarded that ritual rises with development and then drops off with industrialization. However, as it stands, this relationship is unsupportive of $\mathrm{H} 2.1$. 
Fig. 16: Ritual Art and v232 - Intensity of Cultivation

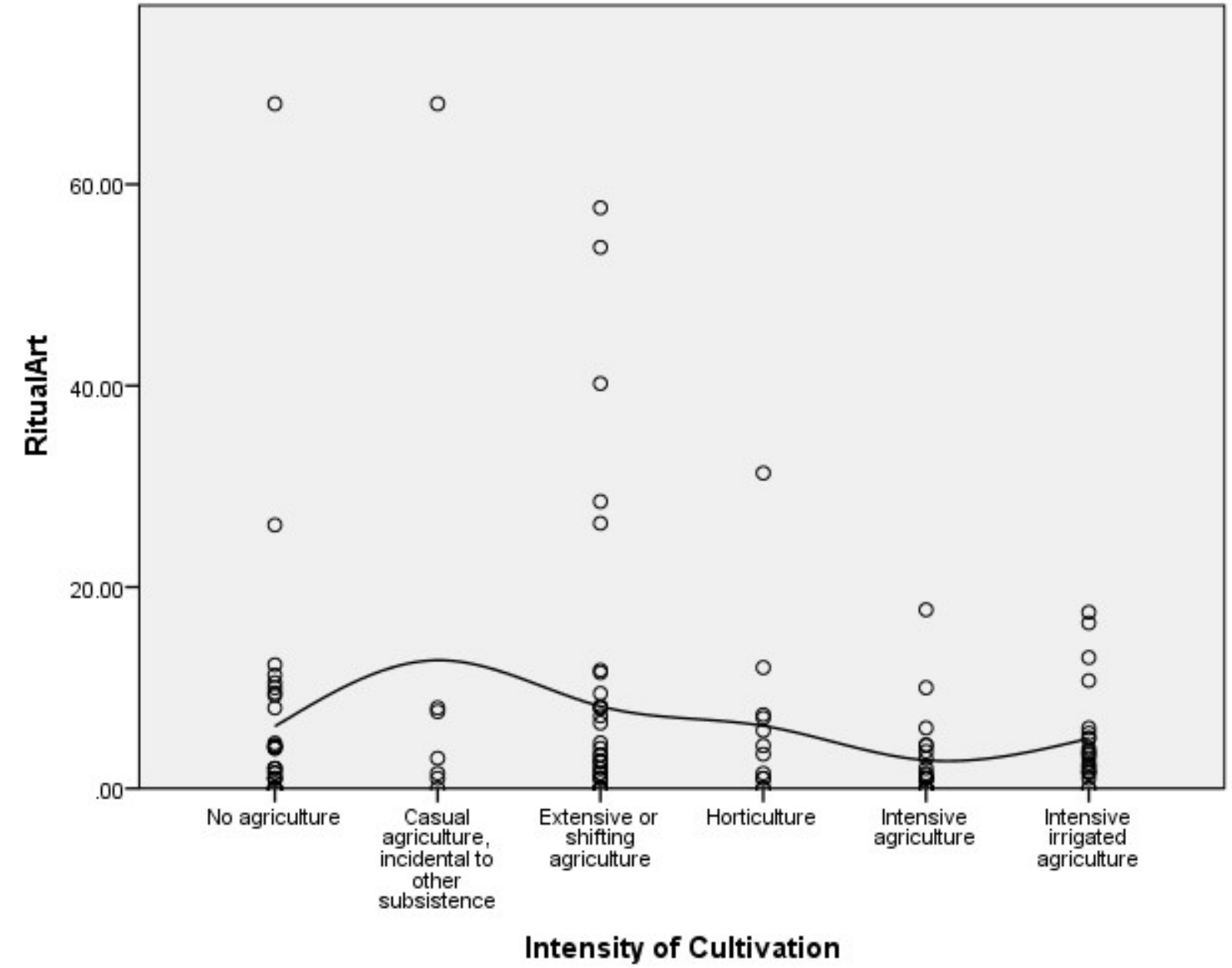

The relationship between "Ritual Art" and v232 is non-monotonic, which may be reflective of an insignificant relationship between the two variables, or a non-linear relationship as the curve peaks at "casual agriculture" and then drops off consistently towards "Intensive agriculture," while peaking once more at "Intensive irrigated agriculture. This relationship is not the positive relationship predicted earlier, though it does resemble the relationship demonstrated in v151. This is not likely significant since the correlation between v151 and v232 is very high: 
Table 11: Correlation between v232 and v151

\begin{tabular}{|c|c|c|c|c|}
\hline & & & $\begin{array}{l}\text { Intensity of } \\
\text { Cultivation }\end{array}$ & Agriculture \\
\hline \multirow[t]{6}{*}{ Spearman's rho } & \multirow[t]{3}{*}{ Intensity of Cultivation } & Correlation Coefficient & 1.000 & $.888^{* *}$ \\
\hline & & Sig. (1-tailed) & & .000 \\
\hline & & $\mathrm{N}$ & 133 & 133 \\
\hline & \multirow[t]{3}{*}{ Agriculture } & Correlation Coefficient & $.888^{* *}$ & 1.000 \\
\hline & & Sig. (1-tailed) & .000 & \\
\hline & & $\mathrm{N}$ & 133 & 133 \\
\hline
\end{tabular}

**. Correlation is significant at the 0.01 level (1-tailed).

The similarities between scatterplots in v151 and v232 is not surprising given the near autocorrelation of v151 to v232. The relationship between v232 and "Ritual Art" is not supportive of $\mathrm{H} 2$. 
Fig. 17: Ritual Art and v1128 - Cropping Index

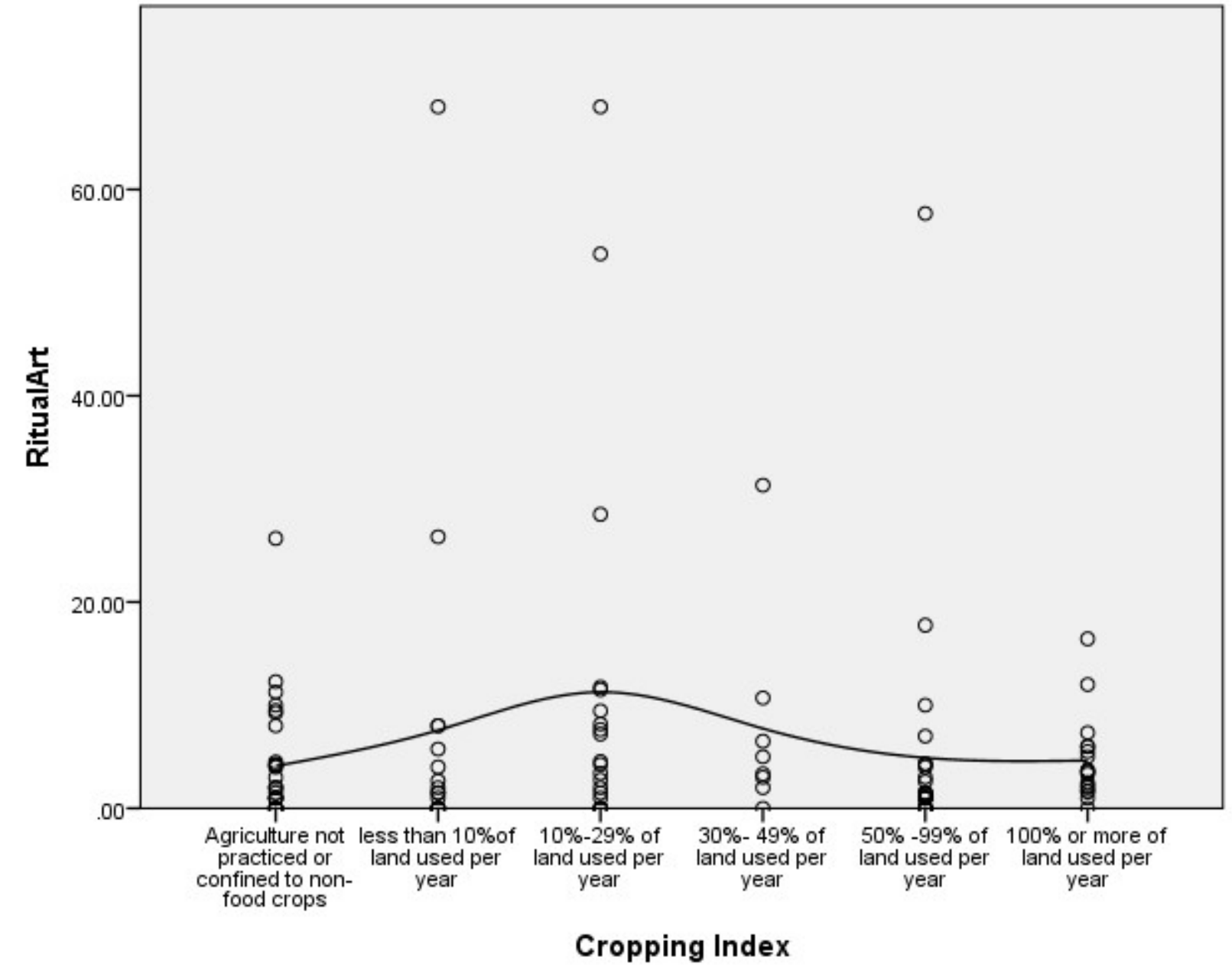

The relationship between "Ritual Art" and v1128 is non-monotonic. Earlier I suggested that this result would not be predictable and present it only for the reader's interest. The nonlinear pattern that is developing in agricultural variables is, however, very interesting. Once again the relationship shows a peak and then a tailing off that resembles the relationship seen in v151 and v232. However, for the reasons mentioned above this should not necessarily be considered overly compelling. 
Fig. 18: Ritual Art and v775 - Compliance of Individuals w/ community norms

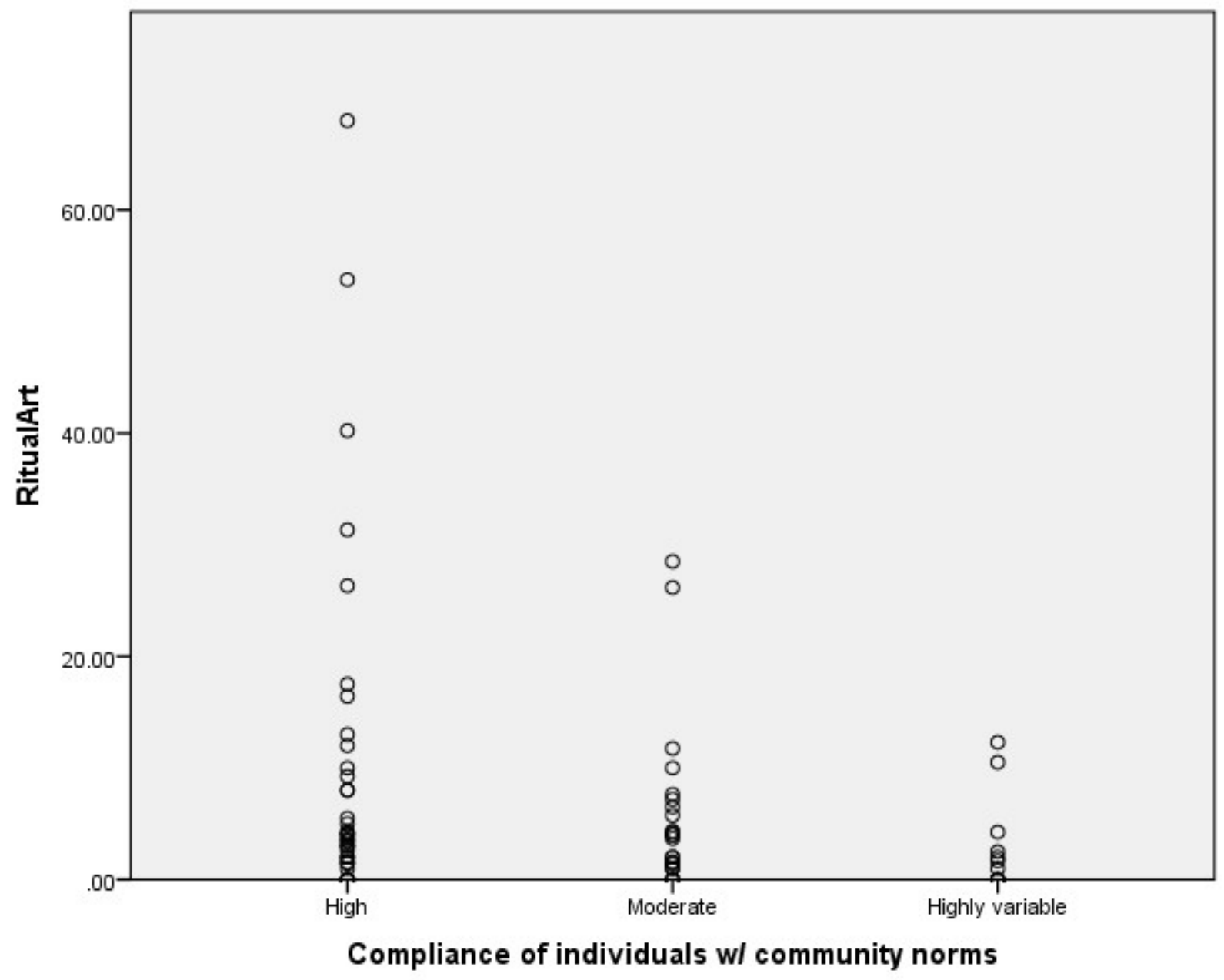

Table 12: Correlation between Ritual Art and v775

\begin{tabular}{|c|c|c|c|c|}
\hline & & & RitualArt & $\begin{array}{c}\text { Compliance of } \\
\text { individuals w/ } \\
\text { community norms }\end{array}$ \\
\hline \multirow[t]{2}{*}{ Spearman's rho } & RitualArt & $\begin{array}{l}\text { Correlation Coefficient } \\
\text { Sig. (1-tailed) } \\
\text { N }\end{array}$ & $\begin{array}{r}1.000 \\
\cdot \\
133 \\
\end{array}$ & $\begin{array}{r}-.186 \\
.057 \\
73 \\
\end{array}$ \\
\hline & $\begin{array}{l}\text { Compliance of individuals w/ } \\
\text { community norms }\end{array}$ & $\begin{array}{l}\text { Correlation Coefficient } \\
\text { Sig. (1-tailed) } \\
\text { N }\end{array}$ & $\begin{array}{r}-.186 \\
.057 \\
73\end{array}$ & $\begin{array}{r}1.000 \\
. \\
73\end{array}$ \\
\hline
\end{tabular}


The relationship between "Ritual Art" and v775 is weakly negative and statistically significant as predicted above. While this result is interesting, the weakness of the correlation makes it difficult to determine whether it is supportive of $\mathrm{H} 2.1$. 
Fig. 19: Ritual Art and v1684 - Threat of Weather or Pest Disasters

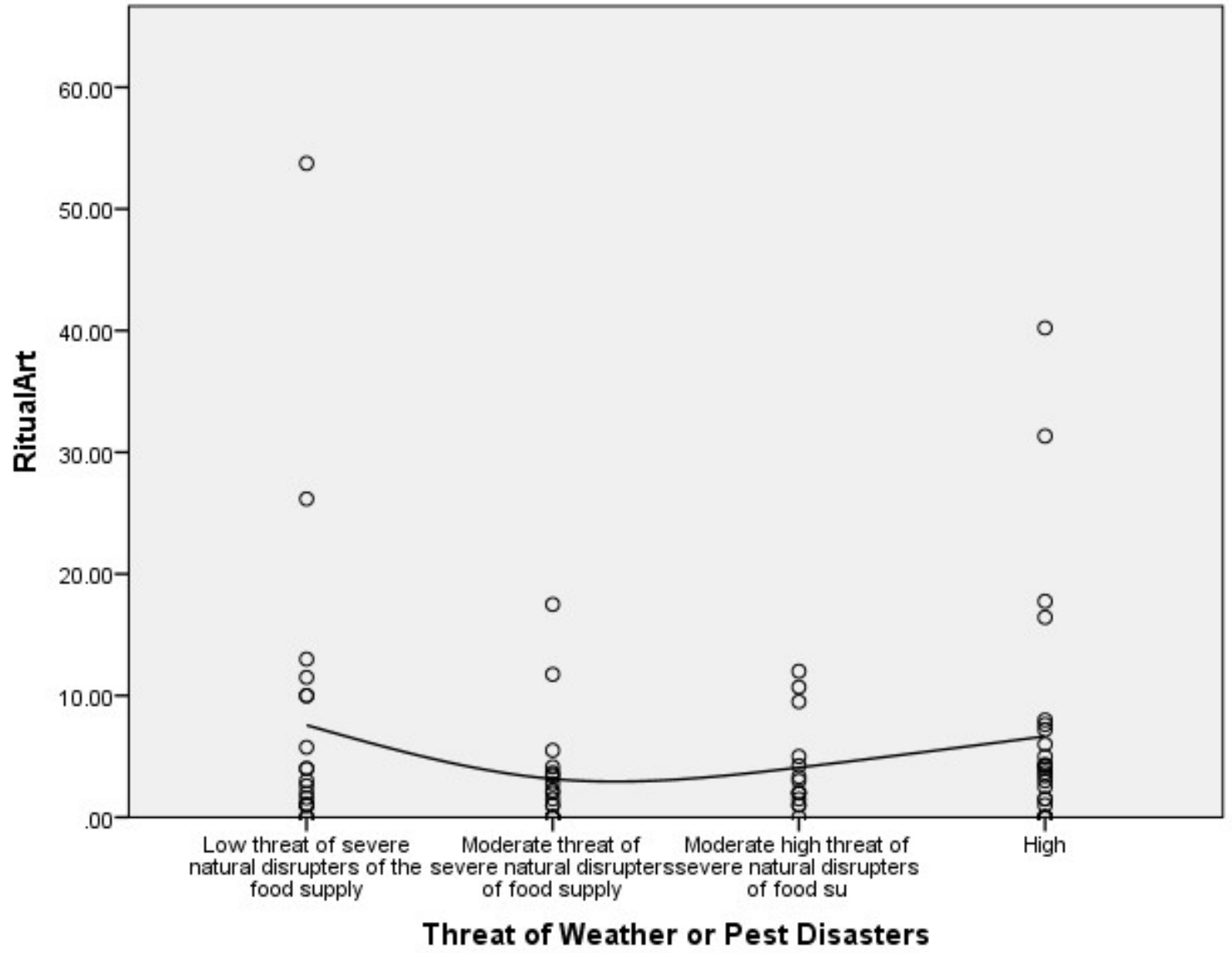

The relationship between "Ritual Art" and v1684 is non-monotonic and is therefore not a clear positive correlation as was predicted. This result is unsupportive of $\mathrm{H} 2$. 
Fig. 20: Ritual Art and v1719 - Periodical Variation of Food Scarcity

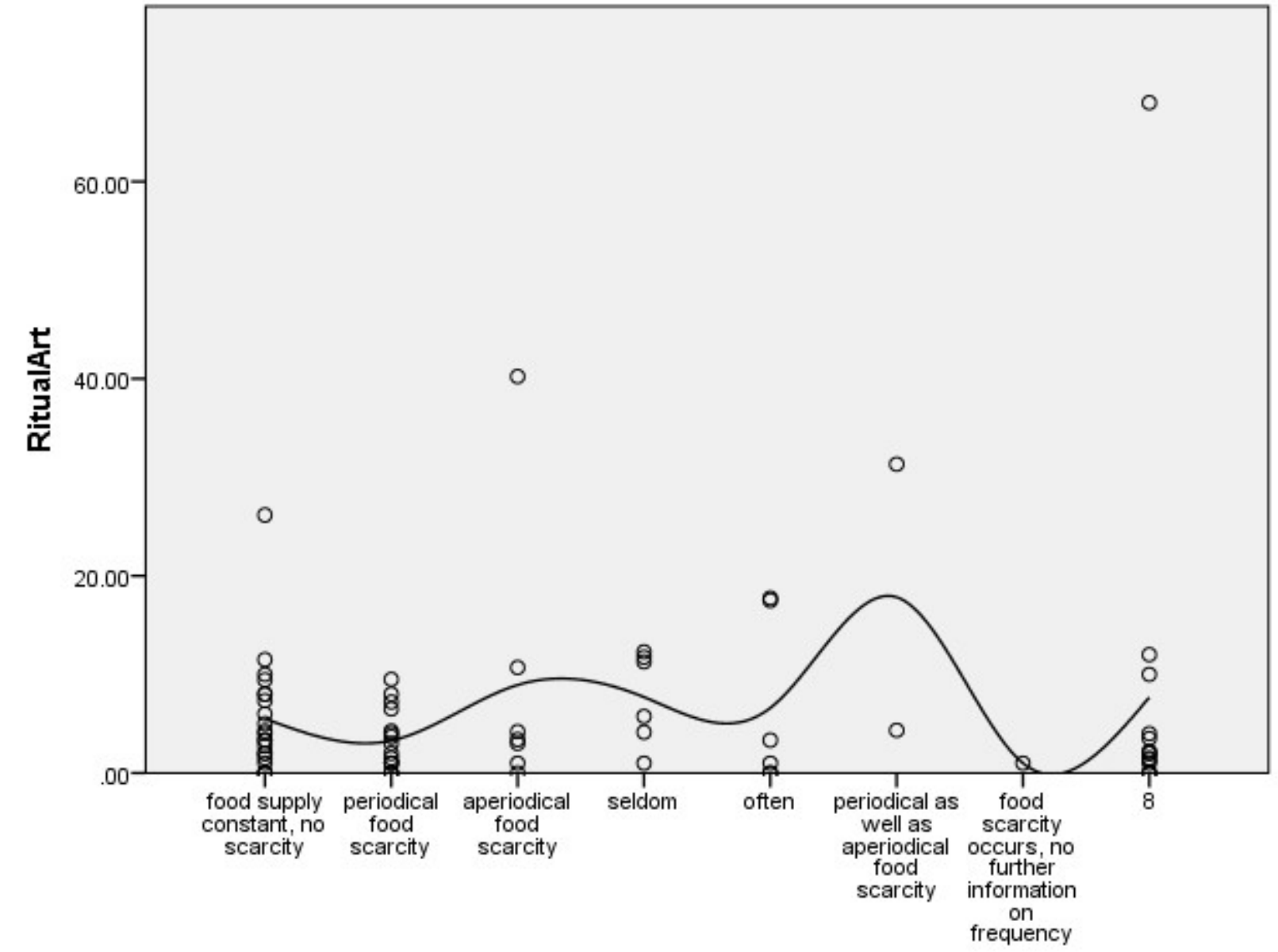

Periodical Variation of Food Scarcity

Even without removing the uncoded category 8 it is clear from this scatterplot that the relationship between "Ritual Art" and v1719 is non-monotonic and therefore fails to meet our prediction of a positive correlation. This relationship is unsupportive of $\mathrm{H} 2$. 
Fig. 21: Ritual Art and v759 - Perception of Political Leader's Power

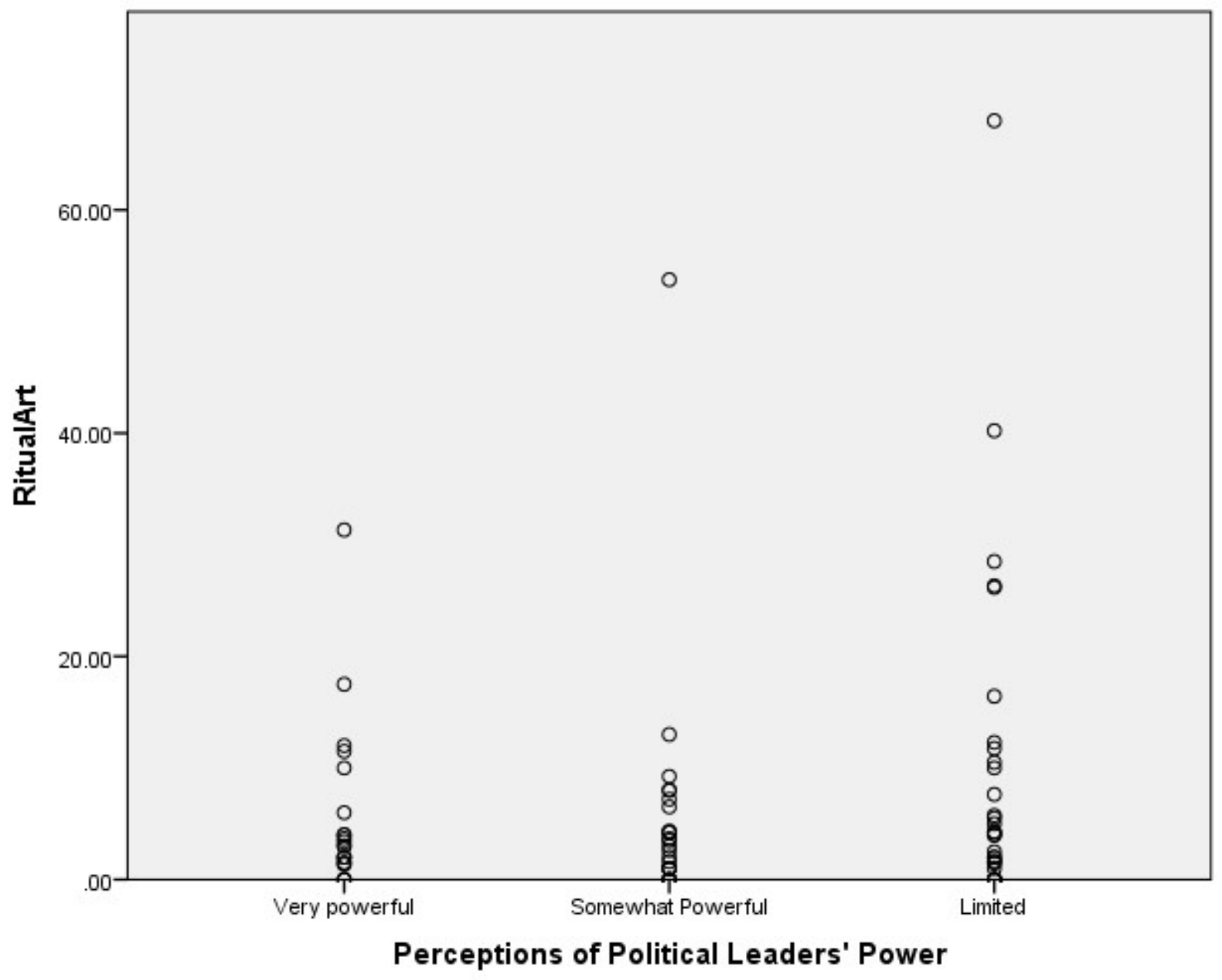

Table 13: Correlation between Ritual Art and v759

\begin{tabular}{|c|c|c|c|c|}
\hline & & & RitualArt & $\begin{array}{c}\text { Perceptions of } \\
\text { Political Leaders' } \\
\text { Power } \\
\end{array}$ \\
\hline \multirow[t]{2}{*}{ Spearman's rho } & RitualArt & $\begin{array}{l}\text { Correlation Coefficient } \\
\text { Sig. (1-tailed) } \\
\mathrm{N}\end{array}$ & $\begin{array}{r}1.000 \\
. \\
133\end{array}$ & $\begin{array}{r}.068 \\
.277 \\
77\end{array}$ \\
\hline & $\begin{array}{l}\text { Perceptions of Political Leaders' } \\
\text { Power }\end{array}$ & $\begin{array}{l}\text { Correlation Coefficient } \\
\text { Sig. (1-tailed) } \\
\text { N }\end{array}$ & $\begin{array}{r}.068 \\
.277 \\
77\end{array}$ & $\begin{array}{r}1.000 \\
77\end{array}$ \\
\hline
\end{tabular}


While not statistically significant, the positive correlation between "Ritual Art" and v759 disconfirms our prediction of a negative correlation. Since the correlation is so insignificant I cannot speculate on why the result is a positive correlation other than to suggest that there is no relationship between "Ritual Art" and v759. This result is unsupportive of H2. 
Fig. 22: Ritual Art and v776 - formal sanctions and enforcement for community decisions

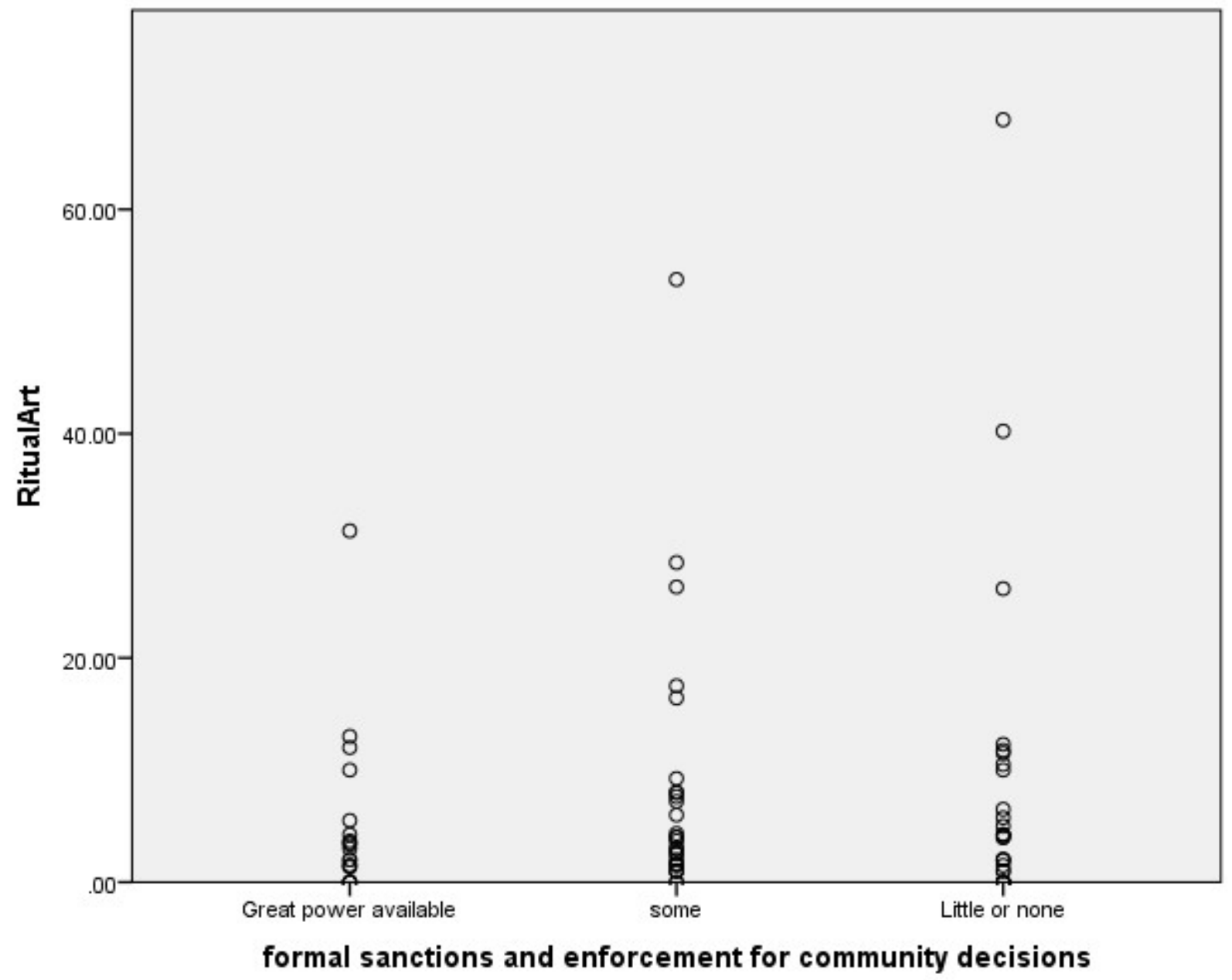

Table 14: Correlation between Ritual Art and v776

\begin{tabular}{|rll|r|r|}
\hline & & & $\begin{array}{r}\text { formal sanctions } \\
\text { and enforcement } \\
\text { for community } \\
\text { decisions }\end{array}$ \\
\hline Spearman's rho & RitualArt & Correlation Coefficient & 1.000 & .063 \\
& & Sig. (1-tailed) &. & .294 \\
& & $\mathrm{~N}$ & 133 & 77 \\
\cline { 2 - 5 } & Cormal sanctions and & Correlation Coefficient & .063 & 1.000 \\
& enforcement for community & Sig. (1-tailed) & .294 & 77 \\
& decisions & $\mathrm{N}$ & 77 \\
\hline
\end{tabular}


The relationship between "Ritual Art" and v776 is a statistically insignificant very weak positive correlation. This disconfirms our prediction of a negative correlation. As such this result is unsupportive of $\mathrm{H} 2$. 
Fig. 23: Ritual Art and v1132 - Political Integration

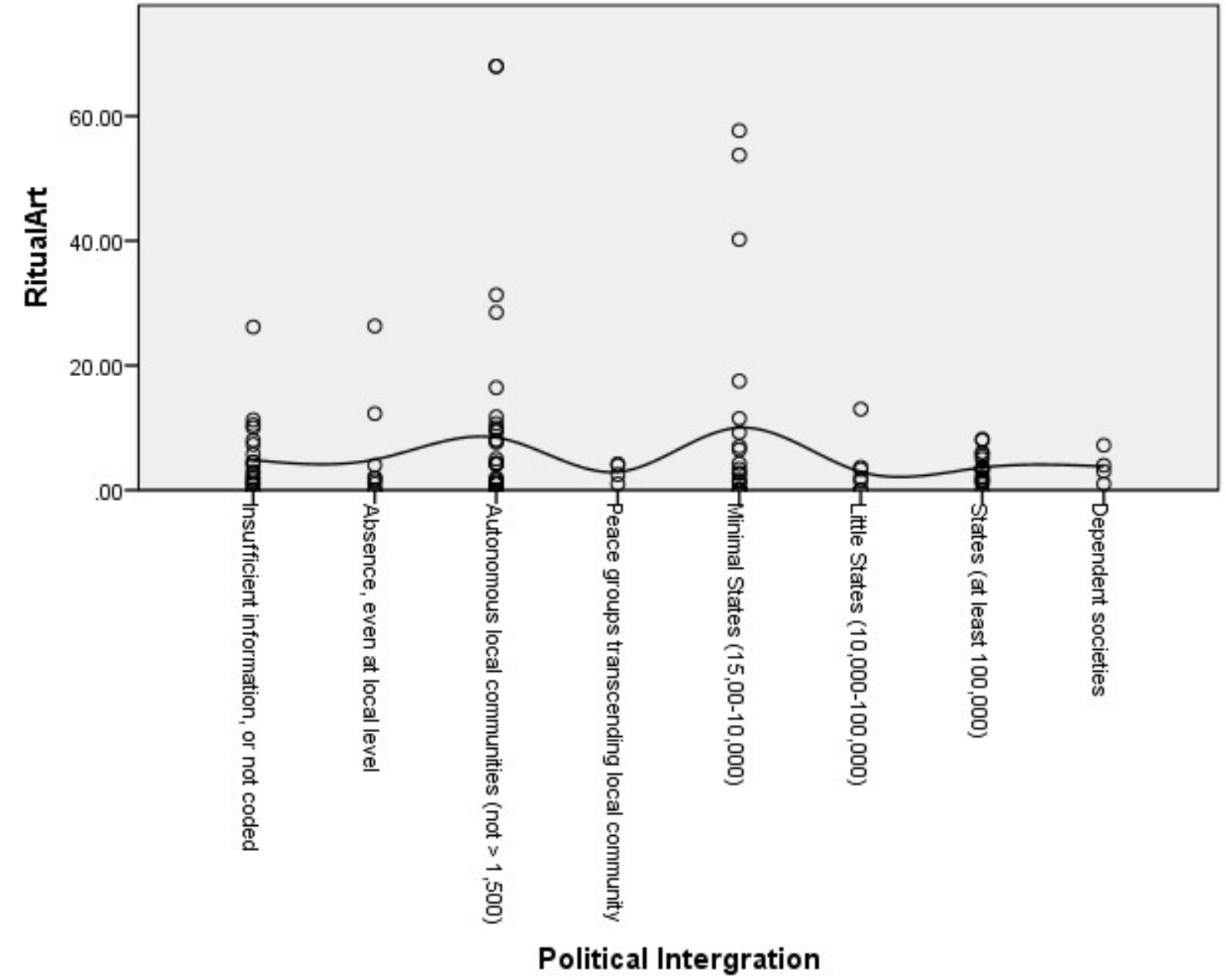

The relationship between "Ritual Art" and v1132 is non-monotonic and does not align with our prediction of a positive correlation between "Ritual Art" and v1132. This result is unsupportive of $\mathrm{H} 2$.

\subsection{Discussion}

The results of various correlations performed above demonstrates largely mixed results. While many results were non-monotonic and unsupportive, and some were surprisingly opposite to our predictions, other results were strong and statistically significant. In fact, those variables 
which most intuitively account for group cohesion, and appeared under the heading of the individual-group dimension in the previous chapter, such as those that measure internal hostilities, were largely supportive of H2.1. This significant result should not be ignored given the overall mixed results. Part of this project involved the difficult undertaking of attempting to define cohesion and then find appropriate proxy variables for it. While some proxies appear to have been poor choices, and others appear unsupportive, the relationship between ritual art and internal violence is consistent across numerous variables. Nonetheless, agricultural variables, which we predicted would be important proxies for group cohesion, and are perhaps the most promising, aside from measures of internal hostility, did not align with our predictions and were unsupportive of $\mathrm{H} 2.1$. This result is somewhat surprising, though the task dimension was admittedly a complex and difficult dimension to operationalize.

What the results do demonstrate is that the relationship between the simplest proxies for group cohesion—internal hostilities—should be those immediately pursued if one was to continue research in this field. The agricultural results, which might be interpreted as aligning with an alternate prediction I made regarding the disappearance of ritual art from industrialized societies, could also be fruitful areas of further research if an alternative hypothesis is offered. This hypothesis would have to account for the apparent quadratic relationship between ritual art and agriculture.

The large number of non-monotonic relationships identified among our proposed variables calls into question either $\mathrm{H} 2$ or the validity of these variables as proxies for group cohesion. The significant and consistent correlation between ritual art and internal violence, however, suggests that there may be some support for $\mathrm{H} 2.1$, and that other proposed variables are simply poor proxies for group cohesion. Internal violence is certainly an intuitive proxy for 
group cohesion. Still the insignificance of the relationship between ritual art and other variables does raise questions. It might be suggested that insignificant variables are not poor proxies for group cohesion, but that they are poor proxies for group cohesion at the size and level under consideration in our cross-cultural analysis. The majority of variables were derived from smallgroup research in the previous chapters and it was already suggested that cultures and societies might be too large for these variables to properly apply. This might explain the significance of the most intuitive variables.

Finally, it is altogether possible that the coarse coding practice used to measure the presence and intensity of ritual art practices does not adequately align with our theoretical definition of ritual art. A much more extensive and exhaustive coding practice would have to be developed to remedy this problem and a much smaller population would likely have to be sampled. Nonetheless, we cannot entirely discredit the significant results that were achieved. Further study in the areas of violence is promising and given the intuitive nature of group cohesion understood as reduced internal conflict, I think the results achieved call for a revisiting of Dissanayake's evolutionary aesthetics. H2.1 is, at the very least, strongly supported by these results. However, even this promising area of study raises some further problems. The direction of causation is not going to be established statistically, though we began with good theoretical reasons for thinking it was ritual art that would cause cohesion, and not otherwise. However, now that our results suggest almost exclusively the significance of internal violence to ritual art a contradictory hypothesis might be proposed that better interprets this data, or at least serves as a compelling alternative. Perhaps ritual art does not promote a decrease in violence (a proxy for group cohesion) but societies that are less violent have the time, resources, and collective interests to practice ritual art. I leave these considerations and others up to the discretion of the 
reader. My results have suggested that given certain intuitive interpretations of group cohesion H2.1 is supported, though many other important variables were unsupportive. Furthermore, these results have, I think, suggested rather clearly in what direction future research should continue. 


\section{Chapter 6 - Conclusion}

\subsection{Review of Methodology}

In this paper I have considered Ellen Dissanayake's evolutionary theory of art as well as criticism that has been leveled against it. Initially I formulated Dissanayake's unmodified position as:

H1) The function of the arts is to promote group cohesion [by making special.]

From a consideration of what I take to be essential to Dissanayake and resistant to much criticism I developed a limited and refined hypothesis that could be subjected to empirical testing. This hypothesis was presented as follows:

H2) The function of ritual art is the promotion of group cohesion [by making special.]

This hypothesis was further refined by consideration of the implications of the term function into two hypotheses, of which I argued the first was most readily subjected to empirical testing. These two hypothesis are as follows:

H2.1) Ritual art promotes group cohesion [which is fitness-enhancing.]

H2.2) Ritual art was selected for its fitness-enhancing promotion of group cohesion. 
While both formulations are relevant to Dissanayake's position, it is H2.1 that I sought to test by a cross cultural analysis.

Towards this end I developed a theoretical definition of "ritual art" and proposed an operational definition and coding practice for this variable. The first coding practice proved problematic and I ultimately chose a straightforward method of measuring the number of relevant paragraphs per relevant document in order to approximate the prominence of ritual art in the literature and, by extension, the culture. After developing a method of measuring ritual art as a variable, I advanced a number of theoretical arguments for ways in which we could understand the concept of group cohesion, and the most appropriate variables to capture these dimensions of the concept. For each variable that I chose as an appropriate proxy for group cohesion, or ecological factor in relation to group cohesion, I hypothesized the relationship that $\mathrm{H} 2.1$ would predict between that variable and "ritual art."

In the previous chapter I developed scatter plots for each variable in order to test the assumption of monotonicity and then calculated the Spearman's rho correlation coefficient and level of significance between each variable and "ritual art." The results were then compared to predictions made in the preceding chapter and deemed supportive or unsupportive of $\mathrm{H} 2.1$ and by extension $\mathrm{H} 2$.

\subsection{Results}

The results of correlations between ritual art and the proposed variables for group cohesion, both proxies and ecological conditions, are presented in the following table: 
Table 15: All correlation Coefficients

\begin{tabular}{|c|c|c|c|}
\hline Variable & Rho & Sig. & $\mathbf{N}=$ \\
\hline v62 & $m$ & $\mathrm{~m}$. & $\mathrm{m}$. \\
\hline v63 & $\mathfrak{m}$ & $\mathrm{m}$. & $m$ \\
\hline v64 & $\mathrm{n}$. & $\mathrm{m}$. & $m$ \\
\hline v892 & 0.123 & 0.088 & 122 \\
\hline v893 & 0.052 & 0.289 & 116 \\
\hline v768 & 0.354 & 0.001 & 77 \\
\hline v891 & 0.165 & 0.035 & 121 \\
\hline v1748 & -0.307 & 0.004 & 73 \\
\hline v1749 & -0.221 & 0.03 & 73 \\
\hline v1750 & -0.349 & 0.003 & 60 \\
\hline v72 & -0.189 & 0.15 & 133 \\
\hline v73 & $\mathrm{m}$ & n.m. & n.m. \\
\hline v151 & $\mathrm{m}$. & n.m. & n.m. \\
\hline v232 & $\mathrm{m}$. & n.m. & n.m. \\
\hline v1128 & n.m. & n.m. & n.m. \\
\hline v775 & -0.186 & 0.057 & 73 \\
\hline v1684 & n.m. & n.m. & n.m. \\
\hline v1719 & n.m. & n.m. & n.m. \\
\hline v759 & 0.068 & 0.277 & 77 \\
\hline v776 & .063 & 0.294 & 77 \\
\hline v1132 & n.m. & n.m. & n.m \\
\hline
\end{tabular}

*n.m. = non-monotonic

As should be clear from the results presented here, and the discussion that appeared in the previous chapter, while the results are largely mixed, a number of variables for internal conflict were highly supportive of H2.1. This suggests that this group of variables and variables akin to it - whether it be measures of internal violence or those variables that most intuitively capture cohesion - may be fruitful ground for future study. Other results, such as those related to intercommunity marriage, were significant, though weak. Nonetheless, this variable (v72) shares 
with those variables of internal conflict a certain intuitive validity as a measure of cohesion. Results related to external conflict (inter-group conflict) were surprisingly opposed to what was theoretically predicted. This interesting result deserves further exploration. Furthermore, as mentioned earlier, the unusual, but not entirely unpredictable relationship between ritual art and measures of agriculture might also be an important area of further study if an appropriate hypothesis and method of measuring and predicting the quadratic equation could be developed. Finally, variables along the dimension of verticality were also surprising in that the results, though not significant, were also opposed to our predictions. This might just be an insignificant and therefore random result but it might also call into question the relationship between verticality and group cohesion in very large groups. Alternatively, the result can be interpreted as calling into question the proposed relationship between ritual art and group cohesion.

While these results are mixed they have served the purpose of defining relevant areas of future study, as I proposed in the introduction. These unsupportive results are unsupportive in an informative way. They likely indicate some problems with the ways in which we attempt to measure group cohesion; they emphasize a statistically supported relationship between internal violence and ritual art; and they show that the relationship between ritual art and agriculture is fairly consistent though not as predicted. Further study of the relationship between agriculture and group cohesion would likely be very fruitful. Furthermore, I believe this project has identified a failure in evolutionary studies, and anthropology, to properly define group cohesion. While a great deal of work has been pursued towards this end in small group studies little has been done to extend this research to larger socio-cultural units. Before further study can be pursued regarding Dissanayake's claim this research into understanding group cohesion in concrete terms at the socio-cultural level may be necessary. Until then, the significant results in 
relation to internal violence and ritual art will hopefully revive some interest in an approach to evolutionary aesthetics that resembles Dissanayake's.

\subsection{Possible Problems with Methodology}

As I have already suggested throughout this paper there may be a number of problems with the methodology pursued here. Much of the work I have done is without significant precedent and pragmatic solutions have been pursued as much as possible. While I hold that some of the results of my research are supportive of $\mathrm{H} 2.1$, further study or challenges to my results could begin by questioning weaknesses in my methodology. Towards the end of developing a more transparent and empirical approach to philosophy I will reiterate those possible methodological weaknesses here.

While I am confident that the theoretical definition of ritual art developed here represents one of the strongest interpretations or examples of Dissanayake's “making special” I acknowledge that the coding practice is not perfect and could be improved. As discussed in Chapter 3, the coding practice ran into a number of problems and had to be simplified into a replicable approach of counting relevant paragraphs per relevant document. The result is a measure of the presence of ritual art in the literature and is no guarantee of an indication of the presence of ritual art in the culture. If a consistent, replicable coding practice could be proposed that more accurately measured the intensity, importance, or prominence of ritual art in the culture then it would likely function more adequately as a measure that could be tested for correlation with group cohesion. As it stands, given the limitations of this paper, I was unable to develop such a measure. Improvement in this area could serve to more accurately test H2.1. 
As already mentioned, group cohesion is a very problematic measure that has no consistent and agreed-upon definition and therefore no variables that we can confidently assert measure degrees of group cohesion. While I think I have proposed some very promising variables for group cohesion, which I have developed largely from small group research, more work could be done to test what counts as an adequate measure of group cohesion before attempting to test the correlation of that variable with something like ritual art. While I have written an entire chapter on this subject there is an incredible amount of rewarding research that could be pursued in this area. I have only scratched the surface and my results have been largely mixed though very encouraging insofar as they expose weaknesses in our common understanding and use of the term "group cohesion" and reveal promising ways of developing supportive empirical arguments for Dissanayake's position.

While the attentive reader may identify many more problems with my methodology, including problems I have not considered, I believe these two suggestions of possible weaknesses are excellent places to start in improving study in this area, replicating my results, or challenging them.

\subsection{Implications for the Philosophy of Art}

While Dissanayake has historically been rejected largely for reasons of vagueness, broadness, and the problem of group selection, as discussed earlier, my project has set out to assess her work on both theoretical and empirical grounds. The result of my project is a much more reasonable and moderate interpretation of her position as well as supportive empirical analysis of the relationship between ritual art and group cohesion. As such my results offer both more compelling grounds for assessing Dissanayke's position without resorting to flimsy 
arguments regarding group selection or uncharitable claims regarding broadness and vagueness, as well as what I consider good reason to return to her work in a new light.

Along with offering alternative grounds for rejecting or accepting Dissnayake this program also demonstrates a viable approach to testing similar theories, even if only in the abstract. Subjecting theoretical arguments to testing of their empirical claims in the format I have put forward here is a viable alternative to purely theoretical consideration of these views. Furthermore, this research provides an example of what a critical approach to aesthetics would look like. That is to say, in this field, as well as others, this research models an approach to testing the empirical claims of theoretical arguments in such a way that they are subjected to a critical and even scientific standard.

\subsection{Where to go from here?}

I have already suggested that research into the relationship between internal violence and ritual art is likely to be very rewarding. Furthermore, the relationship between ritual art and agriculture is surprising, and though not necessarily significant, consideration of alternative hypotheses for the data might further develop both our understanding of group cohesion and the relationship between ritual art and agriculture. This research has also revealed that group cohesion is a subject that would benefit immensely from further study. The results of such research would be beneficial to numerous disciplines, as well as this very project.

While these suggestions capture the areas of fruitful research that lie largely within the purview of a cross-cultural analysis, the significant work that has already been done in small group research may be suggestive of an entirely different approach. Instead of remaining concerned with the large socio-cultural groups that seem immediately relevant to Dissanayake's 
claims, and which are necessarily the subject of a cross-cultural analysis, it might be beneficial to consider the role of art in relation to much smaller groups. If Dissanayake's view is developed from an intuitive or folk psychological understanding of the relationship between art and cohesion in small groups, which seems entirely possible, then the use of small group research methodologies (questionnaires and experiments) could be rewarding. Not only would this approach allow us to use the dimensions of group cohesion at the level that they were originally developed (the small group, the sports team) but it would also allow us to work experimentally in order to determine the direction of causation if any significant relationship between art and cohesion existed. Performance art and groups of participants or viewers would be a very promising subject for these questionnaires and experiments. While this might serve to support or disconfirm hypotheses regarding art and cohesion at the small group level, this is a long way from demonstrating a fitness-enhancing level of cohesion. Nonetheless, these results might minimally suggest where the pervasive colloquialism that art brings us together comes from. 


\section{Bibliography}

Alland Jr., Alexander. "Affect and Aesthetics in Human Evolution." The Journal of Aesthetics and Art Criticism, Volume 47. Number 1 (1989): 1-14.

Avital, Etyan, and Eva Jablonka. Animal Traditions: Behavioral Inheritance in Evolution. Cambridge: Cambridge University Press, 2000.

Barrett, Stanley R. Anthropology: A Student's Guide to Theory and Method. 2nd ed. Toronto: University of Toronto Press, 2009.

Beardsley, Monroe. Aesthetics, Indianapolis: Hackett. 1958.

—. The Aesthetic Point of View, Ithaca: Cornell University Press. 1982.

Bell, Catherine. Ritual Theory, Ritual Practice. New York: Oxford University Press, 1992.

Boas, Franz. Primitive Art. Mineola: Dover Publications, 2010.

Bocock, Robert. Ritual in Industrial Society: A Sociological Analysis of Ritualism in Modern England. London: George Allen \& Unwin Ltd, 1974.

Botero, Carlos A., Beth Gardner, Kathryn R. Kirby, Joseph Bulbulia, Michael C. Gavin, and Russell D. Gray. "The Ecology of Religious Belief," PNAS Vol.111 No.47 November (2014). 16784-16789.

Boyd, Robert, and Peter Richerson. Culture and the Evolutionary Process. Chicago: University of Chicago Press, 1985.

—, The Origin and Evolution of Cultures. Oxford: Oxford University Press, 2005.

—. "Culture and Cooperation." Beyond Self-Interest. Ed. J.J. Mansbridge. Chicago: University of Chicago Press, 1992. 111-132.

_. "Group Selection among Alternative Evolutionarily Stable Strategies," Journal of Theoretical Biology, 145 (1990): 331-342.

—. Not by Genes Alone: How Culture Transformed Human Evolution. Chicago: University of Chicago Press, 2004.

Brawley, Lawrence R., Albert V. Carron, and W. Neil Widmeyer, "Assessing the Cohesion of Teams: Validity of the Group Environment Questionnaire," Journal of Sport Psychology 9 (1987): 275-294. 
Broadhurst, Susan. Liminal Acts: A Critical Overview of Contemporary Performance and Theory. London: Cassell, 1999.

Burke, Edmund. A Philosophical Inquiry into the Origin of our Ideas of the Sublime and Beautiful. Oxford: Oxford University Press, 1999.

Carron, Albert V.. "Cohesiveness in Sport Groups: Interpretations and Considerations," Journal of Sport Psychology, 4 (1982): 123-138.

Carron, Albert V., and Lawrence R. Brawley, "Cohesion: Conceptual and Measurement Issues," Small Group Research 43:6 (2012): 726-743.

Carron, Albert V., W.N. Widmeyer, and L.R. Brawley, "The development of an instrument to assess cohesion in sport teams: The Group Environment Questionnaire," Journal of Sport Psychology 7 (1985): 244-266.

Cavalli-Sforza, Luigi L., and Marcus W. Feldman. Cultural Transmission and Evolution: A Quantitative Approach. Princeton: Princeton University Press, 1981.

Cosmides, Leda, and John Tooby. "Cognitive Adaptations for Social Exchange." The Adapted Mind: Evolutionary Psychology and the Generation of Culture. Ed. J.H. Barkow, L. Cosmides, and J. Tooby. New York: Oxford University Press, 1992. 163-225.

Cota, Albert A., Charles R. Evans, Kenneth L. Dion, Lindy Kilik, R. Stewart Longman, "The Structure of Group Cohesion," Personality and Social Psychology Bulletin Vol. 21 No. 6 (1995): $572-580$.

Darwin, Charles. On the Origin of Species: A Facsimile of the First Edition. Cambridge: Harvard University of Press, 2003.

—. The Descent of Man. London: Wordsworth Editions, 2013.

Davies, David. Philosophy of the Performing Arts. Oxford: Wiley-Blackwell Publishing, 2011.

Davies, Stephen. The Artful Species: Aesthetics, Art, and Evolution. Oxford: Oxford University Press, 2012.

—. The Philosophy of Art. Oxford: Blackwell Publishing, 2006.

Dawkins, Richard. The Blind Watchmaker. London: Penguin, 2006.

- The Extended Phenotype: The Long Reach of the Gene. Oxford: Oxford University Press, 1999.

—. The Selfish Gene. New York: Oxford University Press, 2006. 
Dewey, John. Art As Experience. New York: Perigee Trade, 2005.

Dickie, George. The Century of Taste, Oxford: Oxford University Press. 1996.

—. Evaluating Art, Philadelphia: Temple University Press. 1988.

Dissanayake, Ellen. Art and Intimacy: How the Arts Began. Seattle: University of Washington, 2000 .

—. Homo Aestheticus: Where Art Comes From and Why. New York: Free, 1992.

—. "Retrospective on Homo Aestheticus," Journal of the Canadian Association for Curriculum Studies Vol. 1 No.2 (2003): 7-11.

—. What Is Art For? Seattle: University of Washington, 1988.

Divale, William. Pre-Coded Variables for the Standard Cross-Cultural Sample from World Cultures. Volumes I \& II. York College, CUNY, Spring 2000.

Divale, William, Daria Khaltourina and Andrey Korotayev. "A Corrected Version of the Standard Cross-Cultural Sample Database”. World Cultures 13(1) (2002): 62-98.

Dobzhansky, Theodosius. Evolutionary Biology. New York: Appleton-Century-Crofts, 1967.

Dunbar, R. I. M. "Determinants of Group size in Primates: A General Model," Proceedings of the British Academy Volume 88 (1996): 33-57.

Durham, William H.. Coevolution: Genes, Culture and Human Diversity. Palo Alto, Calif.: Stanford University Press. 1991.

Dutton, Denis. The Art Instinct: Beauty, Pleasure, \& Human Evolution. New York: Bloomsbury Press, 2010.

Dutton, Denis. “Ellen Dissanayake,” Philosophy and Literature 18 (1994): 204-210.

Dyaram, Lata, and T.J. Kamalanabhan, "Unearthed: The Other Side of Group Cohesiveness." Journal of Social Science 10(3) (2005): 185-190.

Ecker, David W. "The Artistic Process as Qualitative Problem Solving." The Journal of Aesthetics and Art Criticism, Volume 21. Number 3 (1963): 283-290.

Eldakar, Omar Tonsi, and David Sloan Wilson. "Eight Criticisms not to Make About Group Selection," Evolution: International Journal of Organic Evolution Vol.65 Issue 6 (2011), 15231526.

Electronic Human Relations Area Files. "SCCS Cases in HRAF.” Accessed August 10, 2016. http://hraf.yale.edu/resources/reference/sccs-cases-in-ehraf/. 
Ember, Carol R. 2007. "Using the HRAF Collection of Ethnography in Conjunction With the Standard Cross-Cultural Sample and the Ethnographic Atlas". Cross-Cultural Research 41: 396427.

Evans-Pritchard, E.E. The Nuer: A Description of the Mode of Livelihood and Political Institutions of a Nilotic People. Oxford: Oxford University Press, 1940.

Evans, Charles R., and Kenneth L. Dion, "Group Cohesion and Performance: A Meta-Analysis," Small Group Research 43:6 (2012): 690-701.

Findlay, C.S. "Phenotypic Evolution under Gene-Culture Transmission in Structured Populations." Journal of Theoretical Biology 156 (1992): 387-400.

Freeland, Cynthia. But is it Art?: An Introduction to Art Theory. Oxford: Oxford University Press, 2002.

Gennep, Arnold van. The Rites of Passage. Trans. Monika B. Vizedom, and Gabrielle L. Caffee. Chicago: University of Chicago Press, 1960.

Godfrey-Smith, Peter. Philosophy of Biology. Princeton: Princeton University Press, 2014.

Goodnight, Charles, J., and Lori Stevens. "Experimental Studies of Group Selection: What They Tell Us about Group Selection in Nature.” American Naturalist 150 (1997): 59-79.

Gould, Stephen Jay. Ontogeny and Phylogeny, Cambridge: Harvard University Press, 1997.

—. The Structure of Evolutionary Theory, Cambridge: Harvard University Press, 2002.

Gould, Stephen Jay, and R. C. Lewontin. "The Spandrels of San Marco and the Panglossian Paradigm: A Critique of the Adaptationist Programme." Proceedings of the Royal Society of London B205 (1979): 581-98.

Greer, Lindred L. "Group Cohesion: Then and Now," Small Group Research 43:6 (2012): 655661.

Kuhn, Thomas S. The Structure of Scientific Revolutions. Chicago: University of Chicago, 1970.

Layton, Robert. "Traditional and Contemporary Art of Aboriginal Australia: Two Case Studies," in Anthropology, Art, and Aesthetics, ed. Jeremy Coote and Anthony Shelton. Oxford: Clarendon Press, 1992.

Lehmann, J., A.H. Korstiens, and R.I.M. Dunbar, "Group size, Grooming and Social Cohesion in Primates," Animal Behaviour 74:6 (2007): 1617-1629. 
Levinson, Jerrold. "Pleasure and the Value of Works of Art," The Pleasures of Aesthetics, Ithaca: Cornell University Press. 1995.

Lévi-Strauss, Claude. Myth and Meaning. New York: Routledge, 2014.

Lewens, Tim. Cultural Evolution: Conceptual Challenges. Oxford: Oxford University Press, 2015.

Linquist, Stefan. "Prospects for a Dual Inheritance Model of Emotional Evolution." Philosophy of Science, Volume 74 (2007): 848-859.

— _ ed. Philosophy of Evolutionary Biology. Farnham: Ashgate, 2010.

Lumsden, Charles J. "Aesthetics." The Sociobiological Imagination. Ed. Mary Maxwell. New York: State University of New York. 253-268. 1991.

Lumsden, Charles J., and E. O. Wilson. "The Relation Between Biological and Cultural Evolution." Journal of Social and Biological Systems 8.4 (1985): 343-59.

Mace, Ruth, and Clare J. Holden. "A Phylogenetic Approach to Cultural Evolution." Trends in Ecology \& Evolution 20.3 (2005): 116-21.

Mace, Ruth and Mark Pagel, "The Comparative Method in Anthropology", Current Anthropology, 35 (5) (1994): 549-564.

Markides, Kyriacos C. and Steven F. Cohn. "External Conflict/Internal Cohesion: A Reevaluation of an Old Theory." American Sociological Review Vol. 47 No. 1 (1982): 88-98.

Meyer-Rochow, Victor Benno. "Food Taboos: Their Origins and Purposes." Journal of Ethnobiology and Ethnomedicine 5:18 (2009), 18-27.

Murdock, George P., Clellan S. Ford, Alfred E. Hudson, Raymond Kennedy, Leo W. Simmons, John W. M. Whiting. Outline of Cultural Materials. 6th revised edition with modifications. New Haven: Human Relations Area Files, 2008.

Murdock, George P., and Douglas R. White. "Standard cross-cultural sample," Ethnology. (1969): 329-369.

Paolilli, Antonio Luigi. “Altruism, Selfishness and Social Cohesion,” Sociology Mind Vol. 1 Issue 4 (2011): 145-150.

Pinker, Steven. How the Mind Works. New York: W.W. Norton, 2009.

Richerson, Peter, J., Robert Boyd, and Robert L. Bettinger. "Was Agriculture Impossible during the Pleistocene but Mandatory during the Holocene? A Climate Change Hypothesis," American Antiquity Vol. 66 No. 3 (2001): 387-411. 
Sachs, Joel L., Ulrich G. Mueller, Thomas P. Wilcox, and James J. Bull, "The Evolution of Cooperation," The Quarterly Review of Biology Vol. 79, No. 2 (2004): 135-160.

Schellekens, Elisabeth. "Taste and Objectivity: The Emergence of the Concept of the Aesthetic." Philosophy Compass 4.5 (2009): 734-43.

Scruton, Roger. Art and Imagination, London: Methuen. 1974.

Simon, Herbert, A. Reason in Human Affairs. Palo Alto, Calif.: Stanford University Press, 1983.

Sober, Elliott, and David Sloan Wilson. Unto Others: The Evolution and Psychology of Unselfish Behavior. Cambridge: Harvard University Press, 1998.

Soltis, Joseph, Robert Boyd and Peter J. Richerson. "Can Group-functional Behaviors Evolve by Cultural Selection?," Current Anthropology Vol. 36 No. 3 (1995): 473-494.

Sosis, Richard. "The Adaptive Value of Religious Ritual: Rituals promote group cohesion by requiring members to engage in behavior that is too costly to fake," American Scientist Vol. 92 No.2 (2004): 166-172.

Stein, Arthur A.. "Conflict and Cohesion: A Review of the Literature," Journal of Conflict Resolution Vol. 20 No. 1 (1976): 143-172.

Sterelny, Kim. The Evolved Apprentice: How Evolution Made Humans Unique. Cambridge: MIT Press, 2012.

—. Dawkins vs. Gould: Survival of the Fittest. Cambridge: Icon, 2001.

- Thought in a Hostile World: The Evolution of Human Cognition. Oxford: Wiley-Blackwell, 2003.

Sterelny, Kim, and Paul Griffiths. Sex and Death: An Introduction to Philosophy of Biology. Chicago: University of Chicago, 1999.

Sueur, Cédric, Jean-Louis Deneubourg, Odile Petit, and Iain D. Couzin. "Group size, grooming and fission in primates: A modelling approach based on group structure," Journal of Theoretical Biology 273 (2011): 156-166

Sytsma, Justin, and Jonathan Livengood. The Theory and Practice of Experiment Philosophy. Peterborough: Broadview Press, 2016.

Tajfel, Henry, M.G. Billig, R.P. Bundy, and Calude Flament. "Social categorization and intergroup behavior." European Journal of Social Psychology 1(2) (1971): 149-178. 
Tatarkiewicz, Wladyslaw. "The Great Theory of Beauty and Its Decline." The Journal of Aesthetics and Art Criticism 31 (1972): 165-80.

Tomasello, Michael, Alicia P. Melis, Claudio Tennie, Emily Wyman, and Esther Herrmann, "Two Key Steps in the Evolution of Human Cooperation: The Interdependence Hypothesis," Current Anthropology Vol. 53, No. 6 (2012): 673-692.

Tooby, John, and Leda Cosmides. "Does Beauty Build Adapted Minds? Toward and Evolutionary Theory of Aesthetics, Fiction and the Arts," SubStance, Vol. 30, No. 1/2, Issue 94/95 (2001): 6-27.

—. "The Psychological Foundations of Culture." The Adapted Mind: Evolutionary Psychology and the Generation of Culture. Ed. J.H. Barkow, L. Cosmides, and J. Tooby. New York: Oxford University Press, 1992. 19-136.

Turner, Victor W. The Forest of Symbols: Aspects of Ndembu Ritual. Ithaca: Cornell University Press, 1967.

—. "Liminal to Liminoid, in Play, Flow, and Ritual: An Essay in Comparative Symbology." The Rice University Studies, Volume 60. Number 3 (1974): 53-92.

—. The Ritual Process: Structure and Anti-Structure. Chicago: Aldine Pub. 1969.

Whitton, Sarah M. and Richard B. Fletcher. "The Group Environment Questionnaire A Multilevel Confirmatory Factor Analysis," Small Group Research Volume 45 no. 1 (2014): 6888.

White, Douglas R. "Standard Cross-Cultural Sample Free Distribution Site (UC Irvine)." Accessed August 10, 2016. http://eclectic.ss.uci.edu/ drwhite/courses/index.html.

Wilson, E.O.. Sociobiology: The New Synthesis. Cambridge: Harvard University Press, 1975.

Wilson, Margaret. "Six Views of Embodied Cognition." Psychonomic Bulletin \& Review 9 (4) (2002): 625-636. 